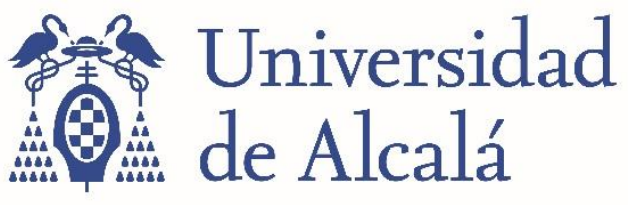

BIBLIOTECA

Document downloaded from the institutional repository of the University of Alcala: http://dspace.uah.es/dspace/

This is a postprint version of the following published document:

Leverkus, A.B. et al., 2018. Salvage logging effects on regulating and supporting ecosystem services - a systematic map. Canadian Journal of Forest Research, 48(9), pp.983-1000.

Available at http://dx.doi.org/10.21829/myb.2017.2311118

(C) Copyright 2020 - Canadian Science Publishing

(Article begins on next page)
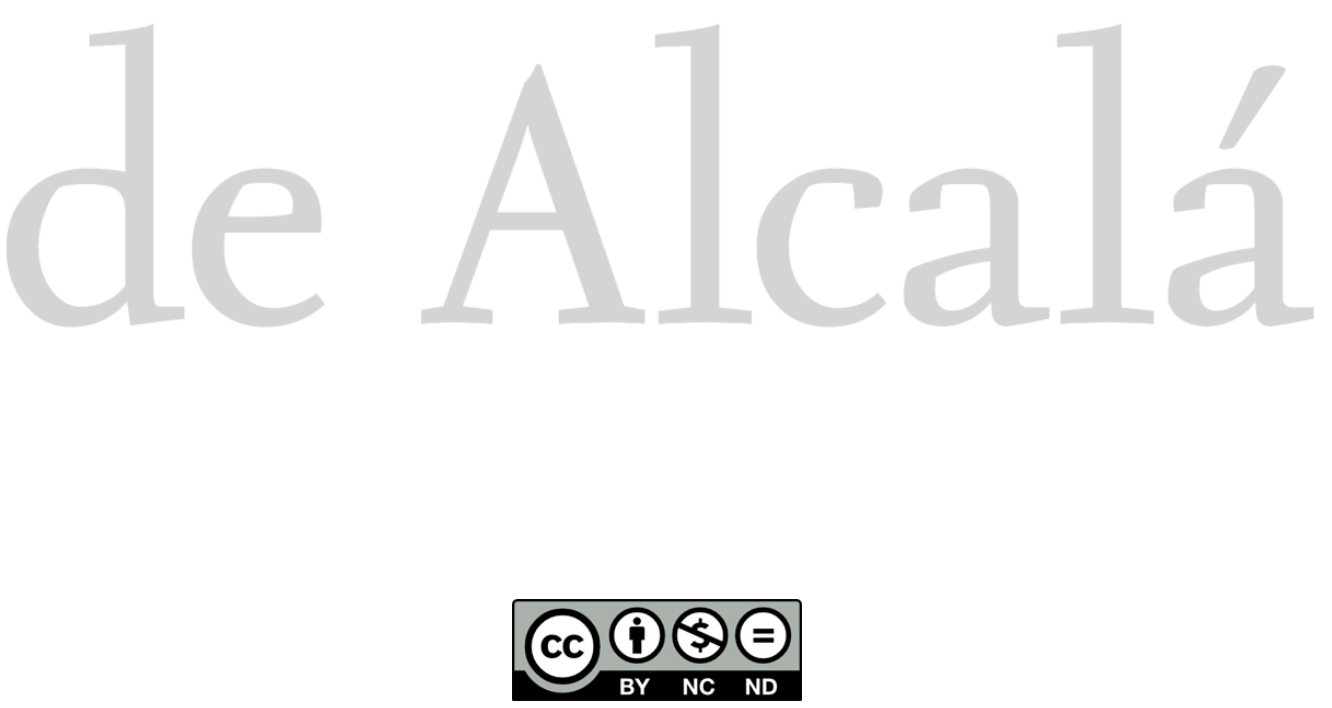

This work is licensed under a

Creative Commons Attribution-NonCommercial-NoDerivatives

4.0 International License. 


\section{Salvage logging effects on regulating and supporting ecosystem services - A systematic map}

\begin{tabular}{|c|c|}
\hline Journal: & Canadian Journal of Forest Research \\
\hline Manuscript ID & cjfr-2018-0114.R1 \\
\hline Manuscript Type: & Review \\
\hline Date Submitted by the Author: & $\mathrm{n} / \mathrm{a}$ \\
\hline Complete List of Authors: & $\begin{array}{l}\text { Leverkus, Alexandro B; Universidad de Alcalá } \\
\text { Rey Benayas, José María; Universidad de Alcalá } \\
\text { Castro, Jorge; University of Granada } \\
\text { Boucher, Dominique; Natural Resources Canada, Canadian Forest Service, } \\
\text { Laurentian Forestry Centre, } 1055 \text { du P.E.P.S., P.O. Box 10380, Stn. Sainte- } \\
\text { Foy, Québec City, Québec, Canada, ; } \\
\text { Brewer, Steve; Univ. of Mississippi, Dept. of Biology } \\
\text { Collins, Brandon; University of California Berkeley, } \\
\text { Donato, Daniel; Washington State Dept. of Nat. Res. } \\
\text { Fraver, Shawn; University of Maine, School of Forest Resources } \\
\text { Kishchuk, Barbara; Natural Resources Canada, Canadian Forest Service, } \\
\text { Science Policy Integration Branch } \\
\text { Lee, Eun-Jae; Urban Planning Research Group, Daejeon Sejong Research } \\
\text { Institute } \\
\text { Lindenmayer, David; Australian National University, } \\
\text { Lingua, Emanuele; University of Padua } \\
\text { Macdonald, Ellen; Department of Renewable Resources, University of } \\
\text { Alberta } \\
\text { Marzano, Raffaella; Department DISAFA, University of Torino } \\
\text { Rhoades, Charles; US Forest Service } \\
\text { Royo, Alejandro; USDA Forest Service, } \\
\text { Thorn, Simon; Technische Universität München, Department of Ecology } \\
\text { and Ecosystem Management } \\
\text { Wagenbrenner, Joseph; USDA Forest Service, Pacific Southwest Research } \\
\text { Station } \\
\text { Waldron, Kaysandra; Centre for Forest Research, Université Laval, } \\
\text { Sciences du bois et de la forêt } \\
\text { Wohlgemuth, Thomas; RU Forest Dynamics, Swiss Federal Institute for } \\
\text { Forest, Snow and Landscape Research WSL } \\
\text { Gustafsson, Lena; Department of Ecology, Swedish University of } \\
\text { Agricultural Sciences (SLU) }\end{array}$ \\
\hline Keyword: & Salvage harvesting, sanitation logging, wildfire, insect outbreak, windthrow \\
\hline $\begin{array}{r}\text { Is the invited manuscript for } \\
\text { consideration in a Special } \\
\text { Issue? : }\end{array}$ & N/A \\
\hline
\end{tabular}


SCHOLARONE ${ }^{\text {m }}$

Manuscripts 
5 Alexandro B. Leverkus ${ }^{1}$, José María Rey Benayas ${ }^{1}$, Jorge Castro $^{2}$, Dominique Boucher ${ }^{3}$,

6 Stephen Brewer ${ }^{4}$, Brandon M. Collins ${ }^{5}$, Daniel Donato ${ }^{6}$, Shawn Fraver ${ }^{7}$, Barbara E.

7 Kishchuk $^{8}$, Eun-Jae Lee ${ }^{9}$, David B. Lindenmayer ${ }^{10}$, Emanuele Lingua ${ }^{11}$, Ellen

8 Macdonald $^{12}$, Raffaella Marzano ${ }^{13}$, Charles C. Rhoades ${ }^{14}$, Alejandro Royo ${ }^{15}$, Simon

9 Thorn $^{16}$, Joseph W. Wagenbrenner ${ }^{17}$, Kaysandra Waldron ${ }^{18}$, Thomas Wohlgemuth ${ }^{19}$, Lena

10 Gustafsson $^{20}$

${ }^{1}$ Departamento de Ciencias de la Vida, UD Ecología, Edificio de Ciencias, Universidad de Alcalá, Alcalá de Henares, Spain. josem.rey@uah.es

${ }^{2}$ Departamento de Ecología, Facultad de Ciencias, Universidad de Granada, Granada, Spain.jorge@ugr.es

${ }^{3}$ Centre de foresterie des Laurentides, Service Canadien des Forêts, Ressources Naturelles Canada, Québec, Québec, Canada. dominique.boucher@canada.ca

${ }^{4}$ Department of Biology, University of Mississippi, Mississippi, USA. jbrewer@olemiss.edu

${ }^{5}$ Center for Fire Research and Outreach, University of California Berkeley, California, USA.bcollins@,berkeley.edu

${ }^{6}$ School of Environmental and Forest Sciences, University of Washington, Seattle, WA, USA. daniel.donato@dnr.wa.gov 
23

24

25

26

27

${ }^{7}$ School of Forest Resources, University of Maine, Orono, Maine, USA.

shawn.fraver@maine.edu

${ }^{8}$ Science Policy Integration Branch, Canadian Forest Service, Natural Resources Canada, Ottawa, Ontario, Canada. barbara.kishchuk@,canada.ca

${ }^{9}$ Urban Planning Research Group, Daejeon Sejong Research Institute, Jung-gu, Daejeon, Korea.2lejae@hanmail.net

${ }^{10}$ Fenner School of Environment and Society, The Australian National University, Canberra, Australia. David.Lindenmayer@anu.edu.au

${ }^{11}$ Department TESAF, University of Padova, Legnaro (PD), Italy. emanuele.lingua@unipd.it

${ }^{12}$ Department of Renewable Resources, University of Alberta, Edmonton, Alberta, Canada.emacdona@ualberta.ca

${ }^{13}$ Department DISAFA, University of Torino, Grugliasco (TO), Italy. raffaella.marzano@unito.it

${ }^{14}$ Rocky Mountain Research Station, USDA Forest Service, Fort Collins, Colorado, USA. crhoades@ff.fed.us

${ }^{15}$ Northern Research Station, USDA Forest Service, Irvine, PA, USA. aroyo@,fs.fed.us

${ }^{16}$ Field Station Fabrikschleichach, Department of Animal Ecology and Tropical Biology (Zoology III), Julius-Maximilians-University Würzburg, Rauhenebrach, Bavaria, Germany.simon@thornonline.de

${ }^{17}$ Pacific Southwest Research Station, USDA Forest Service, Arcata, California, USA. jwagenbrenner@fs.fed.us

${ }^{18}$ Department of Wood and Forest Sciences, Université Laval, Québec, QC, Canada. kaysandra.waldron.1@ulaval.ca 
${ }^{19}$ Research Unit Forest Dynamics, Swiss Federal Institute for Forest, Snow and Landscape Research WSL, Zuercherstrasse 111, CH-8903 Birmensdorf, Switzerland. thomas.wohlgemuth@wsl.ch

${ }^{20}$ Department of Ecology, Swedish University of Agricultural Sciences, Uppsala, Sweden.

$51 \quad$ Lena.Gustafsson@slu.se

* Corresponding author: ABL. Departamento de Ciencias de la Vida, UD Ecología, 622689928. E-mail: alexandro.leverkus@uah.es (ABL) 


\section{$58 \quad$ Abstract}

59

Wildfires, insect outbreaks, and windstorms are increasingly common forest disturbances,

Post-disturbance management often involves salvage logging, i.e. the felling and removal of the affected trees. However, this practice may represent an additional disturbance with effects on ecosystem processes and services. We developed a systematic map to provide an overview of the primary studies on this topic, and created a database with information on the characteristics of the retrieved publications, including information on stands, disturbance, intervention, measured outcomes, and study design. Of 4341 retrieved publications, 90 were retained in the systematic map. These publications represented 49 studies, predominantly from North America and Europe. Salvage logging after wildfire was addressed more frequently than after insect outbreaks or windstorms. Most studies addressed logging after a single disturbance event, and replication of salvaged stands rarely exceeded 10 . The most frequent response variables were tree regeneration, ground cover, and deadwood characteristics. This document aims to help managers find the most relevant primary studies on the ecological effects of salvage logging, It also aims to identify and discuss clusters and gaps in the body of evidence, relevant for scientists who aim to synthesize previous work or identify questions for future studies.
Eliminado: that are increasing in importance

Eliminado: identify

Eliminado: and decision-makers

Eliminado: information

Eliminado: to define

Eliminado: management strategies fo disturbed forests grounded on a sound scientific basis

Eliminado: shows 


\section{Introduction}

Large, episodic, severe forest disturbances such as those caused by wildfires, insect outbreaks, and windstorms are part of the natural dynamics of forest ecosystems across the world (Noss et al. 2006, Turner 2010, Johnstone et al. 2016). However, the frequency, severity and extent of such disturbances have increased in recent decades due to anthropogenic activity (Seidl et al. 2017) and are predicted to further increase in the future (Schelhaas et al. 2003, Kurz et al. 2008, Pausas and Fernández-Muñoz 2012, Seidl et al. 2017). As a result, it is crucial to identify and adopt management strategies that promote regeneration and maintain ecosystem functions of post-disturbance forests, whether through active intervention or passive management (Crouzeilles et al. 2017). A common post-disturbance management approach in many parts of the world is salvage logging, i.e. the widespread felling and removal of the affected trees (McIver and Starr 2000, Lindenmayer et al. 2008, Thorn et al. 2018). Salvage logging has been reported after wildfires (Lindenmayer et al. 2018), volcanic eruptions (Titus and Householder 2007), insect infestations (Thorn et al. 2016), windstorms (Waldron et al. 2014), and ice storms (Sun et al. 2012). It is frequent in disturbed production forests but also common in protected forests in some parts of the world (Schiermeier 2016, Leverkus et al. 2017, Müller et al. 2018). However, there is concern that the additional logging-related disturbance can imperil ecosystem recovery and affect biodiversity and ecosystem services (Karr et al. 2004, Beschta et al. 2004, Donato et al. 2006, Lindenmayer et al. 2008). Besides the mechanical disturbance, salvage logging affects ecosystems through the removal and modification of large amounts of biological legacies -i.e. the organisms, organic materials, and organically-generated environmental patterns that persist through a disturbance and constitute the baseline for post-disturbance recovery and regeneration (Franklin et al. 2000), 
The most frequent motivation for salvage logging across the world is the recovery of some part of the economic value of the forest (Müller et al. 2018). Tree-killing disturbances trigger a set of processes that can rapidly reduce the timber value due to reductions in wood quality (e.g. stain, decay, and the activity of insect borers) and to pulses in wood supply to the market (Prestemon and Holmes 2010). Rapid post-disturbance harvest is a frequent response to disturbance that aims to avoid further deterioration of the damaged wood (Prestemon and Holmes 2010, Lewis and Thompson 2011). In some parts of the world, such as regions of North America, large-scale wildfires and insect outbreaks have become so frequent that salvage logging is no longer a hasty response to unexpected events but rather constitutes an expected source of wood to fill market demands (Mansuy et al. 2015). However, the logging of disturbed forests is not profitable in all cases (e.g. Leverkus et al. 2012), and it may also aim to fulfil other management objectives. Salvage logging can target the reduction of the risk of subsequent disturbances, such as pest outbreaks and wildfire, through the elimination of the substrate or fuel generated by the initial disturbance (Schroeder and Lindelöw 2002, Collins et al. 2012). The simplification of post-disturbance ecosystem structure through the removal of fallen trunks is intended to ease subsequent active restoration activities such as reforestation (Leverkus et al. 2012, Man et al. 2013). Finally, there is a general negative aesthetic perception of disturbed forests that may be offset by removing the visual evidence of what is generally considered a "calamity" (Noss and Lindenmayer 2006). However, these motivations are not always based on scientific evidence, but rather on traditional practices, perceptions and deductions -as is often the case in conservation-related decision-making (Pullin et al. 2004, Sutherland et al. 2004a).

The lack of scientific evidence on the effects of salvage logging was highlighted in 2000 (McIver and Starr 2000). In 2004, Lindenmayer and colleagues (Lindenmayer et al. 2004) called for a revision of post-disturbance management policies, arguing that salvage logging can have long-lasting negative effects on biodiversity, undermine the -largely 
unrecognised- ecological benefits of natural disturbances, and impair ecosystem recovery. Numerous studies were established in subsequent years to assess the ecological consequences of this practice, covering a wide array of disturbance types and severities, biomes, forest compositions, logging methods, and response variables (Thorn et al. 2018). As a result, the above-mentioned motivations for salvage logging have been challenged [e.g. wildfire risk (Donato et al. 2006) and economics (Leverkus et al. 2012)], and many other effects of this practice have been described (e.g. Lindenmayer et al. 2008, Beghin et al. 2010, Priewasser et al. 2013, Wagenbrenner et al. 2015, Hernández-Hernández et al. 2017). Nonetheless, under some circumstances, salvage logging can meet both management and conservation objectives and address societal concerns. For example, post-bark beetle salvage logging lodgepole pine forests in Colorado commonly reduces canopy fuels and regenerates new stands without negatively effecting native plant diversity or soil productivity (Collins et al. 2011, 2012, Fornwalt et al. 2017, Rhoades et al. 2018). As a consequence, controversy surrounding salvage logging among managers, environmentalists, politicians and academics, remains lively (Schiermeier 2016, Leverkus et al. 2017, Lindenmayer et al. 2017, Müller et al. 2018).

The ecological impacts of salvage logging can broadly be categorised according to whether they affect;

a) The physical structure of ecosystems. An immediate consequence of logging is the reduction in parameters such as standing and downed woody debris, living canopy cover, and habitat structural complexity (Lee et al. 2008, Waldron et al. 2013, Peterson et al. 2015).

Eliminado: Removal of woody material is the primary objective of most salvage logging operations, whether for timber extraction or for fuel reduction (Müller et al. 2018). 
b) Particular elements of the biota and species assemblages. The removal of dead wood can affect many species, particularly deadwood-dependent taxa (as concluded in a recent global review on this topic; Thorn et al. 2018).

c) Forest regeneration capacity. Salvage logging has the potential to alter residual growing stock, soil seed bed, canopy and soil seed banks, and species interactions such as competition, seed dispersal, seed predation, and herbivory (Greene et al. 2006, Collins et al. 2010, Puerta-Piñero et al. 2010, Castro et al. 2012, Castro 2013).

d) Key ecosystem processes and services. Ecosystem services are the benefits that people obtain from ecosystems; they are the link between particular elements of the ecosystem or functions that they perform (i.e. the biophysical component), the benefits that society obtains and, ultimately, the value placed on them (i.e. the human well-being component; Fig 1; Haines-Young and Potschin 2010). They are categorised into provisioning, cultural, regulating, and supporting services (Millennium Ecosystem Assessment 2003). As outlined above, salvage logging is most often conducted to recover the value of the affected wood. In the case of timber and other provisioning services, the human well-being component is often well defined and quantified. However, salvage logging also may affect cultural, regulating and supporting ecosystem services throughout the ecosystem services cascade. This implies that some of the effects outlined in a), b) and c) can also be considered to fall into the category of ecosystem services (Fig 1; Leverkus and Castro 2017). In the case of supporting and regulating services, the biophysical component is usually better understood than the human well-being component (Boerema et al. 2016), and this is likely also the case regarding the responses to salvage logging (Leverkus and Castro 2017).
Eliminado: The large amounts of dead or weakened wood created by disturbances constitute the habitat and resource base for numerous taxa.

Eliminado: this 
Although ecosystem services have seldom been explicitly addressed in the scientific literature on salvage logging, they provide a common framework that allows balancing economic benefits from timber against the wide array of ecological variables that are also affected by post-disturbance management (Leverkus and Castro 2017). This framework represents an Ecosystem Approach (Secretariat of the Convention on Biological Diversity 2000), i.e. the consideration of multiple benefits provided by ecosystems -rather than only market values- to guide sustainable management decisions.

Salvage logging can affect ecosystem services by altering processes such as soil erosion and hydrological regimes (Wagenbrenner et al. 2016), nutrient cycling (Kishchuk et al. 2015), carbon sequestration (Serrano-Ortiz et al. 2011b), seed dispersal (Castro et al. 2012), vegetation cover (Macdonald 2007), tree regeneration (Castro et al. 2011, Marzano et al. 2013, Boucher et al. 2014), resistance to invasive species (Holzmueller and Jose 2012), resilience to subsequent disturbances (Fraver et al. 2011), and many others (McIver and Starr 2000, Karr et al. 2004, Beschta et al. 2004, Lindenmayer and Noss 2006, Lindenmayer et al. 2008). Some authors argue that ecological responses to salvage logging may result in synergistic effects due to the two successive disturbance events the natural disturbance and then logging) occurring close in time (Van Nieuwstadt et al. 2001, Wohlgemuth et al. 2002, Karr et al. 2004, Lindenmayer et al. 2004, DellaSala et al. 2006, Lindenmayer and Noss 2006). Others have found that environmental drivers other than salvage logging are more important in determining ecosystem regeneration (Kramer et al. 2014, Peterson and Dodson 2016, Royo et al. 2016, Rhoades et al. 2018). Further, studies often report contradictory results, and there is currently no comprehensive, global assessment of the studies that have addressed salvage logging effects on ecosystem processes.
Eliminado: $\angle \#>$ Forest regeneration capacity. Salvage logging has the potential to alter residual growing stock, soil seed bed, canopy and soil seed banks, and species interactions such as competition, seed dispersal, seed predation, and herbivory (Greene et al. 2006, Collins et al. 2010, Puerta-Piñero et al. 2010, Castro et al. 2012, Castro 2013). As a result, it can influence post-disturbance forest regeneration and stand development and affect all four kinds of ecosystem services. 
Systematic maps aim to collate the empirical evidence on particular topics and describe the characteristics of the studies on those topics (James et al. 2016). In contrast to systematic reviews, they do not aim to synthesise the results of individual studies. Rather, they help managers identify the literature on a topic that is most relevant to their needs as well as knowledge clusters and knowledge gaps to suggest future systematic review lines and topics for further empirical study.

Here, we provide a systematic map addressing the ecological effects of salvage logging, with a focus on regulating and supporting ecosystem services. The focus on ecosystem services intends to leverage the relevance and applicability of academic studies for non-academic stakeholders, including land managers who face the question of how to manage disturbed forests, as well as the general public. A global overview of this subject that also addresses potential reasons for heterogeneity in the effects measured by different studies could aid managers and policy-makers worldwide in finding the necessary scientific information to make decisions regarding salvage logging. Such decisions require answering questions such as: Is salvage logging likely to enhance the recovery of disturbed forests under particular forest types and disturbance conditions? And, Does the trade-off between provisioning and other kinds of ecosystem services result in a positive overall balance for specific management intervention? We describe the state of the literature that addresses these questions.

\section{Materials and methods}

We followed the guidelines for systematic reviews in environmental management as prescribed by the Collaboration for Environmental Evidence (CEBC 2010) and several other texts (Sutherland et al. 2004b, Pullin and Stewart 2006, Koricheva et al. 2013, James 

protocol (Leverkus et al. 2015a).

273 underlying this heterogeneity, we çonsidered the secondary research question:

Does the response of ecosystem services to post-disturbance salvage logging vary with the:

\section{Research question}

We established a, search strategy to identify the studies answering the following primary research question:

Does post-disturbance salvage logging affect regulating and supporting ecosystem services?

This question implies the following key elements:

- Population: Forests affected by one of the following disturbances: windstorms, pest insect outbreaks, or wildfire.

- Intervention: Salvage logging, i.e. the harvesting of trees from areas after disturbance events.

- Comparator: Forests after disturbance where no salvage logging was conducted.

- Outcome: Variables that could be regarded as indicators of regulating or supporting ecosystem services.

We expected that the studies collectively would provide varying and apparently contradictory answers to the primary research question. To search for potential reasons

- type and severity of the disturbance?

- geographic region?

Eliminado: Objective of the systematic map

Eliminado: Systematic maps aim to collate the empirical evidence on particular topics and describe the characteristics of the studies on

those topics (James et al. 2016). In contrast to systematic reviews, they do not aim to

synthesise the results of individual studies. Systematic maps help managers identify the literature on a topic that is most relevant to their needs. They also identify knowledge clusters and knowledge gaps to suggest future systematic review lines and suggest topics for further empirical study.

Eliminado: A

Eliminado: was established

Eliminado: answer 
- type of study design?

\section{$313 \quad$ Literature searches} in titles, abstracts and keywords and were based on the Population and the Intervention. The final search string (Table S1) was established after the scoping exercise described in the protocol (Leverkus et al. 2015a). The search in WoS was initially made on 18 Aug 2015 and updated on 5 May 2017 to encompass all studies published until 31 Dec 2016. In WoS, the search was restricted to the fields of Environmental Sciences and Ecology/ Forestry/ Biodiversity Conservation/ Zoology/ Plant Sciences/ Meteorology and Atmospheric

The primary literature search was conducted in English in Web of Science (WoS) and Scopus with the aim of answering the primary research question. The terms were searched Sciences/ Entomology/ Water Resources, and in Scopus to Agricultural and Biological Sciences/ Environmental Science/ Earth and Planetary Sciences/ Multidisciplinary.

We performed secondary searches to find other publications, including grey literature, with simplified Population and Intervention terms. These searches were made in the Directory of Open Access Journals (https://doaj.org/), the CABI database of forest science (http://www.cabi.org/forestscience/), and websites of the Canadian Forest Service (http://cfs.nrcan.gc.ca/publications) and the US Forest Service (http://www.treesearch.fs.fed.us/). We also searched in Google Scholar. For complete search terms, see Table S1. 

articles and books) were screened for additional articles to complement the list of articles

334 identified using the search terms ${ }_{\vee}$ A list of the publications was sent to all the authors of this systematic map, most of who have research experience on salvage logging. Authors were asked to identify relevant articles that were omitted from the search, and these articles were then assessed against the study inclusion criteria, as described next.

\section{Study inclusion criteria}

To be considered for the review, studies had to be empirical and fulfil each of the following inclusion criteria:

a) Relevant population: forest after wildfire, insect outbreak, or windstorm disturbance. Prescribed burning was not considered, as such fires tend to burn at lower intensity than uncontrolled wildfires.

b) Relevant intervention: salvage logging. Different methods of wood extraction and intensities of intervention were considered. We excluded studies where salvage logging was confounded with other subsequent interventions, such as tree planting or insecticide application, that were not conducted in the comparator.

c) Relevant comparator: forest disturbed by the same disturbance event but not subject to salvage logging. We did not consider areas of disturbed forest prior to logging as a comparator [i.e. Before-After (BA) study designs], as post-disturbance ecosystems are highly dynamic and the effects of salvage logging could be confounded with the effects of the time elapsed since the disturbance. As comparators, we considered the disturbed but 13
Eliminado: Authors of relevant articles were contacted to clarify study designs or provide additional data. 

unsalvaged areas of Control-Intervention (CI) and Before-After-Control-Intervention

358 (BACI) designs. or supporting ecosystem service. As it was expected that ecosystem services would rarely 361 be directly addressed ${ }_{6}$ we used variables considered to be indicators or proxies for ecosystem services (e.g. the quality of stream water for water purification, the abundance of seed dispersers for seed dispersal, plant biomass or cover for primary productivity, or the abundance of invasive species for invasion resistance). We also included studies addressing than neglecting the importance of such ecosystem services (which are a major driver of the decision to salvage $\log$ disturbed forests) our intention was to complement the list of

370 ecosystem services that can be affected by this practice. We also excluded cultural services because we expected few studies on this topic. Also, any variables directly related to the

372 number of standing trees were excluded on the basis that the intervention directly aims at

373 their extraction and reductions are thus a logical outcome. Finally, biodiversity was not recent meta-analysis (Thorn et al. 2018). included in the systematic map because such responses were thoroughly reviewed in a

We did not explicitly impose geographic restrictions on the studies, although the searches were restricted to publications in English.
Eliminado: as such 


\section{Article screening}

The relevance of the articles resulting from the searches of the literature was assessed through a stepwise elimination procedure. The articles were screened in the following steps:

1. Each title was read in the first step, and articles with irrelevant titles were discarded. This step was completed in a conservative way to avoid discarding any potentially relevant publications. Before screening all the titles, two members of the review team (ABL and $\mathrm{LG}$ ) screened 401 titles and the difference in outcomes was assessed through a kappa test. As the results indicated heterogeneity of application of selection criteria (see Results), the inclusion criteria were discussed again prior to screening all the titles. After screening the titles, the word "salvage" was searched in the titles, keywords and abstracts of all the papers that were recorded as irrelevant based on title. Their titles were screened again under a more inclusive approach, and those considered potentially relevant were re-included for the next step.

2. The abstracts of articles with relevant titles were read in the second step, and articles with irrelevant abstracts were discarded. To be classified as relevant in this step, the abstracts had to fulfil the inclusion criteria a), b), and c). In cases where there was doubt about the relevance of a publication, it was kept for the next step. Three authors (ABL, JC, and LG) initially revised 63 randomly-chosen abstracts and kappa tests were again used to assess and improve homogeneity of application of inclusion criteria.

3. The articles with potentially relevant abstracts were read in full. At this stage, articles failing to fulfil any one of the study inclusion criteria were discarded. To select 15 
studies that fulfilled inclusion criterion d), the main objectives of the studies were assessed as well as the study-site descriptions (including tables and figures). Relevant articles were categorised according to the study quality assessment criteria defined below.

\section{Study quality and validity assessment}

Quality appraisal is not a necessary process in systematic mapping (James et al. 2016). Nevertheless, based on the retrieved literature, we jdentified, some quality issues, related both to the methodology and to the reporting in individual publications that provided insight into the validity of the publication for inclusion in the map. First, regarding quality in reporting, the lack of proper description of the study site and the sampling methods (i.e. not possible to assess study inclusion criteria and/or study validity based on methodological quality due to deficiencies in reporting) led to study exclusion.

The remaining studies were placed in the following three broad categories based on methodological quality:

1. Empirical studies with treatments applied at appropriate spatial scales and with true replication at the scale of management operations and with randomised allocation of treatments to spatial units. An appropriate scale was considered as one that would generally be used in post-disturbance management under local conditions, or that would reasonably allow the measured responses to appear.

2. Studies as in 1 above, but without randomisation in the allocation of treatments to spatial units. This is often the case, as the authors of the retrieved articles rarely had control over the salvage logging process. This quality aspect is relevant from the point of view of 16

Eliminado: could

Eliminado: y

Eliminado: aspects

Eliminado: ,

Eliminado: , 

included bibliographic information and data related to the secondary research questions.

susceptibility to bias and it should be considered in subsequent systematic reviews.

Although we did not use this criterion to reject studies in this systematic map, we did record whether the spatial units where the intervention and the comparator were established were chosen by the researchers (see Systematic map database, below).

3. Empirical studies without true replication or at inappropriate spatial scales. Studies with pseudo-replicated designs were placed in this category. One of the most frequent cases was that of one disturbance event affecting a reserve (unsalvaged comparator) and adjacent, unprotected forest (salvaged intervention area). Such designs are highly susceptible to confounding factors related to the management history and objectives of the different management ("treatment") units and hence to bias, so we decided to exclude such studies from the systematic map. As a matter of consistency, we also eliminated all other studies that contained only one true replicate unit per treatment. It should be noted that in some studies, $_{2}$ the degree of true replication was very hard to assess from the study site descriptions, and in other cases there was ambiguity in what could be considered true replication. In such cases, other articles from the same sites were assessed and, where necessary, authors were contacted to clarify their study designs.

\section{Systematic map database and data coding strategy}

We constructed a database with information relative to each publication, which

448 This encompassed data on stand, disturbance and salvage logging characteristics, study 
450 designs, and the response variables that were measured. For a detailed description of the 451 data included in the systematic map database, see Appendix A 1 .

453 Calculations and graphical output were produced in $\mathrm{R}$ version 3.3.1 ( $\mathrm{R}$ Core Team 454 2016).

\section{Results and discussion}

\section{$457 \quad$ Literature searches} publications was assessed at full-text length, and 90 were kept in this systematic map (Fig

460 2; see Supplementary Table S2 for publications excluded at this stage and the reasons for 461 exclusion). For detailed descriptions of the results of the literature searches and screening, 462 see Appendix A2. The remainder of the systematic map is primarily grounded on the 90 463 publications that were kept, which are included in the systematic map database 464 (Supplementary Table S3).

The following results are presented at the level we considered most relevant for each addressed characteristic: some at the level of publications $(n=90)$, others at the level of studies $(n=49)$ (see Appendix A1), and others at the level of stand types within study sites
Eliminado: ;

Eliminado: 739 of these had a potentially relevant title

Eliminado: These and an additional 58 publications retrieved in the secondary searches were screened at the abstract level.

Eliminado: were

Eliminado: rest

Eliminado: focuses 
single study; $n>49$ ). The level of each result is always indicated in the text, and the database allows assessing any data at any desired level.

\section{Origin and distribution of publications}

Of the 90 publications included in the systematic map database, 81 were obtained from the primary search in the Web of Science, The cumulative number of publications has increased dramatically in the last two decades, and particularly in the last decade (Fig 3).

The 90 publications resulted from 49 studies, including studies with multiple study sites. Individual studies produced an average of $1.8 \pm 1.2$ publications (mean $\pm \mathrm{SD}$; range: 1-6), although it should be noted that not all publications from all studies are included in this systematic map [e.g. some papers from the Bavarian Forest National Park in Germany that dealt with salvage logging effects on biodiversity were excluded (Beudert et al. 2015, Thorn et al. 2015a, 2015b)]. Studies were generally established within one clearly defined study area, such as a publicly owned forest (e.g., National Forest) with adjacent private forestland, but eight studies (yielding 12 publications) either addressed two or more study sites that were located in different regions (separated by more than $100 \mathrm{~km}$; e.g. Wagenbrenner et al $、 2015$ ) or had a sampling design of regional scale, with multiple sites (e.g. Priewasser et al,2013) (Table 1).

The publications included in the database were overwhelmingly concentrated in North America and Europe, with only two publications from another continent and no representation from the tropics or the Southern Hemisphere (Fig 4; Table 1). Even within these two geographic clusters, the publications were not equally distributed. In North 19
Eliminado: (those found in Scopus were either repeated or excluded), 1 from the secondary searches (US Forest Service website), and 8 from the supplementary searches (article reference lists)

Eliminado: 10 years

Movido (inserción) [3]

Eliminado: Distribution of studies

Eliminado: se

Eliminado: ,

Eliminado: , 
515 America, there were nearly twice as many publications from the U.S.A than from Canada, and even publications from Canada were more abundant than those from all Europe (where half of the publications came from Spain). One could predict that studies on post-disturbance logging would occur more frequently in places where more natural disturbance occurs, or where natural disturbance is more often followed by logging. However, disturbances are common across forests globally (Seidl et al. 2017), and there is no obvious reason to consider that the countries not included in the systematic map lack $\underline{\text { salvage logging. }}$

A possible explanation for the paucity of studies in the tropics lies in differences in human-related causes and consequences of disturbances across regions. Disturbances like wildfire in regions at the frontline of land-use change, such as many tropical regions, often $\underline{\text { constitute an instrument for deforestation and land conversion rather than a natural process }}$ followed by regeneration. In contrast, developed countries have generally reached more stable land uses, so that disturbed forests will be expected to regrow, either for production or for nature conservation. In this way, assessing the effects of salvage logging on ecosystems makes more sense in cases where management or conservation objectives are to maintain forest cover, as is more often the case in Europe and North America than in other regions. Even in the few exceptions where salvage logging was addressed in tropical areas, the research was conducted by foreign researchers (Van Nieuwstadt et al. 2001). Most of the studies outside these two zones, including studies in Chile (Smith-Ramírez et al. 2014) and Australia (Blair et al. 2016), failed to pass the inclusion criteria regarding the relevance of response variables. Other non-mutually exclusive reasons for the predominance of 
European and North American studies, as highlighted in a systematic map on active interventions for biodiversity conservation (Bernes et al. 2015), are: a) the large extents of forest, b) the greater abundance of researchers and availability of funding, and c) the large emphasis on research in ecology and environmental management in Europe and North America. Finally, an important factor could be the language selected for the literature search -English-, which was originally aimed at identifying scientific studies from over the world but was biased against studies from nations where English is either not the official language or not spoken at a sufficient level of proficiency to facilitate publication in indexed journals.

\section{Disturbance characteristics}

Wildfire was the most frequent disturbance type, with 51 publications (27 studies), followed by wind (26 publications, 12 studies), and insect outbreaks (13 publications, 11 studies). McIver and Starr (2000) conducted a review that highlighted several mechanisms through which burnt forests could be particularly vulnerable to subsequent logging disturbance, including effects on burnt soil and vegetation. This review also noted a lack of empirical evidence regarding the consequences of post-fire logging, which triggered numerous research projects on logging after wildfire [e.g., McIver and McNeil (2006), Donato et al. (2006), Castro et al. (2010)]. Wildfire produces some unique ecological responses, such as significant reductions in small-diameter aboveground biomass, as well as direct and indirect wildlife mortality. Wildfire also generates direct impacts on people living in or near fire-prone forests and spectacular images in the media. These factors have 21
Eliminado: Disturbance and salvage logging descriptions .

Bajado [4]: Wildfire was the most frequent disturbance type, with 51 publications $(27$ studies), followed by wind ( 26 publications, 12 studies), and insect outbreaks (13 publications, 11 studies).

Movido (inserción) [4] 
likely generated more public and political demand for understanding the various implications of wildfire as compared to windstorms or insect outbreaks, including impacts $\underline{\text { related to subsequent salvage logging. However, logging after large storms (e.g., Kramer et }}$ al. 2014), and after massive insect outbreaks (e.g., Collins et al. 2011), has recently attracted increasing attention. The three kinds of disturbances addressed here have increased -and will likely continue to increase- in frequency and extent due to climate change and other factors related to ecosystem conversion and changes in land-use intensity (Seidl et al. 2017). Addressing questions related to post-disturbance management is a logical response to increasingly prevalent situations. which highlights the relevance of studying the response to disturbance, and to subsequent $\underline{\text { logging, under different degrees of severity. The severity of natural disturbance among the }}$ retrieved publications ranged between 10 and 100\% (Fig 5A; note the limitations in these data described in the Systematic map database and coding strategy section in Appendix A1). We found that wildfire was generally described as having greater disturbance severity than insect outbreaks or windstorms. Studies on logging after wildfire or insect outbreaks were generally tightly clustered at high severity values, whereas disturbance severity by wind was less severe and more variable. Most of the studies included in the systematic map were performed within patches subject to disturbances of specific severity, thereby controlling for this factor as much as possible. In only a few cases ( 8 out of 49) did the $\underline{\text { studies directly address disturbance severity as an explanatory variable, either through the }}$ 
sampling severity gradients within plots (e.g. Royo et al., 2016). Although the selection of plots of different disturbance severity is an appropriate way to increase the robustness of the study design, it may come at the cost of lower replication. In contrast, measuring disturbance severity at smaller scales as a covariate can help increase the explanatory power of management variables without sacrificing replication. Of course, this is not always possible, and it hinges on the spatial scale at which disturbance severity varies and the spatial scale required to accurately assess the response variable of interest. many cases this information was not available. However, it can be argued that large disturbances will generally attract more research and provide opportunities for greater replication. For example, disturbances in North America commonly affect large areas (e.g. the 2016 fire near Fort McMurray, Canada, which affected more than half a million ha).

Salvage logging is, however, quite often performed in areas affected by small- or medium-scale disturbances, which are common in Europe and tend to be confined to areas with pre-existing road infrastructure. Scientific studies performed in these areas might suffer from constraints in the sampling design (thus leading to exclusion from the systematic map) but, in these situations, logging intensity is likely to reach $100 \%$ across the disturbed area. As a consequence, subjects worthy of in-depth analysis that are not covered by this systematic map include the relationships among disturbance extent, the extent and intensity of salvage logging, and the ecological response to disturbance and subsequent salvage logging. 
Ecological responses to salvage logging are often considered to vary with the time elapsed between the disturbance and logging, particularly in the case of discrete disturbance events like wildfire. For example, post-fire logging may have greater impact on soils if it is conducted directly after wildfire because it may delay post-fire recovery (Wagenbrenner et al. 2016). If logging occurs during or after the first growing season, natural regeneration can be most severely affected due to the physical destruction of resprouting stems and emerging seedlings (Martínez-Sánchez et al. 1999, Castro et al. 2011). The studies included in the systematic map most often included information on when logging was conducted, yet individual studies did not explicitly test the effect of different timing of salvage logging.

619 Salvage logging took place between immediately and 10.5 years following the disturbance, with an average of $1.8 \pm 2.0$ (mean $\pm 1 \mathrm{SD}$ ) years across publications. Burnt stands were generally those salvage logged most quickly (after $1.1 \pm 0.8$ years), followed by wind-affected stands $(1.7 \pm 0.8$ years; Fig $5 \mathrm{~B})$. In the case of disturbance by insects, salvage the timing of salvage logging was much greater than for the other two disturbance types $(4.4 \pm 3.7$ years $)$. Insect outbreaks most often take several years to develop, during which each tree goes through several stages of decline (Sullivan et al. 2010), and logging can take place at any stage from before the beginning of the outbreak -pre-emptive logging, not addressed here- to logging after several years of infestation. Logging is sometimes conducted in an attempt to prevent the infestation of particular stands or the expansion of

Eliminado: These averages were $1.1 \pm 0.8$ years for wildfire, $4.4 \pm 3.7$ years for insect outbreaks, and $1.7 \pm 0.8$ years for wind disturbance (Fig 5B). . 
decay or the accumulation of fuel once the stand has been affected. These are likely reasons for the greater variability in the timing of salvage logging related to insect outbreaks than after disturbance by fire or wind.

The intensity of salvage logging can be another crucial factor explaining salvage logging effects, as already identified more than six decades ago (Roy 1956). The studies in the systematic map included a wide range of salvage logging intensity for the three disturbance types considered, although intensity was mostly categorised in excess of $90 \%$. Salvage logging intensity ranged between 25 and $100 \%$, and it averaged $80 \pm 24 \%$ (including up to 4 values per publication). Average intensities were $79 \pm 24 \%$ for wildfire, $90 \pm 15 \%$ for insect outbreaks, and $79 \pm 27 \%$ for wind damage (Fig $5 \mathrm{C}_{2}$ as with disturbance severity, note the limitations in these data, described in Appendix A1). In some cases, the effect of different logging intensity was assessed within individual studies; this often included qualitative differences in logging practices such as the removal of slash or the retention of standing dead trees. Notably, in one experimental study, stands under five classes of logging intensity were established, ranging from 0 to $100 \%$ (Ritchie et al. 2013). The authors further assessed the effect of amount of basal area retained, which explained the variation in some of the response variables better than the categorical experimental factor (Ritchie et al. 2013). Such studies can provide important insights into the responses to salvage logging and can evaluate the effectiveness of Best Management Practices, as $\underline{\text { logging -and other disturbances- may not necessarily produce generalizable effects but }}$ rather effects that vary nonlinearly according to disturbance intensity or severity (Buma 2015, Foster et al. 2016, Leverkus et al. 2018). This has long been acknowledged in

Eliminado: The intensity of s
Eliminado: alvage logging
Eliminado: across the retrieved publications
Eliminimado: these values of logging intensity
represent a broad approximation due to the
various ways in which it was measured in the
retrieved publications



traditional green-tree silviculture, where the retention forestry approach was created under the acknowledgement that the effects of commercial clearcutting can be greatly mitigated by leaving behind structures that favour the continuity of the forest ecosystem (Gustafsson et al. 2012, Lindenmayer et al. 2012). The rapid deterioration of wood quality following disturbance-induced mortality reduces the profitability of salvage operations compared to green-tree silviculture, and this could be a limitation for retention approaches. Nevertheless, the potential benefits of the retention of biological legacies (Franklin et al. 2000) during post-disturbance harvest operations should be more profoundly explored (Lindenmayer et al. 2018, Thorn et al. 2018).

methods employed in salvage logging operations can also modulate the effect of the intervention. For example, mechanized harvesting equipment is more likely to compact soils than manual cutting with chainsaws, but it may also produce novel, positive effects like forming ruts that fill with water and create persistent aquatic habitat (Ernst et al. 2016). Logging operations were often not described well enough in publications included in the systematic map to identify logging methods, sometimes because the operations were not

Eliminado: the

Eliminado: obtain observed by the researchers. Harvesting with feller-bunchers was mentioned in 15 studies (not publications), and manual cutting in 10 studies. Ground-based yarding was mentioned in 20 studies, and by helicopter in two studies. Extraction of wood by helicopter is well known to reduce soil impacts compared to ground-based yarding. However, helicopter use is extremely costly; this, combined with the low economic value of disturbance-affected timber and depressed price that typically follow large disturbance events, are likely reasons for the scant mentions of helicopters. 
690

691 characteristics of stands among the retrieved studies, see Appendix A3.
Eliminado: (stand age, leaf habit, and dominant tree species)

\section{Characteristics of study designs}

True replication is an important factor reducing the potential for bias of individual studies. True replication of salvage logging generally did not exceed $\mathrm{N}=10$ stands (Fig 6; presented at the scale of publications because some publications of the same studies made use of different subsets of a larger design; e.g., Leverkus et al. 2014, 2016). Most studies addressed the issue of low replication by establishing hierarchical sampling designs (i.e. with several sub-units within salvage and control units) and by controlling the effects of potentially confounding co-variables. These strategies were also employed in many of the studies that were excluded due to lack of true replication (Table S2). As a result, we do not discard the possibility that some of those excluded studies could provide valuable insights despite pseudo-replication, yet for the purpose of inclusion in the systematic map, we elected to stay with the study inclusion criteria established in the protocol aimed at reducing the potential for bias (Leverkus et al. 2015a). 
714 treatments to spatial units. In the rest of the studies, researchers made use of areas that were

either salvaged or left unsalvaged to achieve management objectives rather than to conduct research Both approaches provided several advantages and disadvantages.

Non-experimental studies have a risk of bias between intervention and comparator stands, for example due to the selection of more productive stands, or those nearest to roads, for salvage operations. Further, the choice not to salvage log particular stands is sometimes justified by reasons such as fiscal constraints and litigation; stream, hillside, and habitat protection; or inaccessibility (McGinnis et al. 2010), highlighting the potential for bias. $\underline{\text { Still, in non-experimental studies, care was generally taken to select salvaged and }}$ unsalvaged stands of similar pre-disturbance conditions to minimise such bias. In addition, some studies controlled for random spatial variation by implementing a BACI design -i.e. by measuring how the response variables changed over time from pre-logging to post-logging and in stands with and without the salvage logging intervention, thus providing a robust method for addressing bias. Such a BACI design was implemented in $36 \%$ of the 11 studies where salvage logging was performed experimentally and in $19 \%$ of the 37 non-experimental studies, One good example of experimental design is the one established after the Summit Fire in Oregon, which included randomisation, blocking, treatments applied at an appropriate spatial scale, replication, consideration of disturbance severity and salvage logging intensity, and a BACI sampling design (McIver and Ottmar 2007). Such studies are extremely difficult to implement, as exemplified by one paper that 28
Eliminado: for reasons

Eliminado: beyond their control

Eliminado: O

Eliminado: , 36\% (four studies) employed a Before-After Control-Intervention (BACI) design in at least some part of their sampling

Eliminado: . Only

Eliminado: (seven studies)

Eliminado: used a BACI design

Eliminado: 
reports the conceptualisation of a randomised complete block design that, however, could not be turned to practice due to legal constraints and which resulted in a pseudo-replicated design comparing salvaged private forest vs unsalvaged public land (Slesak et al. 2015) hence leading to exclusion from our systematic map.

$\underline{\text { Not all true experimental studies are necessarily ideal, and some can suffer problems of }}$ inappropriate spatial scale and lack of replication (e.g., Francos et al. 2018)_but such problems were not detected in the retrieved studies. However, a general disadvantage of experiments that were under the control of researchers is that the logging intervention was typically performed in close compliance with environmental prescriptions (e.g., Ne'eman et al. 1997, McIver and Ottmar 2007, Leverkus et al. 2014), so that the intervention may have lesser effects than under non-experimental, "real-world" management. Besides, some non-experimental studies had the advantage that they could be conducted at spatial scales larger than what would be possible under experimental approaches by selecting several disturbance patches with and without intervention that fulfilled certain criteria across entire regions or countries (Priewasser et al. 2013, Águas et al. 2014). In this systematic map, most studies (36) were established within the perimeter of a single disturbance event, thereby establishing the disturbance as the constraint on the inference population. However, two studies (one post-fire and one post-insect) included two disturbance events, four included four events, one included five, one included 14, and one included 20 (all post-fire). Three studies on post-windthrow logging addressed one disturbance event (e.g. one storm) but within 7,11 , or 30 spatially independent blowdown patches; one study assessed 90 individual patches caused by two storms. 
As a corollary of the previous discussion, it is difficult to apply strict, identical quality criteria to all studies, and there is not one single ideal study design. We consider all studies included in this systematic map to be of sufficient quality for providing relevant information under certain conditions.

\section{Characteristics of the responses}

Studies explicitly focusing on the response of ecosystem services to salvage logging were scant. Most publications addressed ecosystem elements and structures, fewer studied ecosystem functions, and very few addressed the human well-being component of ecosystem services directly (Fig 1). This is consistent with the findings of a global literature review on ecosystem service studies, (Boerema et al. 2016), and it highlights the need to better address the human component of salvage logging effects to improve the transferability of results to management decisions (Leverkus and Castro 2017). It should also be noted that most of the publications $(79 \%)$ included data on one or two measurements of the response variable undertaken at different times, and the maximum was 20 measurements (Fig 7, inset). Four publications included continuous measurements taken over 3 or 6 years.

The most frequent response variables examined were related to tree regeneration (addressed by $51 \%$ of the publications; Fig. 7). These included the density, basal area, growth, and survival of trees established after disturbance. This was no surprise, as establishment of trees is perhaps the most direct indicator of the recovery of the previous ecosystem. Further, some agencies, such as the US Forest Service, are required by law to 30

\begin{tabular}{l} 
Bajado [5]: The systematic map presented \\
here provides a rigorous account of the \\
empirical studies addressing the effects of \\
salvage logging on supporting and regulating \\
ecosystem services that fulfil some qualitative \\
requirements. It shows that substantial \\
research has been conducted in the last two \\
decades, particularly after the publication of an \\
article in Science in 2004 calling for a careful \\
revision of post-disturbance management \\
practices (Lindenmayer et al. 2004). \\
Eliminado: \\
Distribution of studies \\
Subido [3]: Distribution of studies \\
Eliminado: Distribution of studies \\
Movido (inserción) [2] \\
Eliminado: the studies on \\
\hline
\end{tabular}

Eliminado: $\mathrm{s}$ 
812 Try to save the high costs of artificial regeneration." micro-topographic habitat availability and heterogeneity. Bare soil cover could be an

818 indicator of available seedbed in measurements made right after the disturbance, or of

819 ground disturbance and lack of regeneration in both early and subsequent measurements.

Finally, skid trail cover would indicate, soil disturbance and compaction.

monitor and rectify tree regeneration failure associated with management activities. In many situations, lack of appropriate regeneration means that trees would have to be planted, so that natural regeneration provides direct value for society (Fig 1). In fact, as early as in 1956, a report (Roy 1956) already advised "When you find good reproduction, protect it. by $42 \%$ of publications). Typically, this would include vegetation cover, a useful measure of protection from soil erosion or primary productivity. Cover of pits and mounds, as well as cover of deadwood, may be used as indicators of the microclimatic and The third most frequent response variable type was related to the availability and characteristics of deadwood_(addressed by $41 \%$ of publications). This included snags, downed logs, branches and twigs, often separated by species, size and decay stage. Deadwood after disturbance is an important component associated with many post-disturbance specialists, including birds and beetles (Thorn et al. 2018). Standing trees can act as habitat for species that live in tree hollows (Lindenmayer and Possingham 1996) and as perches or visual cues for seed dispersers (Castro et al. 2012, Cavallero et al. 2013). Deadwood constitutes a pool of nutrients that is released to the soil in the mid- and 
long-term through decomposition (Marañón-Jiménez and Castro 2013, Molinas González et al. 2017). It can also ameliorate microclimatic conditions to enhance tree regeneration (Castro et al. 2011) and help reduce herbivory by large ungulates (Leverkus et al. 2015b). However, there is also a risk that the wood left behind by disturbance constitutes the means of propagation of a subsequent disturbance such as wildfire or insect outbreaks. As a result, in many studies, the aim of deadwood characterisation was to assess the amount and features of fuels, including the modelling of future fuel characteristics and of potential fire behaviour (McIver and Ottmar 2007, Keyser et al. 2009, Donato et al. 2013, Hood et al. 2017). One publication with a chronosequence approach that was excluded from the map for design-related reasons provides a thorough assessment of the time frames at which fuels are enhanced or reduced by salvage logging (Peterson et al. 2015). In fact, risk reduction of subsequent disturbance is one of the main justifications for salvage logging (Müller et al. 2018), including fire but also the risk of bark beetle outbreaks after windstorms (Leverkus et al. 2017) and other linked disturbances (Buma 2015). Nevertheless, we identified only two studies addressing resilience to subsequent wildfire as a response variable (Fraver et al. 2011, Buma and Wessman 2012). This is likely due to the complex concatenation of disturbance events required to assess such a variable empirically: it requires both intervention and comparator stands to be followed by the same subsequent disturbance and compliance with the additional criteria established in our protocol. Fuel characterisation and modelling of fire behaviour are thus logical ways to address such questions, and our systematic map may have left out relevant studies in this regard. Conversely, the amount of deadwood also can be used as an indicator of the size of the carbon pool in disturbed 32 
ecosystems. The trade-off between $\mathrm{C}$ retention and wildfire prevention can be solved by assessing the $\mathrm{C}$ cycle directly (Serrano-Ortiz et al. 2011a) or by focusing independently on recalcitrant $\mathrm{C}$ pools (large trees, snags, coarse wood, and soil) and labile fuels (understory shrubs, fine wood, and duff) (Powers et al. 2013); the studies in the systematic map generally allow this approach due to the explicit consideration of different size classes.

The fourth most frequent type of response variable was non-tree vegetation (beyond mere percent cover values; addressed by $28 \%$ of publications). Although we avoided including biodiversity responses in this map due to the existence of a recent review on the topic (Thorn et al. 2018), we did include vegetation as an indicator of the recovery of ecosystem structure, habitat, and soil retention.

Next, soil physical and chemical properties_addressed by $26 \%$ of publications) included measurements related to soil fertility. The remaining response variable categories were addressed by $<15 \%$ of the publications (Fig 7). Both erosion control and the abundance of exotic or invasive species were addressed in only six publications, which is surprising given that they constitute some of the core concerns of managers after natural

Eliminado: $\mathrm{F}$

Eliminado: in frequency disturbances. Negative results and the absence of invasive species could partially explain the lack of published results on this topic (e.g., Leverkus et al. 2014). Next, non-deadwood C pool was addressed in five studies. Biological indicators of nutrient cycling and riparian ecosystem functioning were addressed in four publications. Again, the latter variable comes as one of the main concerns regarding salvage logging yet with very little research (Karr et al. 2004). This likely has to do with the spatial scale defined for inclusion in the systematic 
map (that of salvage logging intervention), which excluded several studies implemented at the scale of watersheds and with problems of replication. Only one study addressed seed dispersal and one addressed drinking water quality (perhaps the one publication most clearly focusing on the human well-being side of the ecosystem services cascade; Fig 1). Avalanche protection in steep hills is another important ecosystem service affected by salvage logging (Wohlgemuth et al. 2017), yet it was not included in the systematic map as a response because the one study addressing it (Schönenberger et al. 2005) lacked replication.

\section{Conclusions}

The systematic map presented here provides a rigorous account of the empirical studies addressing the effects of salvage logging on supporting and regulating ecosystem services that fulfil some qualitative requirements. It shows that substantial research has been conducted in the last two decades, particularly after the publication of an article in Science in 2004 calling for a careful revision of post-disturbance management practices (Lindenmayer et al. 2004). Our systematic map is based on a comprehensive and systematic screening of the scientific literature on post-disturbance logging written in English and considers a range of stand, disturbance and logging characteristics and of outcomes. It should help managers and policy makers identify the most relevant studies addressing the effects of salvage logging and thus spare them the work of searching from scratch. It is also relevant for scientists who aim to synthesize previous work and it identifies knowledge gaps to help direct future work. For example, we identified a large geographic gap across

Subido [2]: In summary, studies explicitly focusing on the response of ecosystem services to salvage logging were scant. Most publications addressed ecosystem elements and structures, fewer studied ecosystem functions, and very few addressed the human well-being component of ecosystem services directly (Fig 1). This is consistent with the findings of a global literature review on the studies on ecosystem services (Boerema et al. 2016), and it highlights the need to better address the human component of salvage logging effects to improve the transferability of results to management decisions (Leverkus and Castro 2017).

Eliminado:

Movido (inserción) [5]

Con formato: Sangría: Primera línea: 0

Eliminado:

Eliminado: $\mathrm{n}$

Eliminado: or

Eliminado: y

Eliminado: for 
924 very limited research focusing on the link between ecosystem elements and processes and

925 the benefits and values for human society, which ultimately define many management

926 schemes. It should also be noted that very few of the retrieved studies specifically

927 addressed the effects of deadwood retention. Whereas small-scale retention is nowadays a

well-known practice in green-tree harvesting and much research has been conducted on the

topic (Fedrowitz et al. 2014), the benefits of such practices in disturbed forests are not yet

well known and require substantial additional research (Lindenmayer et al. 2018, Thorn et

al. 2018). Finally, the systematic map identified some areas with substantial research where systematic review or meta-analysis can be performed:

- The effect of salvage logging on recalcitrant $v$ s. labile deadwood components (i.e. C pool vs. fuel loads) and how these vary over time.

- The effect of salvage logging on tree regeneration.

- The effect of the time between disturbance and subsequent logging on response variables.

- The effect of disturbance type on the ecological effects of salvage logging.

\section{Acknowledgments}

941 ABL acknowledges postdoctoral funding from the Spanish Ministerio de Economía y 942 Competitividad (FJCI-2015-23687) and mobility grant (CAS17/00374) from Ministerio de 
944 Educación, Cultura y Deporte. Additional funding was provided by projects 945 P12-RNM-2705 from Junta de Andalucía, CGL2014-53308-P of the Spanish Government, 946 and Remedinal 3 (S2013/MAE-2719) of the Madrid Government.

\section{References}

[Millennium Ecosystem Assessment], M. 2003. MA Conceptual Framework. In Ecosystems and human well-being: A framework for assessment. Island Press. pp. 2536. doi:10.1079/PHN2003467.

Águas, A., Ferreira, A., Maia, P., Fernandes, P.M., Roxo, L., Keizer, J., Silva, J.S., Rego, F.C., and Moreira, F. 2014. Natural establishment of Eucalyptus globulus Labill. in burnt stands in Portugal. For. Ecol. Manage. 323: 47-56. Elsevier B.V. doi:10.1016/j.foreco.2014.03.012.

Beghin, R., Lingua, E., Garbarino, M., Lonati, M., Bovio, G., Motta, R., and Marzano, R. 2010. Pinus sylvestris forest regeneration under different post-fire restoration practices in the northwestern Italian Alps. Ecol. Eng. 36(10): 1365-1372. Elsevier B.V. doi:10.1016/j.ecoleng.2010.06.014.

Bernes, C., Jonsson, B.G., Junninen, K., Lõhmus, A., Macdonald, E., Müller, J., and Sandström, J. 2015. What is the impact of active management on biodiversity in boreal and temperate forests set aside for conservation or restoration? A systematic map. Environ. Evid. 4(1): 25. BioMed Central. doi:10.1186/s13750-015-0050-7. 
Beschta, R.L., Rhodes, J.J., Kauffman, J.B., Gresswell, R.E., Minshall, G.W., Karr, J.R., Perry, D.A., Hauer, F.R., and Frissell, C.A. 2004. Postfire management on forested public lands of the Western United States. Conserv. Biol. 18(4): 957-967. doi:10.1111/j.1523-1739.2004.00495.x

Beudert, B., Bässler, C., Thorn, S., Noss, R., Schröder, B., Dieffenbach-Fries, H., Foullois, N., and Müller, J. 2015. Bark beetles increase biodiversity while maintaining drinking water quality. Conserv. Lett. 8(4): 272-281. doi:10.1111/conl.12153.

Blair, D.P., McBurney, L.M., Blanchard, W., Banks, S.C., and Lindenmayer, D.B. 2016. Disturbance gradient shows logging affects plant functional groups more than fire. Ecol. Appl.: n/a-n/a. doi:10.1002/eap.1369.

Boerema, A., Rebelo, A.J., Bodi, M.B., Esler, K.J., and Meire, P. 2016. Are ecosystem services adequately quantified? J. Appl. Ecol. In press: 10.1111/1365-2664.12696. doi:10.1111/1365-2664.12696.

Boucher, D., Gauthier, S., Noël, J., Greene, D.F., and Bergeron, Y. 2014. Salvage logging affects early post-fire tree composition in Canadian boreal forest. For. Ecol. Manage. 325: 118-127. Elsevier B.V. doi:10.1016/j.foreco.2014.04.002.

Brewer, J.S., Bertz, C.A., Cannon, J.B., Chesser, J.D., and Maynard, E.E. 2012. Do natural disturbances or the forestry practices that follow them convert forests to early-successional communities? Ecol. Appl. 22(2): 442-458. doi:10.1890/11-0386.1.

Buma, B. 2015. Disturbance interactions: characterization, prediction, and the potential for cascading effects. Ecosphere 6(April): Art70. doi:10.1890/ES15-00058.1. 
Buma, B., and Wessman, C.A. 2012. Differential species responses to compounded perturbations and implications for landscape heterogeneity and resilience. For. Ecol. Manage. 266: 25-33. Elsevier B.V. doi:10.1016/j.foreco.2011.10.040.

Castro, J. 2013. Postfire Burnt-Wood Management Affects Plant Damage by Ungulate Herbivores. Int. J. For. Res. 2013: 1-6. doi:10.1155/2013/965461.

Castro, J., Allen, C.D., Molina-Morales, M., Marañón-Jiménez, S., Sánchez-Miranda, Á., and Zamora, R. 2011. Salvage logging versus the use of burnt wood as a nurse object to promote post-fire tree seedling establishment. Restor. Ecol. 19(4): 537-544. doi:10.1111/j.1526-100X.2009.00619.x.

Castro, J., Moreno-Rueda, G., and Hódar, J.A. 2010. Experimental test of postfire management in pine forests: Impact of salvage logging versus partial cutting and nonintervention on bird-species assemblages. Conserv. Biol. 24(3): 810-819. doi:10.1111/j.1523-1739.2009.01382.x.

Castro, J., Puerta-Piñero, C., Leverkus, A.B., Moreno-Rueda, G., and Sánchez-Miranda, A. 2012. Post-fire salvage logging alters a key plant-animal interaction for forest regeneration. Ecosphere 3(10): art90.

Cavallero, L., Raffaele, E., and Aizen, M.A. 2013. Birds as mediators of passive restoration during early post-fire recovery. Biol. Conserv. 158: 342-350. doi:10.1016/j.biocon.2012.10.004.

CEBC. 2010. Guidelnes for Systematc Reviews in Environmenta Management Version 4.0. In Environmental Evidence. Bangor, UK. 
Collins, B.J., Rhoades, C.C., Battaglia, M.A., and Hubbard, R.M. 2012. The effects of bark beetle outbreaks on forest development, fuel loads and potential fire behavior in salvage logged and untreated lodgepole pine forests. For. Ecol. Manage. 284: 260268. Elsevier B.V. doi:10.1016/j.foreco.2012.07.027.

Collins, B.J., Rhoades, C.C., Hubbard, R.M., and Battaglia, M.A. 2011. Tree regeneration and future stand development after bark beetle infestation and harvesting in Colorado lodgepole pine stands. For. Ecol. Manage. 261(11): 2168-2175. Elsevier B.V. doi:10.1016/j.foreco.2011.03.016.

Collins, B.J., Rhoades, C.C., Underhill, J., and Hubbard, R.M. 2010. Post-harvest seedling recruitment following mountain pine beetle infestation of Colorado lodgepole pine stands: a comparison using historic survey records. Can. J. For. Res. 40(12): 24522456. doi:10.1139/X10-172.

Crouzeilles, R., Ferreira, M.S., Chazdon, R.L., Lindenmayer, D.B., Sansevero, J.B.B., Monteiro, L., Iribarrem, A., Latawiec, A.E., and Strassburg, B.B.N. 2017. Ecological restoration success is higher for natural regeneration than for active restoration in tropical forests. Sci. Adv. 3: 1701345. doi:10.1126/sciadv.1701345.

DellaSala, D.A., Karr, J.R., Schoennagel, T., Perry, D., Noss, R.F., Lindenmayer, D., Beschta, R., Hutto, R.L., Swanson, M.E., and Evans, J. 2006. Post-fire logging debate ignores many issues. Science (80-. ). 314(October): 51-52.

Donato, D.C., Fontaine, J.B., Campbell, J.L., Robinson, W.D., Kauffman, J.B., and Law, B.E. 2006. Post-wildfire logging hinders regeneration and increases fire risk. Science 
Donato, D.C., Simard, M., Romme, W.H., Harvey, B.J., and Turner, M.G. 2013. Evaluating post-outbreak management effects on future fuel profiles and stand structure in bark beetle-impacted forests of Greater Yellowstone. For. Ecol. Manage. 303: 160-174. Elsevier B.V. doi:10.1016/j.foreco.2013.04.022.

Ernst, R., Hölting, M., Rodney, K., Benn, V., Thomas-Caesar, R., and Wegmann, M. 2016. A frog's eye view: logging roads buffer against further diversity loss. Front. Ecol. Environ. 14(7): 353-355.

Fedrowitz, K., Koricheva, J., Baker, S.C., Lindenmayer, D.B., Palik, B., Rosenvald, R., Beese, W., Franklin, J.F., Kouki, J., Macdonald, E., Messier, C., Sverdrup-Thygeson,

Fornwalt, P.J., Rhoades, C.C., Hubbard, R.M., Harris, R.L., Faist, A.M., and Bowman,

Foster, C.N., Sato, C.F., Lindenmayer, D.B., and Barton, P.S. 2016. Integrating theory into effects on short-term evolution of soil properties (Catalonia, Spain, SW-Europe). Sci. 
1048

1049

1050

1051

1052

1053

1054

1055

1056

1057

1058

Franklin, J.F., Lindenmayer, D., Macmahon, J.A., Mckee, A., Perry, D.A., Waide, R., and Foster, D. 2000. Threads of continuity. Conserv. Pract. 1(1): 8-17.

Fraver, S., Jain, T., Bradford, J.B., D’Amato, A.W., Kastendick, D., Palik, B., Shinneman, D., and Stanovick, J. 2011. The efficacy of salvage logging in reducing subsequent fire severity in conifer-dominated forests of Minnesota, USA. Ecol. Appl. 21(May 2007): 1895-1901.

Greene, D.F., Gauthier, S., Noël, J., Rousseau, M., and Bergeron, Y. 2006. A field experiment to determine the effect of post-fire salvage on seedbeds and tree regeneration. Front. Ecol. Environ. 4(2): 69-74. doi:10.1890/1540-9295(2006)004[0069:AFETDT]2.0.CO;2.

Gustafsson, L., Baker, S.C., Bauhus, J., Beese, W.J., Brodie, A., Kouki, J., Lindenmayer, D.B., Lõhmus, A., Martínez Pastur, G., Messier, C., Neyland, M., Palik, B., Sverdrup-Thygeson, A., Volney, W.J.A., Wayne, A., and Franklin, J.F. 2012. Retention forestry to maintain multifunctional forests: A world perspective. Bioscience 62(7): 633-645. doi:10.1525/bio.2012.62.7.6.

Haines-Young, R., and Potschin, M. 2010. The links between biodiversity, ecosystem services and human well-being. In Ecosystem Ecology: A new Synthesis. Edited by D.G. Raffaelli and C.L. Frid. Cambridge University Press. pp. 110-139. doi:10.1017/CBO9780511750458.007.

Hernández-Hernández, R., Castro, J., Del Arco Aguilar, M., Fernández-López, Á.B., and 41 

González-Mancebo, J.M. 2017. Post-fire salvage logging imposes a new disturbance that retards succession: The case of bryophyte communities in a Macaronesian laurel forest. Forests 8(7): 252. doi:10.3390/f8070252.

Holzmueller, E.J., and Jose, S. 2012. Response of the invasive grass Imperata cylindrica to disturbance in the southeastern forests, USA. Forests 3(4): 853-863. doi:10.3390/f3040853.

Hood, P.R., Nelson, K.N., Rhoades, C.C., and Tinker, D.B. 2017. The effect of salvage logging on surface fuel loads and fuel moisture in beetle-infested lodgepole pine forests. For. Ecol. Manage. 390: 80-88. Elsevier B.V. doi:10.1016/j.foreco.2017.01.003.

James, K.L., Randall, N.P., and Haddaway, N.R. 2016. A methodology for systematic mapping in environmental sciences. Environ. Evid. 5(1): 7. BioMed Central. doi:10.1186/s13750-016-0059-6.

Johnstone, J.F., Allen, C.D., Franklin, J.F., Frelich, L.E., Harvey, B.J., Higuera, P.E., Mack, M.C., Meentemeyer, R.K., Metz, M.R., Perry, G.L.W., Schoennagel, T., and Turner, M.G. 2016. Changing disturbance regimes, ecological memory, and forest resilience. Front. Ecol. Environ. 14(7): 369-378. doi:10.1002/fee.1311.

Karr, J.R., Rhodes, J.J., Minshall, G.W., Hauer, F.R., Beschta, R.L., Frissell, C.A., and Perry, D.A. 2004a. The effects of postfire salvage logging on aquatic ecosystems in the American West. Bioscience 54(11): 1029-1033. doi:10.1641/0006-3568.

Karr, J.R., Rhodes, J.J., Minshall, G.W., Hauer, F.R., Beschta, R.L., Frissell, C. a., and 42 
Perry, D. a. 2004b. The effects of postfire salvage logging on aquatic ecosystems in $\begin{array}{lllll}\text { the } & \text { American } & \text { West. } & \text { Bioscience } & \end{array}$ doi:10.1641/0006-3568(2004)054[1029:TEOPSL]2.0.CO;2.

Keyser, T.L., Smith, F.W., and Shepperd, W.D. 2009. Short-term impact of post-fire salvage logging on regeneration, hazardous fuel accumulation, and understorey development in ponderosa pine forests of the Black Hills, SD, USA. Int. J. Wildl. Fire 18: 451-458. doi:10.1071/WF08004.

Kishchuk, B.E., Thiffault, E., Lorente, M., Quideau, S., Keddy, T., and Sidders, D. 2015. Decadal soil and stand response to fire, harvest, and salvage-logging disturbances in the western boreal mixedwood forest of Alberta, Canada. Can. J. For. Res. 45: 141152.

Koricheva, J., Gurevitch, J., and Mengersen, K. (Editors). 2013. Handbook of Meta-analysis in Ecology and Evolution. Princeton University Press, Princeton and Oxford.

Kramer, K., Brang, P., Bachofen, H., Bugmann, H., and Wohlgemuth, T. 2014. Site factors are more important than salvage logging for tree regeneration after wind disturbance in Central European forests. For. Ecol. Manage. 331: 116-128. Elsevier B.V. doi:10.1016/j.foreco.2014.08.002.

Kurz, W.A., Dymond, C.C., Stinson, G., Rampley, G.J., Neilson, E.T., Carroll, A.L., Ebata, T., and Safranyik, L. 2008. Mountain pine beetle and forest carbon feedback to climate change. Nature 452(April): 987-990. doi:10.1038/nature06777. 
1111 Lee, E.-J., Lee, W.-S., and Rhim, S.-J. 2008. Characteristics of small rodent populations in

1112 post-fire silvicultural management stands within pine forest. For. Ecol. Manage.

1113 255(5-6): 1418-1422. doi:10.1016/j.foreco.2007.10.055.

1114 Leverkus, A.B., and Castro, J. 2017. An ecosystem services approach to the ecological 1115 effects of salvage logging: valuation of seed dispersal. Ecol. Appl. 27(4): 1057-1063. doi:10.1002/eap.1539.

1117 Leverkus, A.B., Gustafsson, L., Rey Benayas, J.M., and Castro, J. 2015a. Does 1118 post-disturbance salvage logging affect the provision of ecosystem services? A

Leverkus, A.B., Jaramillo-López, P.F., Brower, L.P., Lindenmayer, D.B., and Williams, E.H. 2017. Mexico’s logging threatens butterflies. Science (80-. ). 358(6366): 1008.

Leverkus, A.B., Lorite, J., Navarro, F.B., Sánchez-Cañete, E.P., and Castro, J. 2014. Post-fire salvage logging alters species composition and reduces cover, richness, and diversity in Mediterranean plant communities. J. Environ. Manage. 133: 323-331. Elsevier Ltd. doi:10.1016/j.jenvman.2013.12.014. 
Leverkus, A.B., Rojo, M., and Castro, J. 2015b. Habitat complexity and individual acorn protectors enhance the post-fire restoration of oak forests via seed sowing. Ecol. Eng. 83: 276-280. Elsevier B.V. doi:10.1016/j.ecoleng.2015.06.033.

Leverkus, A.B., Thorn, S., Gustafsson, L., and Lindenmayer, D.B. 2018. Salvage logging in the world's forests: Interactions between natural disturbance and logging need recognition. Under Rev.

Lewis, K., and Thompson, D. 2011. Degradation of wood in standing lodgepole pine killed by mountain pine beetle. Wood Fiber Sci. 43(2): 130-142.

Lindenmayer, D., Thorn, S., and Banks, S. 2017. Please do not disturb ecosystems further. Nat. Ecol. Evol. 1(January): art31. Macmillan Publishers Limited. doi:10.1038/s41559-016-0031

Lindenmayer, D.B., Burton, P.J., and Franklin, J.F. 2008. Salvage logging and its ecological consequences. Island Press, Washington, D.C

Lindenmayer, D.B., Foster, D.R., Franklin, J.F., Hunter, M.L., Noss, R.F., Schmiegelow, F.A., and Perry, D. 2004. Salvage harvesting policies after natural disturbance. Science (80-. ). 303(February): 1303.

Lindenmayer, D.B., Franklin, J.F., Lõhmus, a., Baker, S.C., Bauhus, J., Beese, W., Brodie, a., Kiehl, B., Kouki, J., Pastur, G.M., Messier, C., Neyland, M., Palik, B., Sverdrup-Thygeson, a., Volney, J., Wayne, a., and Gustafsson, L. 2012. A major shift to the retention approach for forestry can help resolve some global forest 

sustainability issues. Conserv. Lett. 5(6): 421-431.

1154 doi:10.1111/j.1755-263X.2012.00257.x.

1155 Lindenmayer, D.B., McBurney, L., Blair, D., Wood, J., and Banks, S.C. 2018. From

1156 unburnt to salvage logged: quantifying bird responses to different levels of disturbance severity. J. Appl. Ecol. In press.

1158 Lindenmayer, D.B., and Noss, R.F. 2006. Salvage logging, ecosystem processes, and 1159 biodiversity conservation. Conserv. Biol. 20(4): 949-958. $1160 \quad$ doi:10.1111/j.1523-1739.2006.00497.x.

1161 Lindenmayer, D.B., and Possingham, H.P. 1996. Ranking Conservation and Timber Management Options for Leadbeater's Possum in Southeastern Australia Using Population Viability Analysis. Conserv. Biol. 10(1): 235-251.

1164 Macdonald, S.E. 2007. Effects of partial post-fire salvage harvesting on vegetation 1165 communities in the boreal mixedwood forest region of northeastern Alberta, Canada. For. Ecol. Manage. 239(1-3): 21-31. doi:10.1016/j.foreco.2006.11.006. early aspen stand structure after catastrophic wind. For. Ecol. Manage. 308: 1-8. Elsevier B.V. doi:10.1016/j.foreco.2013.07.039.

1170 Mansuy, N., Thiffault, E., Lemieux, S., Manka, F., Paré, D., and Lebel, L. 2015. 1171 Sustainable biomass supply chains from salvage logging of fire-killed stands: a case study for wood pellet production in eastern Canada. Appl. Energy 154: 62-73. Elsevier Ltd, Oxford. doi:10.1016/j.apenergy.2015.04.048. 
1174 Marañón-Jiménez, S., and Castro, J. 2013. Effect of decomposing post-fire coarse woody

1175 debris on soil fertility and nutrient availability in a Mediterranean ecosystem.

1176 Biogeochemistry 112(1-3): 519-535. doi:10.1007/s10533-012-9744-x.

1177 Martín-López, B., Gómez-Baggethun, E., García-Llorente, M., and Montes, C. 2014.

1178 Trade-offs across value-domains in ecosystem services assessment. Ecol. Indic.

1179 37(PART A): 220-228. Elsevier Ltd. doi:10.1016/j.ecolind.2013.03.003.

1180 Martínez-Sánchez, J.J., Ferrandis, P., De las Heras, J., and Herranz, J.M. 1999. Effect of

1181 burnt wood removal on the natural regeneration of Pinus halepensis after fire in a pine

1182 forest in Tus valley (SE Spain). For. Ecol. Manage. 123: 1-10.

1183 Marzano, R., Garbarino, M., Marcolin, E., Pividori, M., and Lingua, E. 2013. Deadwood

1184 anisotropic facilitation on seedling establishment after a stand-replacing wildfire in Aosta Valley (NW Italy). Ecol. Eng. 51: 117-122. Elsevier B.V. doi:10.1016/j.ecoleng.2012.12.030.

McGinnis, T.W., Keeley, J.E., Stephens, S.L., and Roller, G.B. 2010. Fuel buildup and potential fire behavior after stand-replacing fires, logging fire-killed trees and herbicide shrub removal in Sierra Nevada forests. For. Ecol. Manage. 260(1): 22-35. Elsevier B.V. doi:10.1016/j.foreco.2010.03.026.

McIver, J.D., and McNeil, R. 2006. Soil disturbance and hill-slope sediment transport after logging of a severly burned site in Northeastern Oregon. West. J. Appl. For. 21: 123133.

1194 McIver, J.D., and Ottmar, R. 2007. Fuel mass and stand structure after post-fire logging of 47 
1195 a severely burned ponderosa pine forest in northeastern Oregon. For. Ecol. Manage. 1196 238(1-3): 268-279. doi:10.1016/j.foreco.2006.10.021.

1197 McIver, J.D., and Starr, L. 2000. Environmental effects of postfire logging: Literature 1198 review and annotated bibliography. Gen. Tech. Rep. PNW-GTR-486. Portland, OR: U.S. Department of Agriculture, Forest Service, Pacific Northwest Research Station.

1200 Moher, D., Liberati, A., Tetzlaff, J., Altman, D.G., and The PRISMA Group. 2009. 1201 Preferred reporting items for systematic reviews and meta-analyses: The PRISMA statement. PLoS Med. 6(7). doi:10.1371/journal.pmed.1000097.

Molinas-González, C.R., Leverkus, A.B., Marañón-Jiménez, S., and Castro, J. 2017. Fall rate of burt pines acroos an elevational gradient in a mediterranean mountain. Eur. J. For. Res. 136(3): 401-409. doi:10.1007/s10342-017-1040-9.

Molinas González, C., Castro, J., and Leverkus, A.B. 2017. Deadwood decay in a burnt Mediterranean pine reforestation. Forests 8: art158.

Müller, J., Noss, R., Thorn, S., Bässler, C., Leverkus, A.B., and Lindenmayer, D. 2018. Increasing disturbance demands new policies to conserve intact forest. Conserv. Lett.: e12449. doi:10.1111/conl.12449.

Ne'eman, G., Perevolotsky, A., and Schiller, G. 1997. The management implications of the Mt. Carmel research project. Int. J. Wildl. Fire 7(4): 343-350. doi:10.1071/WF9970343.

1214 Van Nieuwstadt, M.G.. L., Sheil, D., and Kartawinata, K. 2001. The Ecological 

fire-prone forests in the western United States. Front. Ecol. Environ. 4: 481-487.

Noss, R.F., and Lindenmayer, D.B. 2006. The ecological effects of salvage logging after natural disturbance. Conserv.

Biol.

20(4):

946-948. doi:10.1111/j.1523-1739.2006.00498.x.

Pausas, J.G., and Fernández-Muñoz, S. 2012. Fire regime changes in the Western Mediterranean Basin: from fuel-limited to drought-driven fire regime. Clim. Change 110(1-2): 215-226.

Peterson, D.W., and Dodson, E.K. 2016. Post-fire logging produces minimal persistent impacts on understory vegetation in northeastern Oregon, USA. For. Ecol. Manage. 370: 56-64. Elsevier B.V. doi:10.1016/j.foreco.2016.04.004.

Peterson, D.W., Dodson, E.K., and Harrod, R.J. 2015. Post-fire logging reduces surface woody fuels up to four decades following wildfire. For. Ecol. Manage. 338: 84-91. Elsevier B.V. doi:10.1016/j.foreco.2014.11.016.

Powers, E.M., Marshall, J.D., Zhang, J., and Wei, L. 2013. Post-fire management regimes

Prestemon, J.P., and Holmes, T.P. 2010. Economic impacts of hurricanes on forest owners. 
Priewasser, K., Brang, P., Bachofen, H., Bugmann, H., and Wohlgemuth, T. 2013. Impacts of salvage-logging on the status of deadwood after windthrow in Swiss forests. Eur. J. For. Res. 132(2): 231-240. doi:10.1007/s10342-012-0670-1.

Puerta-Piñero, C., Sánchez-Miranda, A., Leverkus, A., and Castro, J. 2010. Management of burnt wood after fire affects post-dispersal acorn predation. For. Ecol. Manage. 260(3): 345-352. ELSEVIER SCIENCE BV. doi:10.1016/j.foreco.2010.04.023.

Pullin, A.S., Knight, T.M., Stone, D.A., and Charman, K. 2004. Do conservation managers use scientific evidence to support their decision-making? Biol. Conserv. 119(2): 245252. doi:10.1016/j.biocon.2003.11.007.

Pullin, A.S., and Stewart, G.B. 2006. Guidelines for systematic review in conservation and environmental management. Conserv. Biol. 20(6): 1647-1656. doi:10.1111/j.1523-1739.2006.00485.x.

R Core Team. 2016. R: A language and environment for statistical computing. $\mathrm{R}$ Foundation for Statistical Computing, Vienna, Austria, R Foundation for Statistical Computing, Vienna, Austria.

Rhoades, C.C.., Pelz, K.A.., Fornwalt, P.J.., Wolk, B.H.., and Cheng, A.S. 2018. Overlapping bark beetle outbreaks, salvage logging and wildfire restructure a lodgepole pine ecosystem. Forests In press.

Ritchie, M.W., Knapp, E.E., and Skinner, C.N. 2013. Snag longevity and surface fuel accumulation following post-fire logging in a ponderosa pine dominated forest. For. Ecol. Manage. 287: 113-122. Elsevier B.V. doi:10.1016/j.foreco.2012.09.001. 
Roy, D.F. 1956. Salvage logging may destroy Douglas-fir reproduction. USDA For. Serv. Calif. For. Range Exp. Station. For. Res. Notes No. 107: 5.

Royo, A.A., Peterson, C.J., Stanovick, J.S., and Carson, W.P. 2016. Evaluating the ecological impacts of salvage logging: Can natural and anthropogenic disturbances promote coexistence? Ecology 97(6): 1566-1582. doi:10.1890/15-1093.1.

Schelhaas, M.J., Nabuurs, G.J., and Schuck, A. 2003. Natural disturbances in the European forests in the 19th and 20th centuries. Glob. Chang. Biol. 9: 1620-1633. doi:10.1046/j.1365-2486.2003.00684.x.

Schiermeier, Q. 2016. Pristine forest at risk. Nature 530: 393. doi:10.1038/530394a.

Schönenberger, W., Noack, A., and Thee, P. 2005. Effect of timber removal from windthrow slopes on the risk of snow avalanches and rockfall. For. Ecol. Manage. 213(1-3): 197-208. doi:10.1016/j.foreco.2005.03.062.

Schroeder, L.M., and Lindelöw, A. 2002. Attacks on living spruce trees by the bark beetle Ips typographus (Col . Scolytidae) following a storm-felling: a comparison between stands with and without removal of wind-felled trees. Agric. 4: 47-56.

Secretariat of the Convention on Biological Diversity. 2000. Sustaining life on Earth: How the Convention on Biological Diversity promotes nature and human well-being. Secr. Conv. Biol. Divers.: 14.

Seidl, R., Thom, D., Kautz, M., Martin-Benito, D., Peltoniemi, M., Vacchiano, G., Wild, J., Ascoli, D., Petr, M., Honkaniemi, J., Lexer, M.J., Trotsiuk, V., Mairota, P., Svoboda, 

doi:10.1038/nclimate3303.

Serrano-Ortiz, P., Marañón-Jiménez, S., Reverter, B.R., Sánchez-Cañete, E.P., Castro, J., Zamora, R., and Kowalski, A.S. 2011a. Post-fire salvage logging reduces carbon sequestration in Mediterranean coniferous forest. For. Ecol. Manage. 262(12): 22872296. Elsevier B.V. doi:10.1016/j.foreco.2011.08.023.

Serrano-Ortiz, P., Marañón-Jiménez, S., Reverter, B.R., Sánchez-Cañete, E.P., Castro, J., Zamora, R., and Kowalski, A.S. 2011b. Post-fire salvage logging reduces carbon sequestration in Mediterranean coniferous forest. For. Ecol. Manage. 262(12): 22872296. doi:10.1016/j.foreco.2011.08.023.

Slesak, R.A., Schoenholtz, S.H., and Evans, D. 2015. Hillslope erosion two and three years

Smith-Ramírez, C., Maturana, V., Gaxiola, A., and Carmona, M. 2014. Salvage logging by retention and life after the beetle: Stand structure and small mammals 30 years after salvage harvesting. Silva Fenn. 44(5): 749-774.

Sun, Y., Gu, L., Dickinson, R.E., and Zhou, B. 2012. Forest greenness after the massive 2008 Chinese ice storm: integrated effects of natural processes and human intervention. Environ. Res. Lett. 7(3): 35702. doi:10.1088/1748-9326/7/3/035702. 
1300 Sutherland, W.J., Pullin, A.S., Dolman, P.M., and Knight, T.M. 2004a. The need for evidence-based conservation. Trends Ecol. Evol. 19(6): 305-308. doi:10.1016/j.tree.2004.03.018.

Sutherland, W.J., Pullin, A.S., Dolman, P.M., and Knight, T.M. 2004b. The need for evidence-based conservation. Trends Ecol. Evol. 19(6): 305-8. doi:10.1016/j.tree.2004.03.018.

Thorn, S., Bässler, C., Bernhardt-Römermann, M., Cadotte, M., Heibl, C., Schäfer, H., Seibold, S., and Müller, J. 2015a. Changes in the dominant assembly mechanism drives species loss caused by declining resources. Ecol. Lett. 19(2): 109-215. doi:10.1111/ele.12548.

Thorn, S., Bässler, C., Brandl, R., Burton, P., Cahall, R., Campbell, J.L., Castro, J., Choi, C.-Y., Cobb, T., Donato, D., Durska, E., Fontaine, J., Gauthier, S., Hebert, C., Hothorn, T., Hutto, R., Lee, E.-J., Leverkus, A., Lindenmayer, D., Obrist, M., Rost, J., Seibold, S., Seidl, R., Thom, D., Waldron, K; Wermelinger, B., Winter, M.-B., Zmihorski, M., and Müller, J. 2018. Impacts of salvage logging on biodiversity - a meta-analysis. J. Appl. Ecol. 55: 279-289. doi:10.1111/1365-2664.12945.

Thorn, S., Bässler, C., Svoboda, M., and Müller, J. 2016. Effects of natural disturbances and salvage logging on biodiversity - Lessons from the Bohemian Forest. For. Ecol. Manage. Elsevier B.V. doi:10.1016/j.foreco.2016.06.006.

Thorn, S., Hacker, H.H., Seibold, S., Jehl, H., Bässler, C., and Müller, J. 2015b. Guild-specific responses of forest Lepidoptera highlight conservation-oriented forest 

management - Implications from conifer-dominated forests. For. Ecol. Manage. 337: 41-47. Elsevier B.V. doi:10.1016/j.foreco.2014.10.031.

Titus, J.H., and Householder, E. 2007. Salvage logging and replanting reduce understory cover and richness compared to unsalvaged-unplanted sites at Mount St. Helens, Washington. West. North Am. Nat. 67(2): 219-231. doi:10.3398/1527-0904(2007)67[219:SLARRU]2.0.CO;2.

Turner, M.G. 2010. Disturbance and landscape dynamics in a changing world. Ecology 91(10): 2833-2849. doi:10.1890/10-0097.1.

Wagenbrenner, J.W., MacDonald, L.H., Coats, R.N., Robichaud, P.R., and Brown, R.E. 2015. Effects of post-fire salvage logging and a skid trail treatment on ground cover, soils, and sediment production in the interior western United States. For. Ecol. Manage. 335: 176-193. Elsevier B.V. doi:10.1016/j.foreco.2014.09.016.

Wagenbrenner, J.W., Robichaud, P.R., and Brown, R.E. 2016. Rill erosion in burned and salvage logged western montane forests: Effects of logging equipment type, traffic level, and slash treatment. J. Hydrol. 541(Part B): 889-901. Elsevier B.V. doi:10.1016/j.jhydrol.2016.07.049.

Waldron, K., Ruel, J.C., and Gauthier, S. 2013. Forest structural attributes after windthrow and consequences of salvage logging. For. Ecol. Manage. 289: 28-37. Elsevier B.V. doi:10.1016/j.foreco.2012.10.006.

Waldron, K., Ruel, J.C., Gauthier, S., De Grandpré, L., and Peterson, C.J. 2014. Effects of post-windthrow salvage logging on microsites, plant composition and regeneration. 

Appl. Veg. Sci. 17(2): 323-337. doi:10.1111/avsc.12061. regeneration after windthrow in Swiss mountain forests due to the winter storm Vivian 1990. For. Snow Landsc. Res. 77(1/2): 17-47. management in protection forests of the Swiss Alps. Eur. J. For. Res. 136: 1029-1040. 
1351 Tables

1352

Table 1. Distribution of publications and study sites across geographic areas

\begin{tabular}{lllll}
\hline Continent & Country & N Publications & N Studies & N multi-site studies \\
\hline North America & USA & 42 & 25 & 3 \\
& Canada & 25 & 12 & 4 \\
Europe & Spain & 10 & 4 & 0 \\
& Switzerland & 4 & 1 & 1 \\
& Germany & 2 & 2 & 0 \\
& Portugal & 2 & 1 & 1 \\
& Estonia & 1 & 1 & 0 \\
& Czech Republic & 2 & 1 & 0 \\
Asia & Israel & 1 & 1 & 0 \\
& South Korea & 1 & 1 & 0 \\
\hline Total & & 90 & 49 & 9 \\
\hline
\end{tabular}

1354 


\section{Figure captions}

1357

Figure 1. Ecosystem services cascade illustrated for the case of seed dispersal by European jays (Garrulus glandarius L.) within a post-fire management experimental setting. The diagram shows the link between the biophysical and the human well-being components of ecosystem services. Particular elements of the ecosystem perform functions that produce benefits for society via an ecosystem service. Society places a value on these benefits, whether economic or not. The resulting value feeds back to affect the ecosystem elements through management decisions. In the example (shown in the dashed boxes below each component of the conceptual diagram), burnt snags represent a supporting element for the seed caching activity of a major seed disperser, whose activity yields natural colonisation of the burnt area and reduces the economic cost of reforestation. Appreciation of this value can enhance the likelihood that snags be retained in post-fire management. Figure adapted from Haines-Young and Potschin (2010), Martín-López et al. (2014), and Leverkus and Castro (2017). References in the diagram: (1) = Molinas-González et al. (2017); (2) = Castro et al. (2012); (3) = Leverkus et al. (2016); (4) = Leverkus and Castro (2017).

\section{Figure 2. Preferred Reporting Items for Systematic Reviews and Meta-Analyses}

(PRISMA) diagram. Shown are the numbers of publications retrieved in the literature searches and the number excluded in each step. Diagram adapted from Moher et al. (2009).

Figure 3. Cumulative number of publications per disturbance type included in this systematic map. 
Figure 4. Location of the individual studies included in the systematic map. Number codes are indicated for reference (column Site_ref in the systematic map database, Table S3). Inset: Korean Peninsula.

Figure 5. Disturbance and salvage logging characteristics. A) Disturbance severity considered in the analysed publications. This includes 1-3 points per publication, according to whether one general disturbance severity was reported or the publication explicitly included sampling areas of different severity levels. B) Time elapsed between the disturbance and subsequent salvage logging. Each data point represents one publication. C) Logging intensity in the analysed publications. This includes 1-4 points per publication. Note that this applies to the Intervention only, as each publication also included a Comparator with $0 \%$ logging intensity. In all plots, the thick horizontal lines are medians, and the boxes indicate the first and third quartiles of the values. Whiskers are either the minimum/maximum values or 1.5 times the interquartile range of the data, in which case outliers are shown as points. The values of disturbance severity and logging intensity are broad approximations. Sample sizes for the graphics are: for fire 53, 51 and 69 (panels A, B and C, respectively); for insect outbreaks 15, 13 and 15; and for wind 31, 26 and 21 for wind.

Figure 6. The number of spatially independent salvage logging replicate units used in the 90 publications, classified by disturbance type.

\section{Figure 7. Number of publications that reported different measured response} variables, for each disturbance type. Nutrient= biological indicators of nutrient cycling; Carbon= non-wood carbon pool; Water= drinking water quality; Erosion= soil 
1406 erosion by wind or water; Invasives= Invasive and/or exotic species; Cover= ground 1407 cover, including cover of vegetation; Resilience $=$ capacity to regenerate after 1408 subsequent wildfire (i.e. wildfire after salvage logging); Riparian= riparian ecosystem 1409 functioning; Dispersal $=$ seed dispersal; Soil chem.= soil chemical properties; Soil 1410 phys. $=$ soil physical properties; Deadwood $=$ stand structure and deadwood amount and 1411 characteristics; Temp. $=$ air, water or soil temperature; Regen. $=$ tree regeneration;

1412 Vegetation= Vegetation composition. Note that biodiversity responses were excluded 1413 from the systematic map. Inset: distribution of publications according to the number of 1414 individual measurements taken for the response variables. Both y axes have the same 1415 meaning. 


\section{Supporting Information}

Appendix A1. Systematic map database and data coding strategy

Appendix A2. Literature searches and screening-Results

Appendix A3. Stand characteristics -Results and Discussion

Table S1. Search strings used in the systematic map.

Table S2. Publications excluded at full-text screening and reasons for exclusion.

1425 Table S3. Systematic Map Database. For details on coding and variable names, see 1426 Appendix A1. 
Systematic maps aim to collate the empirical evidence on particular topics and describe the characteristics of the studies on those topics (James et al. 2016). In contrast to systematic reviews, they do not aim to synthesise the results of individual studies. Systematic maps help managers identify the literature on a topic that is most relevant to their needs. They also identify knowledge clusters and knowledge gaps to suggest future systematic review lines and suggest topics for further empirical study.

Here, we aim to collate the studies addressing the ecological effects of salvage logging, with a focus on regulating and supporting ecosystem services. The focus on ecosystem services intends to leverage the relevance and applicability of academic studies for non-academic stakeholders, including land managers who face the question of how to manage disturbed forests, as well as the general public. A global overview of this subject that also addresses potential reasons for heterogeneity in the effects measured by different studies could aid managers and policy-makers worldwide in finding the necessary scientific information to make decisions regarding salvage logging. Such decisions require understanding of questions such as: is salvage logging likely to enhance the recovery of disturbed forests under particular forest types and disturbance conditions? And, does the trade-off between provisioning and other kinds of ecosystem services result in a positive overall balance for specific management intervention?

\section{Characteristics of included publications}




\section{Distribution of studies}

The publications included in the database were overwhelmingly concentrated in North America and Europe, with only two publications from another continent and no representation of the tropics or the Southern Hemisphere. Even within these two geographic clusters, the publications were not equally distributed. In North America, there were nearly twice as many publications from the U.S.A than from Canada, and even Canadian publications were more abundant than those of all Europe, where half of the publications came from Spain. One could predict that studies on post-disturbance logging would occur more frequently in places where more natural disturbance occurs, or where natural disturbance is more often followed by logging. However, disturbances are common across forests globally (Seidl et al. 2017), and there is no obvious reason to consider that the countries not included in the systematic map lack salvage logging.

A possible explanation for the paucity of studies in the tropics lies in differences in human-related causes and consequences of disturbances across regions. Disturbances like wildfire in regions at the frontline of land-use change, such as many tropical regions, often constitute an instrument for deforestation and land conversion, rather than a natural process followed by regeneration. In contrast, developed countries have generally reached more stable land uses, so that disturbed forests will be expected to regrow, either for production or for nature conservation. In this way, assessing the effects of salvage logging on ecosystems makes more sense in cases where management or conservation objectives are to maintain forest cover, as is more often the case in Europe and North America than in other regions. Even in the few exceptions where salvage logging was addressed in tropical areas, the research was carried out by foreign researchers (Van Nieuwstadt et al. 2001). Most of the studies outside these two zones, including studies in Chile (Smith-Ramírez et al. 2014) and Australia (Blair et al. 2016), 
failed to pass the inclusion criteria regarding the relevance of response variables. Other non-mutually exclusive reasons for the predominance of European and North American studies, as highlighted in a systematic map on active interventions for biodiversity conservation (Bernes et al. 2015), are: a) the large extents of forest, b) the greater density of researchers and availability of funding, and c) the large emphasis on research in ecology and environmental management in Europe and North America. Finally, an important factor could be the language selected for the literature search -English-, which was originally aimed at identifying scientific studies from over the world but was biased against studies from nations where English is either not the official language nor spoken at a sufficient level of proficiency to facilitate publication in indexed journals.

The geographic distribution of the publications was strongly clustered in two continents (Fig 4): most came from North America, followed by Europe, and one from each of the Middle East and East Asia (Table 1).

Most studies (36) were established within the perimeter of a single disturbance event, thereby establishing the disturbance as the constraint on the inference population. Two studies (one post-fire and one post-insect) included two disturbance events, four included four events, one included five, one included 14, and one included 20 (all these were post-fire). Three studies on post-windthrow logging addressed one disturbance event (e.g. one storm) but within 7, 11, or 30 spatially independent blowdown patches; one study assessed 90 individual patches caused by two storms. True replication of salvage logging within studies was generally below $\mathrm{N}=10$ (Fig 6). We present this information at the scale of publications because some publications of the same studies 
made use of different subsets of the larger design, leading to different replication across publications (e.g., Leverkus et al. 2014, 2016).

Tree regeneration was the most frequent response variable, and it was addressed by $51 \%$ of the publications (Fig 7). Second in frequency, $42 \%$ of the publications included estimations of ground cover (e.g. percent cover of vegetation, rocks, bare ground, pits and mounds, etc.). Third, $41 \%$ of the publications measured variables linked to the remaining deadwood, such as the number of snags or the amount of downed woody debris of different diameter, species, and/ or decay classes. Some of these studies focused on the habitat that the wood provides for living organisms, some on habitat structure, others on the $\mathrm{C}$ sink that it represents, and others on the quantity, quality and distribution of fuels in the face of subsequent wildfires. Fourth, $28 \%$ of publications analysed the recovering non-tree vegetation. Fifth, 26\% included measurements of soil physical properties, such as moisture, compaction, shear strength, and penetrability. The remaining response variable categories were addressed by $<15 \%$ of the publications, and the number of studies addressing them, separated by disturbance type, can be found in Fig 7. Most of the publications (79\%) included data on one or two measurements of the response variable undertaken at different times, and the maximum was 20 measurements (Fig 7, inset). Four publications included continuous measurements taken over 3 or 6 years.

\section{Discussion}




\section{Distribution of studies}

The publications included in the database were overwhelmingly concentrated in North America and Europe, with only two publications from another continent and no representation of the tropics or the Southern Hemisphere. Even within these two geographic clusters, the publications were not equally distributed. In North America, there were nearly twice as many publications from the U.S.A than from Canada, and even Canadian publications were more abundant than those of all Europe, where half of the publications came from Spain. One could predict that studies on post-disturbance logging would occur more frequently in places where more natural disturbance occurs, or where natural disturbance is more often followed by logging. However, disturbances are common across forests globally (Seidl et al. 2017), and there is no obvious reason to consider that the countries not included in the systematic map lack salvage logging.

A possible explanation for the paucity of studies in the tropics lies in differences in human-related causes and consequences of disturbances across regions. Disturbances like wildfire in regions at the frontline of land-use change, such as many tropical regions, often constitute an instrument for deforestation and land conversion, rather than a natural process followed by regeneration. In contrast, developed countries have generally reached more stable land uses, so that disturbed forests will be expected to regrow, either for production or for nature conservation. In this way, assessing the effects of salvage logging on ecosystems makes more sense in cases where management or conservation objectives are to maintain forest cover, as is more often the case in Europe and North America than in other regions. Even in the few exceptions where salvage logging was addressed in tropical areas, the research was carried out by foreign 
researchers (Van Nieuwstadt et al. 2001). Most of the studies outside these two zones, including studies in Chile (Smith-Ramírez et al. 2014) and Australia (Blair et al. 2016), failed to pass the inclusion criteria regarding the relevance of response variables. Other non-mutually exclusive reasons for the predominance of European and North American studies, as highlighted in a systematic map on active interventions for biodiversity conservation (Bernes et al. 2015), are: a) the large extents of forest, b) the greater density of researchers and availability of funding, and c) the large emphasis on research in ecology and environmental management in Europe and North America. Finally, an important factor could be the language selected for the literature search -English-, which was originally aimed at identifying scientific studies from over the world but was biased against studies from nations where English is either not the official language nor spoken at a sufficient level of proficiency to facilitate publication in indexed journals.

\section{Disturbance characteristics}

The most frequent disturbance type that defined our study population was wildfire. In 2000, a USDA review (McIver and Starr 2000) highlighted several mechanisms through which burnt forests could be particularly vulnerable to subsequent logging disturbance, including effects on burnt soil and vegetation. The report also noted a lack of empirical evidence regarding the consequences of salvage logging, which triggered numerous research projects on logging after wildfire [e.g., McIver and McNeil (2006), Donato et al. (2006), Castro et al. (2010)]. Wildfire also produces some unique ecological responses, such as significant reductions in small-diameter aboveground biomass, as well as direct and indirect wildlife mortality. This, combined with the direct impacts of wildfire on those living in or near fire-prone forests and spectacular images in the media that suggest death and destruction, has likely generated more public and political 
demand for understanding the various implications of wildfire as compared to windstorms or insect outbreaks, including impacts related to subsequent salvage logging. However, logging after some large storms such as Vivian (1990) and Lothar (1999) in Switzerland (Kramer et al. 2014), and after massive insect outbreaks throughout western North America (Collins et al. 2011), has recently attracted increasing attention. The three kinds of disturbances addressed here have increased -and will likely continue to increase - in frequency and extent due to climate change and other factors related to ecosystem conversion and changes in land-use intensity (Seidl et al. 2017), and addressing questions related to post-disturbance management is a logical response to increasingly prevalent situations.

Wildfire was generally described as having greater disturbance severity than insect outbreaks or windstorms. Studies on logging after wildfire or insect outbreaks were generally tightly clustered at high severity values, whereas disturbance severity by wind was less severe and more variable. Many ecological responses to disturbances largely depend on their severity, which highlights the relevance of studying the response to disturbance, and to subsequent logging, under different degrees of severity. Most of the studies included in the systematic map were performed within patches subject to disturbances of specific severity, thereby controlling for this factor as much as possible. In only a few cases (8 out of 49) did the studies directly address disturbance severity as an explanatory variable, either through the selection of stands within different degrees of severity (e.g. Brewer et al., 2012) or by sampling severity gradients within plots (e.g. Royo et al., 2016). Whereas the selection of plots of different disturbance severity is an appropriate way to increase the robustness of the study design, it may come at the cost of lower replication. In contrast, measuring disturbance severity at smaller scales as a covariate can help increase the explanatory power of management variables without 
sacrificing replication. Of course, this is not always possible, and it hinges on the spatial scale at which disturbance severity varies.

We did not collect information on the spatial extent of the disturbances because in many cases this information was not available. However, it can be argued that large disturbances will generally attract more research and provide opportunities for greater replication. For example, disturbances in North America commonly affect large areas (e.g. the fire near 2016 Fort McMurray in Canada, which affected more than half a million ha). Salvage logging is, however, quite often performed in areas affected by small- or medium-scale disturbances, which are common in Europe. Scientific studies performed in these areas might suffer from constraints in the sampling design (thus leading to exclusion from the systematic map), but in these situations, logging intensity is likely to reach $100 \%$ across the disturbed area. As a consequence, subjects worthy of in-depth analysis that are not covered by this systematic map include the relationship between disturbance extent, the extent and intensity of salvage logging, and the ecological response to disturbance and subsequent salvage logging.

\section{Intervention}

Ecological responses to salvage logging are often predicted to vary with the time elapsed between the disturbance and logging, particularly in the case of discrete disturbance events like wildfire. For example, post-fire logging may have greater impact on soils if it is conducted directly after wildfire because it may delay post-fire recovery (Wagenbrenner et al. 2016). If logging occurs during or after the first growing season, natural regeneration can be most severely affected due to the physical destruction of resprouting stems and emerging seedlings (Martínez-Sánchez et al. 1999, Castro et al. 2011). The studies of the systematic map most often included information on when 
logging was conducted, yet individual studies did not explicitly test the effect of different timing of salvage logging on the ecosystem response. Burnt stands were generally those salvage logged most quickly, followed by wind-affected stands. In the case of disturbance by insects, salvage logging often started several years after the beginning of the outbreak, and the variability in the timing of salvage logging was much greater than for the other two disturbance types. Insect outbreaks most often take several years to develop, during which each tree goes through several stages of decline (Sullivan et al. 2010), and logging can take place at any stage from before the beginning of the outbreak - pre-emptive logging, not addressed here- to logging after several years of infestation. Logging is sometimes conducted in an attempt to prevent the infestation of particular stands or the expansion of insect populations (Müller et al. 2018), and in other cases it is performed to avoid wood decay or the accumulation of fuel once the stand has been affected. These are likely reasons for the greater variability in the timing of salvage logging related to insect outbreaks than after disturbance by fire or wind.

The methods employed in salvage logging operations and their intensity also likely define the effect of the intervention. For example, mechanized harvesting equipment is more likely to compact soils than manual cutting with chainsaws, but it may also produce novel, positive effects like forming ruts that fill with water and create persistent aquatic habitat (Ernst et al. 2016). Extraction of wood by helicopter is well known to reduce soil impacts compared to ground-based yarding. However, helicopter use is extremely costly; this, combined with the low economic value of disturbance-affected timber and depressed price that typically follow large disturbance events, are likely reasons why helicopters were only mentioned in two of the 49 included studies.

Finally, the intensity of salvage logging can be a crucial factor explaining salvage logging effects, as identified six decades ago (Roy 1956). Due to this awareness, land 
managers can -and in some situations do- implement Best Management Practices to reduce potential negative salvage logging effects on soil, vegetation and water, such as by restricting wet season and steep slope operations or by favouring mechanical operations over winter snowpack. The studies in the systematic map included a wide range of salvage logging intensity for the three disturbance types considered here, although intensity was mostly categorised in excess of $90 \%$. In some cases, the effect of different logging intensity was assessed within individual studies; this often included qualitative differences in logging practices such as the removal of slash or the retention of standing dead trees. Notably, in one experimental study, stands under five classes of logging intensities were established, ranging from 0 to $100 \%$ (Ritchie et al. 2013). The authors further assessed the effect of amount of basal area retained, which explained the variation in some of the response variables better than the categorical experimental factor (Ritchie et al. 2013). Such studies can provide important insights into the responses to salvage logging and can evaluate the effectiveness of Best Management Practices, as logging -and other disturbances- may not necessarily produce generalizable effects but rather effects that vary nonlinearly according to disturbance intensity or severity (Buma 2015, Foster et al. 2016, Leverkus et al. 2018). This has long been acknowledged in traditional green-tree silviculture, where the retention forestry approach was created under the acknowledgement that commercial clearcutting can greatly differ from that of forestry operations that leave behind structures that favour the continuity of the forest ecosystem (Gustafsson et al. 2012, Lindenmayer et al. 2012). Only seven out of 49 studies were designed to compare different logging intensity levels, which highlights the need to better address salvage logging throughout a range of logging intensity. The need for salvage operations to generate profits, something more difficult to achieve than in green-tree silviculture, could be a limitation 
in this regard. Nevertheless, the potential benefits of the retention of biological legacies (Franklin et al. 2000) during post-disturbance harvest operations should be more profoundly explored.

\section{Study designs}

In most studies, salvage logging was not performed experimentally, which provided several advantages and disadvantages. Salvage logging was generally described as a process to achieve management objectives rather than to conduct research. Such reasons generate a risk of bias between intervention and comparator stands, for example due to the selection of more productive stands, or those nearest to roads, for salvage operations. Further, the choice not to salvage particular stands is sometimes justified by reasons such as fiscal constraints and litigation; stream, hillside, and habitat protection; or inaccessibility (McGinnis et al. 2010), highlighting the potential for bias. Still, in non-experimental studies, care was generally taken to select salvaged and unsalvaged stands of similar pre-disturbance conditions to minimise such bias. In addition, some of the studies -both experimental and non-experimental- controlled for random spatial variation by implementing a BACI design -i.e. by measuring how the response variables changed over time from pre-logging to post-logging and in stands with and without the salvage logging intervention, thus providing a robust method for addressing bias.

True replication is another important factor reducing the potential for bias. In this regard, it should be noted that replication of the salvage logging intervention was generally low. Most studies addressed this issue by establishing hierarchical sampling designs (i.e. with several sub-units within salvage and control units) and by controlling the effects of potentially confounding co-variables. These strategies were also employed 
in many of the studies that were excluded due to lack of true replication (Appendix I). As a result, we do not exclude the possibility that some of those excluded studies could provide valuable insights despite the pseudo-replication, yet for the purpose of inclusion in the systematic map we decided to stick to the study inclusion criteria established in the protocol aimed at reducing the potential for bias (Leverkus et al. 2015a).

Experimental design, with appropriate replication at the scale of management and randomised allocation of treatments to spatial units, can also minimise bias resulting from spatial variation. In eleven studies, researchers designed the salvage logging experiment. One good example of such an experiment is the one established after the Summit Fire in Oregon: it included randomisation, blocking, treatments applied at an appropriate spatial scale, replication, consideration of disturbance severity and salvage logging intensity, and a BACI sampling design (McIver and Ottmar 2007). Such studies are extremely difficult to implement, as exemplified by one paper that reports the design of a randomised complete block design that, however, could not be turned to practice due to legal constraints and which resulted in a pseudo-replicated design comparing salvaged private forest vs unsalvaged public land (Slesak et al. 2015) -hence leading to exclusion from our systematic map. The downside of experiments that are under the control of researchers is that the logging intervention was generally performed under close compliance with environmental prescriptions (e.g., Ne'eman et al. 1997, McIver and Ottmar 2007, Leverkus et al. 2014), so that the intervention may have lesser effects than under non-experimental, "real-world" management. Besides, some non-experimental studies had the advantage that they could be conducted at spatial scales larger than what would be possible under experimental approaches by selecting several disturbance patches with and without intervention that fulfilled certain criteria across entire regions or countries (Priewasser et al. 2013, Águas et al. 2014). As a 
result, it is difficult to apply strict, identical quality criteria to all the included studies, and there is not one single ideal study design. We consider all studies included in this systematic map to be of sufficient quality for providing relevant information under certain conditions.

\section{Response variables}

In summary, $\mathrm{s}$

The map presented here provides the first systematic account on the scientific evidence of ecosystem responses to salvage logging. It 


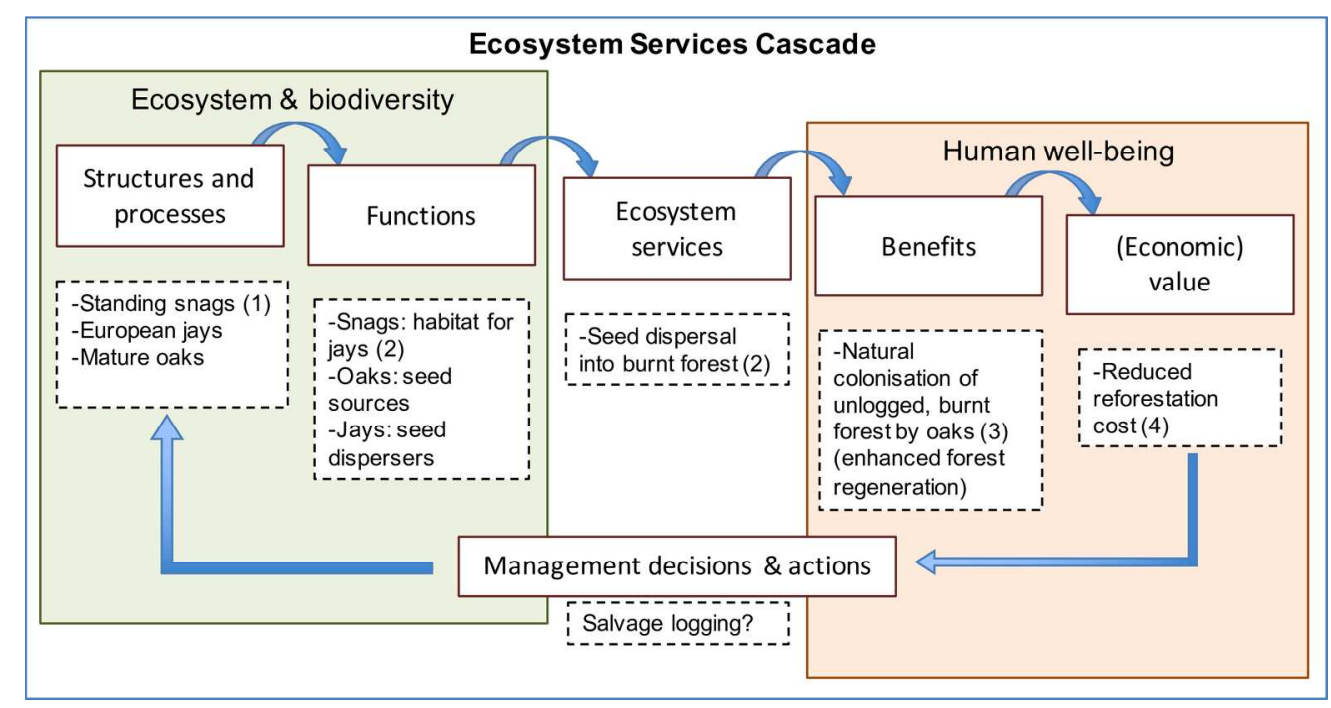

Figure 1. Ecosystem services cascade illustrated for the case of seed dispersal by European jays within a post-fire management experimental setting. The diagram shows the link between the biophysical and the human well-being components of ecosystem services. Particular elements of the ecosystem perform functions that produce benefits for society via an ecosystem service. Society places a value on these benefits, whether economic or not. The resulting value feeds back to affect the ecosystem elements through management decisions. In the example (shown in the dashed boxes below each component of the conceptual diagram), burnt snags represent a supporting element for the seed caching activity of a major seed disperser, whose activity yields natural colonisation of the burnt area and reduces the economic cost of reforestation. Appreciation of this value can enhance the likelihood that snags be retained in post-fire management. Figure adapted from Haines-Young and Potschin (2010), Martín-López et al. (2014), and Leverkus and Castro (2017). References in the diagram: (1) = Molinas-González et al. (2017); (2) = Castro et al. (2012); (3) = Leverkus et al. (2016); (4) = Leverkus and Castro (2017).

$190 \times 99 \mathrm{~mm}(300 \times 300 \mathrm{DPI})$ 
PRISMA 2009 Flow Diagram

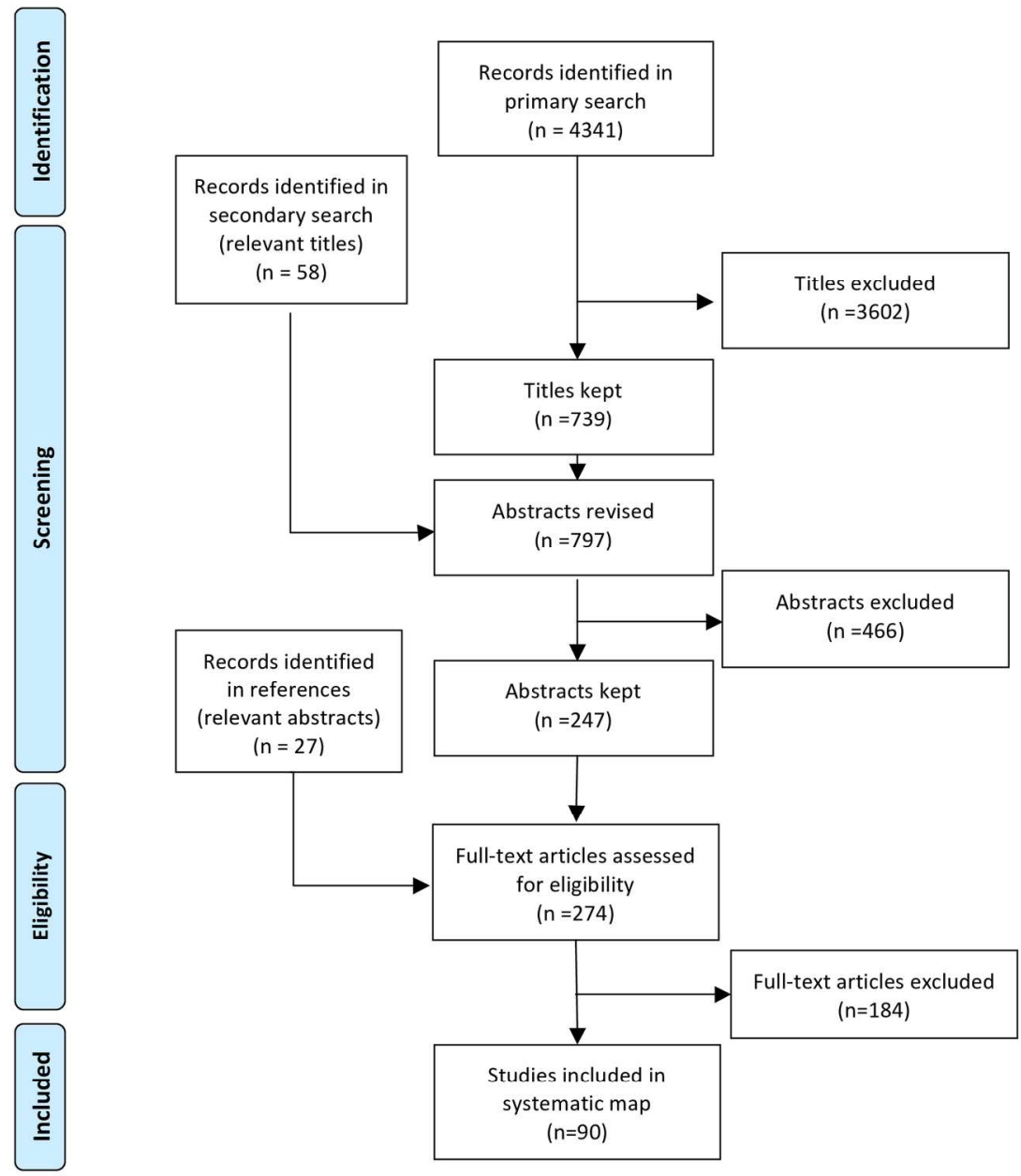

Adapted From: Moher D, Liberati A, Tetzlaff J, Altman DG, The PRISMA Group (2009). Preferred Reporting /tems for Systematic Reviews and Meta-Analyses: The PRISMA Statement. PLoS Med 6(6): e1000097. doi:10.1371/journal.pmed1000097

For more information, visit www.prisma-statement.org.

Figure 2. Preferred Reporting Items for Systematic Reviews and Meta-Analyses (PRISMA) diagram. Shown are the numbers of publications retrieved in the literature searches and the number excluded in each step. Diagram adapted from Moher et al. (2009).

$172 \times 222 \mathrm{~mm}(300 \times 300 \mathrm{DPI})$ 


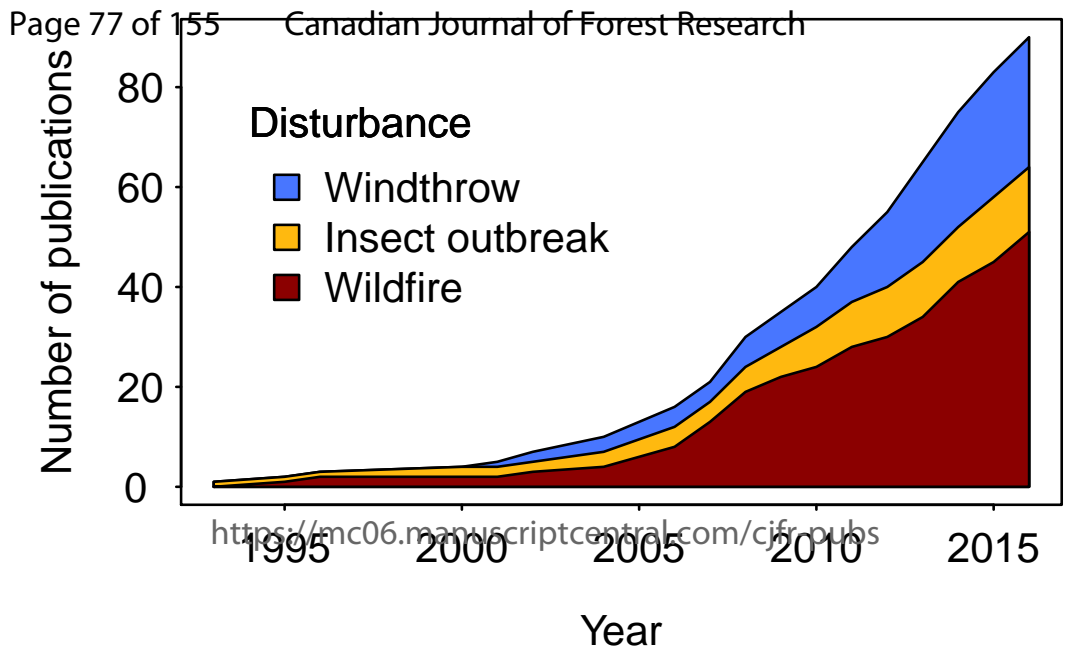




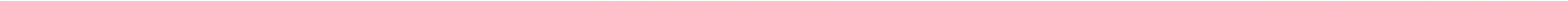




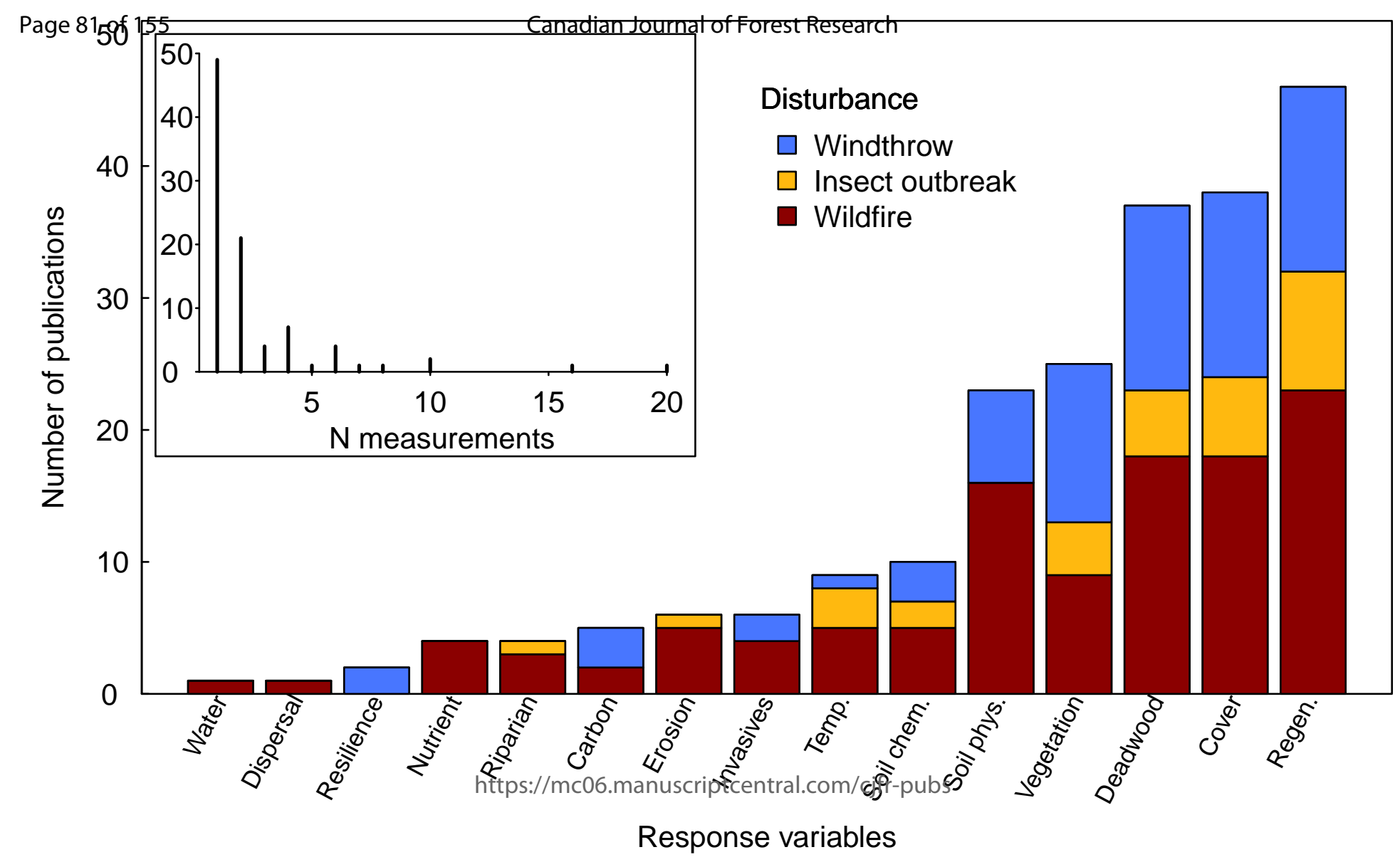




\section{Appendix A1}

Supporting information for Leverkus et al., Salvage logging effects on regulating and supporting ecosystem services - A systematic map

\section{Systematic map database and data coding strategy}

Databases for systematic maps are usually encouraged at the level of individual study sites (James et al. 2016). However, due to the characteristics of the retrieved studies, we decided that the most coherent presentation of the data would be at the publication level. This was, on the one hand, because some publications included two to several disturbance events and/or study sites across a region. Also, some study sites resulted in multiple publications which used different subsets of the overall experimental design. In these cases, some variables such as forest type or replication varied even within one study site (e.g. Castro et al. 2012, Leverkus et al. 2014), and our database (Table A3) thus provides detailed information for each publication. Despite the publication-level structure of the database, we included one column with the name of the study site(s) of each publication to allow relating publications from the same study and obtaining study-level summary information.

We aimed to populate the database with information items from each publication (see below), either directly from the publication, from different publications related to the same study, or directly from the authors; however, not all this information was always available and exceptions were noted in the database with "NA". For each publication, the database includes:

1. Bibliographic information. Columns: Authors, Year, Title, Publication, Volume and pages, DOI.

2. Source of obtention of the publication. This was one of the following: a) Primary search (in Web of Science or Scopus); b) Secondary search (in specialised search engines and websites); c) Supplementary search (in reference lists of review articles and other publications). Column: Source.

3. Location of the study. Columns: Country, Region/state, X, Y.

4. Name of the study site. This variable aims to relate different publications in the database to each other due to them addressing the same study. Columns: Site, Site_ref (the latter relates to Fig 4). 
5. We also recorded whether a study addressed one or multiple study sites or sites across a geographic region. Column: Regional or multi-site ( $y=y e s ; n=n o)$.

6. Type of disturbance: wildfire, insect outbreak, or windstorm. Column: Disturbance.

7. Disturbance severity. This was obtained in a coarse way through indications of percent tree mortality or percent basal area dead or through qualitative indications. Where a severity range was provided, we recorded the median of that range. Some studies only provided a qualitative estimation of severity. On the basis of our experience in the relationship between qualitative and quantitative estimates in the retrieved publications, and with the aim of describing the retrieved literature in homogeneous terms, we attributed the following severity percentages to them: "Low": 30\%, "Low to moderate": 45\%, "Moderate": 60\%, "Moderate to high" or "Mixed" or "Variable": 75\%, "High": 90\%, and "Severe": 100\%. Where one publication explicitly addressed sampling areas of different severities, we included all values in separate columns. Note that disturbance severity can be spatially quite variable and that we only provide one median value per publication or per severity class within each publication. Columns: Disturbance Severity (mean percentage provided for all publications), Disturbance Severity "b" (for publications that explicitly addressed a second level of severity) and Disturbance Severity "c" (for publications that explicitly addressed a third level of severity). NA values in the latter columns indicate that the publication did not explicitly address a second or third disturbance severity level.

8. Time between disturbance and logging. We obtained the time (in years) elapsed between the disturbance and logging. As for disturbance severity, we recorded median values in the cases for which a range of values was provided. This was because some studies included a range of time periods, for example due to disturbance not happening in one discrete moment but over a period of time (particularly insect outbreaks), salvage logging occurring over some period of time, or lack of exact knowledge on when salvage logging took place. Column: Time disturbance-logging.

9. Logging intensity. Similar to the data on disturbance severity, we obtained an approximation of logging intensity through quantitative or qualitative indications available in the publications. The quantitative indications referred to the percentage of basal area or of trees that were removed. For descriptive purposes, we transformed qualitative indicators to percentages as follows. The intensity category "Moderate to low" was given 50\%, "Moderate" or "Variable": 75\%, "High": 90\%, and "Clearcut": 
$100 \%$. When one publication explicitly addressed sampling areas of different logging intensity, we included all values in different columns. Columns: Logging Intensity (mean percentage, provided for all publications), Logging Intensity " $b$ " (for publications that explicitly addressed a second level of intensity), Logging Intensity "c" (for publications that explicitly addressed a third level of intensity), and Logging Intensity "d" (for publications that explicitly addressed a fourth level of intensity). NA values in the latter columns indicate that the publication did not explicitly address a second, third or fourth logging intensity level.

10. Logging method. We recorded any indication of machinery or methods employed in the felling and extraction of the wood. More than one method was employed in some studies, in which case we recorded all the methods that were mentioned. We categorised these logging methods into: Manual cut or use of chainsaws; harvesting with feller bunchers, harvesters, or similar machinery; ground-based yarding with skidders, tractors, log forwarders, cable, or winch; and helicopter yarding. In the database, we provide one column containing all the methods mentioned in one publication (column Logging method) and six columns with entries on the use of each individual method (columns Tractor/ Skidder/ Forwarder, Fellet-buncher, Winch/ cable yarding, Helicopter, Manual cut/ chainsaws, and Slash treatment).

11. Forest type. According to study descriptions, for each publication we recorded whether it included broadleaf, conifer, and/or mixed stands, or a combination of these with no differentiation. The database contains four columns with binomial entries (1/0) for each of: Broadleaf, Conifer, Mixed, Scrambled (i.e. combination of stand types without differentiation). Individual studies may have values of 1 for one or more stand types.

12. Forest age before disturbance. We obtained information on the age of stands, which was generally provided as a number of years since previous standreplacing disturbance. For consistency of information among studies, we categorised this information into three broad categories: a) young forest ( $<50$ years old), b) mature forest (50-99 years), and c) old forest ( $\geq 100$ years).

13. Dominant canopy species. We recorded the name of the species dominating the studied stands. In case there was more than one, we recorded up to five dominant species, and above this amount we specified that it was a mixed stand. In cases where one study included multiple stands of different composition, we recorded the names of all species dominating at least some of the stands. The names of all 
dominant species in any individual study are provided in the column "Main tree species". The presence of each individual species is provided with binomial entries in the columns "Abies alba" through "Tsuga mertensiana".

14. Randomisation. We recorded whether salvage logging was under control of the researchers, with randomisation in the allocation of treatments to spatial units. Column: Randomisation.

15. Type of design: Control-Intervention, Before-After-Control-Intervention, or a mixture of both approaches. Before-After designs without controls were excluded, as indicated in Study Inclusion Criteria. Column: Design (the entry CI/ BACI indicates that each approach was used for a subset of the measurements).

16. Replication of population (disturbed forest). We recorded the number of disturbance events that defined the study population (i.e. excluding subsequent disturbances). In the case of wildfire, this was relatively easy to define. For insect outbreaks, we considered that one event affected a whole region. As wind does not produce continuous disturbance surfaces as fire does, we also recorded the number of blowdown patches considered in windthrow studies. Column: $\mathrm{N}$ disturbed sites.

17. Replication of intervention. We assessed the number of spatially independent stands or patches that were salvage logged in each study. This task was often difficult due to the great variability in the scale of studies, sampling strategies, and plot layouts. In designed experimental studies the replication was easy to obtain, but in other studies we provided a minimum number of replicates based on study site descriptions, maps, or contact with authors. Column: Replication SL.

18. Number of measurements. We recorded the number of times that field measurements were taken. Column: $\mathrm{N}$ measurements.

19. Response variables measured. We recorded whether each publication sampled each of the following: a) stand structure and deadwood amount and characteristics, b) tree regeneration, c) ground cover [cover of plants, bare soil, rocks, etc.], d) soil physical properties, e) soil chemical properties, f) biological activity related to nutrient cycling, g) vegetation, h) soil erosion [by wind or water], i) abundance of exotic or invasive species, $\mathrm{j}$ ) air, soil or water temperature, $\mathrm{k}$ ) resilience to subsequent disturbance [e.g. tree regeneration after another, subsequent disturbance], 1) ecosystem $\mathrm{C}$ pools [excluding those in a)], $\mathrm{m}$ ) riparian ecosystem functioning, $\mathrm{n}$ ) seed dispersal, o) drinking water quality. 


\section{References}

Castro, J., Puerta-Piñero, C., Leverkus, A.B., Moreno-Rueda, G., and Sánchez-Miranda, A. 2012. Post-fire salvage logging alters a key plant-animal interaction for forest regeneration. Ecosphere 3(10): art90.

James, K.L., Randall, N.P., and Haddaway, N.R. 2016. A methodology for systematic mapping in environmental sciences. Environ. Evid. 5(1): 7. BioMed Central. doi:10.1186/s13750-016-0059-6.

Leverkus, A.B., Lorite, J., Navarro, F.B., Sánchez-Cañete, E.P., and Castro, J. 2014. Post-fire salvage logging alters species composition and reduces cover, richness, and diversity in Mediterranean plant communities. J. Environ. Manage. 133: 323331. Elsevier Ltd. doi:10.1016/j.jenvman.2013.12.014. 


\section{Appendix A2}

Supporting information for Leverkus et al., Salvage logging effects on regulating and supporting ecosystem services - A systematic map

\section{Literature searches and screening -Results}

The initial search in Web of Science provided 3979 results, with an additional 292 publications after the update in 2017 (Fig 2 of the main text). The search in Scopus provided additional 70 non-duplicated publications, adding to a total of 4341 . Of these, roughly $10 \%(\mathrm{~N}=401)$ were randomly selected to assess homogeneity in the application of criteria among reviewers. This initial exercise, performed by ABL and LG, provided a value of the kappa test $\kappa=0.47$, indicating only "moderate" agreement among reviewers and thus heterogeneity in the application of inclusion criteria (Landis and Koch 1977). After revising the inclusion criteria and performing the test again, the new kappa value was 0.69 , which is considered "substantial" agreement (Landis and Koch 1977). The subsequent title selection resulted in 3649 titles being removed. Of these, 323 included the word "salvage" in the title, keywords or abstract; their titles were again screened and 47 were brought back to the abstract selection phase. This resulted in 3602 titles being discarded and 739 being kept. The secondary search provided an additional 58 non-duplicated articles with a relevant title, yielding 797 abstracts to be reviewed.

Before abstract selection, homogeneity of application of inclusion criteria was again assessed. A total of 63 articles was randomly selected for independent evaluation by three members of the review team. The values that were obtained were $\kappa=0.68$ $(\mathrm{ABL} \& \mathrm{LG}), \kappa=0.43$ (LG \& JC) and $\kappa=0.43$ (JC \& ABL). After discussing the criteria again and reassessing abstract inclusion, the obtained kappa values were 0.71 , 0.62 , and 0.72 , respectively, so the process continued. Of the 797 abstracts, 466 were considered irrelevant and 247 were kept. An additional 27 studies with relevant titles and abstracts were obtained from the reference lists of selected articles and reviews on the topic. This resulted in a total of 274 full-length articles being assessed (Fig 2).

Of the full-text articles assessed, 90 were kept and 184 were excluded for the reasons outlined in Table A1 in this file (see Supplementary Table S2 for references of excluded publications and reasons for exclusion). The most frequent cause for exclusion 
was the lack of true replication, which led to the exclusion of 47 articles. Second in frequency, 38 articles did not measure a response variable that was appropriate for this systematic map. These studies mostly focused on the response of individual organisms or biotic communities, and they were excluded only at the last stage of article screening (i.e. there was no limitation on the Outcome in the search string and the articles were allowed to pass the title and abstract selection despite obvious focus on biodiversity components). We chose not to broaden the scope of this systematic map to include biodiversity as a response variable because this was the target of a recent, global review (Thorn et al. 2018). Next, 18 of the retrieved studies included a response variable of interest, but the same data were also found in another publication by the same authors. This mostly included data related to study site descriptions (e.g. percent ground cover of vegetation and other cover categories), rather than dual publication of research outcomes. The five following reasons for exclusion relate to the lack of an appropriate design for inclusion (Table A1). We were not able to obtain nine full-text documents. One article was excluded because the methods were not described well enough to assess the inclusion criteria, and one was excluded because we lacked fluency in the publication's language (Slovenian) despite it having an abstract translation in English. 


\section{Table A1. Reasons for exclusion from the systematic map at full-text screening}

\begin{tabular}{lll}
\hline Reason for exclusion* & Criterion type & $\mathrm{N}$ articles \\
\hline No true replication & Validity & 47 \\
No appropriate response variable & Inclusion & 38 \\
Redundant data & Validity & 18 \\
No appropriate comparator & Inclusion & 14 \\
Not empirical study & Inclusion & 13 \\
Study design not appropriate & Validity & 13 \\
No appropriate population & Inclusion & 11 \\
Intervention confounded with other interventions & Inclusion & 10 \\
Paper not available & & 9 \\
No appropriate intervention & Inclusion & 6 \\
B-A design & Inclusion & 3 \\
Methods not well described & Validity & 1 \\
Language & Inclusion & 1 \\
\hline Total & & 184
\end{tabular}

* In cases where one study had more than one reason for exclusion, only the first unmet study inclusion/ validity criterion (in the order described in the methods) was recorded.

\section{References}

Landis, J.R., and Koch, G.G. 1977. The measurement of observer agreement for categorical data. Biometrics 33(1): 159-174. doi:10.2307/2529310.

Thorn, S., Bässler, C., Brandl, R., Burton, P., Cahall, R., Campbell, J.L., Castro, J., Choi, C.-Y., Cobb, T., Donato, D., Durska, E., Fontaine, J., Gauthier, S., Hebert, C., Hothorn, T., Hutto, R., Lee, E.-J., Leverkus, A., Lindenmayer, D., Obrist, M., Rost, J., Seibold, S., Seidl, R., Thom, D., Waldron, K; Wermelinger, B., Winter, M.-B., Zmihorski, M., and Müller, J. 2018. Impacts of salvage logging on biodiversity - a meta-analysis. J. Appl. Ecol. 55: 279-289. doi:10.1111/13652664.12945. 


\section{Appendix A3}

Supporting information for Leverkus et al., Salvage logging effects on regulating and supporting ecosystem services - A systematic map

\section{Stand characteristics}

\section{Results}

Of the 49 studies included in the systematic map, 11 were established in broadleaf forests or included broadleaf stands, 33 were established in or included conifer stands, 10 included mixed stands, and 3 included combinations of stand types without differentiation (“scrambled"). Regarding pre-disturbance forest age, 5 studies included young stands, 28 included mature stands, 12 included old stands, and 10 studies did not provide sufficient information to assess this variable. Note that these figures add to more than 49 (the number of studies included in the systematic map) because some studies included more than one stand type and/or forest age. Table A2 (below) shows the number of studies that included each stand type by stand age combination.

We recorded 37 tree species as dominating (or co-dominating) the canopy of individual stands in the included studies (Table A3). At the publication level, quaking aspen (Populus tremuloides) was the most frequent dominant species among broadleaved tree species and lodgepole pine (Pinus contorta) among conifers (Table A3). Pinus was by far the most frequent genus, with 67 cases, followed by Picea (32 cases), Populus (24 cases), Abies (14 cases), Fagus and Pseudotsuga (each 6 cases). Wind was the disturbance type where the largest number of dominant broadleaf species was included among the identified studies $(n=10, v s \mathrm{n}=4$ for wildfire or insect outbreak; Table 3). In contrast, wildfire studies contained the largest number of 
dominant conifer species $(\mathrm{n}=15, v s \mathrm{n}=11$ for insect outbreaks and $\mathrm{n}=10$ for wind; Table A3). 
Table A2. Number of studies containing stands of each stand type and age combination

\begin{tabular}{lrrrr}
\hline & \multicolumn{4}{l}{ Stand type (number of studies) } \\
\cline { 2 - 6 } Stand age & Broadleaf & Conifer & Mixed & Scrambled \\
\hline Young & 1 & 4 & 0 & 0 \\
Mature & 6 & 19 & 9 & 2 \\
Old & 2 & 8 & 2 & 0 \\
N/A* & 2 & 7 & 1 & 1 \\
\hline
\end{tabular}

$* \mathrm{~N} / \mathrm{A}=$ information not available 
Table A3. Distribution of publications relative to disturbance type and the occurrence of dominant tree species

\begin{tabular}{|c|c|c|c|c|}
\hline \multirow[b]{2}{*}{ Dominant tree species } & \multicolumn{4}{|c|}{ Disturbance type ( $\mathrm{N}$ of publications) } \\
\hline & Wildfire & Insect outbreak & Windthrow & Total \\
\hline \multicolumn{5}{|l|}{$\underline{\text { Broadleaves }}$} \\
\hline Acer rubrum & 0 & 0 & 1 & 1 \\
\hline Acer saccharum & 0 & 0 & 1 & 1 \\
\hline Betula papyrifera & 0 & 1 & 1 & 2 \\
\hline Carya spp. & 0 & 0 & 2 & 2 \\
\hline Eucalyptus globulus & 2 & 0 & 0 & 2 \\
\hline Fagus grandifolia & 0 & 0 & 1 & 1 \\
\hline Fagus sylvatica & 0 & 1 & 4 & 5 \\
\hline Populus balsamifera & 5 & 1 & 0 & 6 \\
\hline Populus spp. & 0 & 0 & 1 & 1 \\
\hline Populus tremuloides & 12 & 1 & 4 & 17 \\
\hline Prunus serotina & 0 & 0 & 1 & 1 \\
\hline Quercus ilex & 1 & 0 & 0 & 1 \\
\hline Quercus spp. & 0 & 0 & 2 & 2 \\
\hline $\mathbf{N}$ species $\dagger$ & 4 & 4 & 10 & 13 \\
\hline \multicolumn{5}{|l|}{$\underline{\text { Conifers }}$} \\
\hline Abies alba & 0 & 1 & 3 & 4 \\
\hline Abies balsamea & 0 & 1 & 2 & 3 \\
\hline Abies grandis & 1 & 0 & 0 & 1 \\
\hline Abies lasiocarpa & 4 & 0 & 2 & 6 \\
\hline Larix occidentalis & 1 & 0 & 0 & 1 \\
\hline Picea abies & 0 & 3 & 4 & 7 \\
\hline Picea engelmannii & 4 & 0 & 2 & 6 \\
\hline Picea glauca & 7 & 1 & 0 & 8 \\
\hline Picea mariana & 6 & 1 & 2 & 9 \\
\hline Picea spp. & 0 & 1 & 0 & 1 \\
\hline Picea $\mathrm{x}$ lutzii & 0 & 1 & 0 & 1 \\
\hline Pinus banksiana & 5 & 0 & 4 & 8 \\
\hline Pinus contorta & 7 & 6 & 3 & 16 \\
\hline Pinus densiflora & 1 & 0 & 0 & 1 \\
\hline Pinus elliottii & 0 & 0 & 1 & 1 \\
\hline Pinus halepensis & 2 & 0 & 0 & 2 \\
\hline Pinus nigra & 6 & 0 & 0 & 6 \\
\hline Pinus pinaster & 11 & 0 & 0 & 11 \\
\hline Pinus ponderosa & 12 & 2 & 0 & 14 \\
\hline Pinus spp. & 0 & 1 & 0 & 1 \\
\hline
\end{tabular}


Pinus sylvestris

Pinus taeda

\begin{tabular}{rrrr}
4 & 0 & 0 & 4 \\
0 & 0 & 2 & 2 \\
6 & 0 & 0 & 6 \\
0 & 1 & 0 & 1 \\
\hline 15 & 11 & 10 & 24
\end{tabular}

$\mathbf{N}$ species $\dagger$

Mixed broadleaves*

$\begin{array}{llll}0 & 0 & 2 & 2\end{array}$

Mixed conifers*

$1 \quad 0$

Mixed conifers and broadleaves*

0

0

12

*Included more than five dominant species in individual stands

$\dagger$ Number of species with non-zero values 


\section{Discussion}

Conifer stands were the most frequent forest type addressed by the studies on salvage logging. This can partially be explained by the abundance of studies in boreal or sub-boreal areas of North America and the fact that severe insect outbreaks often occur in forests with low species diversity, such as the even-aged, lodgepole pine-dominated forests of the Rocky Mountains. Wildfire is also a major driver the dynamics of conifer forests (Mutch 1970, Kuuluvainen and Ankala 2011). Broadleaf species are also generally deciduous in temperate and boreal ecosystems, which makes them less susceptible to major wind disturbances occurring in winter (Mayer et al. 2005) and more likely to regenerate after defoliation by insects.

Among the conifers, pines (Pinus) were by far the most frequent genus that dominated the study areas, with 66 cases, followed by spruce (Picea, 32 cases), fir (Abies, 14 cases), and Douglas-fir (Pseudotsuga, 6 cases). The diversity of pine species and the genus' adaptation to broad climatic conditions such as drought-resistant species like $P$. halepensis in the Mediterranean and to cold-resistant ones like P. banksiana in boreal North America explain its abundance. The most common dominant broadleaf genera were Populus (24 cases) and Fagus (6 cases). In combination, these genera span large portions of Europe and North America; this highlights the potential applicability of results from studies included in this systematic map to post-disturbance management in many places throughout these two regions. The distribution of forest age can also be considered representative of typical forest conditions in these regions. Most forests in developed nations are under some form of management and should thus be expected not to be in the "old" category, as documented by the systematic map. However, lack of understanding regarding the effects of disturbance and subsequent salvage logging on young forests represents a significant knowledge gap, since this forest age is relatively 
abundant. Although young and typically small-diameter trees are less susceptible to windthrow and insect attack, they are susceptible to wildfire and post-fire salvage logging despite their comparatively low wood volume (Leverkus et al. 2018).

\section{References}

Kuuluvainen, T., and Ankala, T. 2011. Natural forest dynamics in boreal Fennoscandia: a review and classification. Silva Fenn. 45(5): 823-841. doi:10.14214/sf.73.

Leverkus, A.B., Thorn, S., Gustafsson, L., and Lindenmayer, D.B. 2018. Salvage logging in the world's forests: Interactions between natural disturbance and logging need recognition. Under Rev.

Mayer, P., Brang, P., Dobbertin, M., Hallenbarter, D., Renaud, J.-P., Walthert, L., and Zimmermann, S. 2005. Forest storm damage is more frequent on acidic soils. Ann. For. Sci. 62: 303-311. doi:10.1051/forest.

Mutch, R.W. 1970. Wildland fires and ecosystems-A hypothesis. Ecology 51(6): 1046-1051. 


\section{$1 \quad$ Salvage logging effects on regulating and supporting}

5 Alexandro B. Leverkus ${ }^{1}$, José María Rey Benayas ${ }^{1}$, Jorge Castro $^{2}$, Dominique Boucher ${ }^{3}$,

6 Stephen Brewer ${ }^{4}$, Brandon M. Collins ${ }^{5}$, Daniel Donato ${ }^{6}$, Shawn Fraver ${ }^{7}$, Barbara E.

7 Kishchuk $^{8}$, Eun-Jae Lee ${ }^{9}$, David B. Lindenmayer ${ }^{10}$, Emanuele Lingua ${ }^{11}$, Ellen Macdonald ${ }^{12}$,

8 Raffaella Marzano ${ }^{13}$, Charles C. Rhoades ${ }^{14}$, Alejandro Royo ${ }^{15}$, Simon Thorn ${ }^{16}$, Joseph W.

9 Wagenbrenner ${ }^{17}$, Kaysandra Waldron ${ }^{18}$, Thomas Wohlgemuth $^{19}$, Lena Gustafsson ${ }^{20}$

$10{ }^{1}$ Departamento de Ciencias de la Vida, UD Ecología, Edificio de Ciencias, Universidad de

$11 \quad$ Alcalá, Alcalá de Henares, Spain.josem.rey@uah.es

$12{ }^{2}$ Departamento de Ecología, Facultad de Ciencias, Universidad de Granada, Granada,

$13 \quad$ Spain.jorge@ugr.es

$14{ }^{3}$ Centre de foresterie des Laurentides, Service Canadien des Forêts, Ressources Naturelles

15 Canada, Québec, Québec, Canada. dominique.boucher@canada.ca

$16{ }^{4}$ Department of Biology, University of Mississippi, Mississippi, USA.

17 jbrewer@olemiss.edu

$18{ }^{5}$ Center for Fire Research and Outreach, University of California Berkeley, California,

$19 \quad$ USA. bcollins@,berkeley.edu

$20{ }^{6}$ School of Environmental and Forest Sciences, University of Washington, Seattle, WA, $21 \quad$ USA. daniel.donato@dnr.wa.gov 
$22{ }^{7}$ School of Forest Resources, University of Maine, Orono, Maine, USA.

23 shawn.fraver@maine.edu

$24{ }^{8}$ Science Policy Integration Branch, Canadian Forest Service, Natural Resources Canada,

25 Ottawa, Ontario, Canada. barbara.kishchuk@,canada.ca

$26{ }^{9}$ Urban Planning Research Group, Daejeon Sejong Research Institute, Jung-gu, Daejeon,

27 Korea.2lejae@hanmail.net

$28{ }^{10}$ Fenner School of Environment and Society, The Australian National University,

29 Canberra, Australia. David.Lindenmayer@anu.edu.au

$30{ }^{11}$ Department TESAF, University of Padova, Legnaro (PD), Italy.

$31 \quad$ emanuele.lingua@,unipd.it

$32{ }^{12}$ Department of Renewable Resources, University of Alberta, Edmonton, Alberta, Canada.

33 emacdona@ualberta.ca

$34{ }^{13}$ Department DISAFA, University of Torino, Grugliasco (TO), Italy.

$35 \quad$ raffaella.marzano@,unito.it

$36{ }^{14}$ Rocky Mountain Research Station, USDA Forest Service, Fort Collins, Colorado, USA.

$37 \quad$ crhoades@fs.fed.us

$38 \quad{ }^{15}$ Northern Research Station, USDA Forest Service, Irvine, PA, USA. aroyo@,fs.fed.us

$39{ }^{16}$ Field Station Fabrikschleichach, Department of Animal Ecology and Tropical Biology

40 (Zoology III), Julius-Maximilians-University Würzburg, Rauhenebrach, Bavaria,

$41 \quad$ Germany. simon@thornonline.de

$42{ }^{17}$ Pacific Southwest Research Station, USDA Forest Service, Arcata, California, USA.

$43 \quad$ jwagenbrenner@,fs.fed.us 
$44{ }^{18}$ Department of Wood and Forest Sciences, Université Laval, Québec, QC, Canada.

$45 \quad$ kaysandra.waldron.1@ulaval.ca

$46{ }^{19}$ Research Unit Forest Dynamics, Swiss Federal Institute for Forest, Snow and Landscape

47 Research WSL, Zuercherstrasse 111, CH-8903 Birmensdorf, Switzerland.

$48 \quad$ thomas.wohlgemuth@wsl.ch

$49{ }^{20}$ Department of Ecology, Swedish University of Agricultural Sciences, Uppsala, Sweden.

$50 \quad$ Lena.Gustafsson@slu.se

51

52 * Corresponding author: ABL. Departamento de Ciencias de la Vida, UD Ecología,

53 Edificio de Ciencias, Universidad de Alcalá, Alcalá de Henares, Spain. Tel. +34

54 622689928. E-mail: alexandro.leverkus@uah.es (ABL) 


\section{$57 \quad$ Abstract}

58 Wildfires, insect outbreaks, and windstorms are increasingly common forest disturbances.

59 Post-disturbance management often involves salvage logging, i.e. the felling and removal of 60 the affected trees. However, this practice may represent an additional disturbance with

61 effects on ecosystem processes and services. We developed a systematic map to provide an 62 overview of the primary studies on this topic, and created a database with information on the 63 characteristics of the retrieved publications, including information on stands, disturbance, 64 intervention, measured outcomes, and study design. Of 4341 retrieved publications, 90 were 65 retained in the systematic map. These publications represented 49 studies, predominantly 66 from North America and Europe. Salvage logging after wildfire was addressed more 67 frequently than after insect outbreaks or windstorms. Most studies addressed logging after a 68 single disturbance event, and replication of salvaged stands rarely exceeded 10 . The most 69 frequent response variables were tree regeneration, ground cover, and deadwood 70 characteristics. This document aims to help managers find the most relevant primary studies 71 on the ecological effects of salvage logging. It also aims to identify and discuss clusters and 72 gaps in the body of evidence, relevant for scientists who aim to synthesize previous work or 73 identify questions for future studies. 


\section{Introduction}

77

78

Large, episodic, severe forest disturbances such as those caused by wildfires, insect outbreaks, and windstorms are part of the natural dynamics of forest ecosystems across the world (Noss et al. 2006, Turner 2010, Johnstone et al. 2016). However, the frequency, severity and extent of such disturbances have increased in recent decades due to anthropogenic activity (Seidl et al. 2017) and are predicted to further increase in the future (Schelhaas et al. 2003, Kurz et al. 2008, Pausas and Fernández-Muñoz 2012, Seidl et al. 2017). As a result, it is crucial to identify and adopt management strategies that promote regeneration and maintain ecosystem functions of post-disturbance forests, whether through active intervention or passive management (Crouzeilles et al. 2017). A common post-disturbance management approach in many parts of the world is salvage logging, i.e. the widespread felling and removal of the affected trees (McIver and Starr 2000, Lindenmayer et al. 2008, Thorn et al. 2018). Salvage logging has been reported after wildfires (Lindenmayer et al. 2018), volcanic eruptions (Titus and Householder 2007), insect infestations (Thorn et al. 2016), windstorms (Waldron et al. 2014), and ice storms (Sun et al. 2012). It is frequent in disturbed production forests but also common in protected forests in some parts of the world (Schiermeier 2016, Leverkus et al. 2017, Müller et al. 2018). However, there is concern that the additional logging-related disturbance can imperil ecosystem recovery and affect biodiversity and ecosystem services (Karr et al. 2004, Beschta et al. 2004, Donato et al. 2006, Lindenmayer et al. 2008). Besides the mechanical disturbance, salvage logging affects ecosystems through the removal and modification of large amounts of biological legacies i.e. the organisms, organic materials, and organically-generated environmental patterns that persist through a disturbance and constitute the baseline for post-disturbance recovery and regeneration (Franklin et al. 2000). 
The most frequent motivation for salvage logging across the world is the recovery of

101 some part of the economic value of the forest (Müller et al. 2018). Tree-killing disturbances

102 trigger a set of processes that can rapidly reduce the timber value due to reductions in wood

103 quality (e.g. stain, decay, and the activity of insect borers) and to pulses in wood supply to the

104 market (Prestemon and Holmes 2010). Rapid post-disturbance harvest is a frequent response

105 to disturbance that aims to avoid further deterioration of the damaged wood (Prestemon and

106 Holmes 2010, Lewis and Thompson 2011). In some parts of the world, such as regions of

107 North America, large-scale wildfires and insect outbreaks have become so frequent that

108 salvage logging is no longer a hasty response to unexpected events but rather constitutes an

109 expected source of wood to fill market demands (Mansuy et al. 2015). However, the logging

110 of disturbed forests is not profitable in all cases (e.g. Leverkus et al. 2012), and it may also

111 aim to fulfil other management objectives. Salvage logging can target the reduction of the

112 risk of subsequent disturbances, such as pest outbreaks and wildfire, through the elimination

113 of the substrate or fuel generated by the initial disturbance (Schroeder and Lindelöw 2002,

114 Collins et al. 2012). The simplification of post-disturbance ecosystem structure through the

115 removal of fallen trunks is intended to ease subsequent active restoration activities such as

116 reforestation (Leverkus et al. 2012, Man et al. 2013). Finally, there is a general negative

117 aesthetic perception of disturbed forests that may be offset by removing the visual evidence

118 of what is generally considered a "calamity" (Noss and Lindenmayer 2006). However, these

119 motivations are not always based on scientific evidence, but rather on traditional practices,

120 perceptions and deductions -as is often the case in conservation-related decision-making

121 (Pullin et al. 2004, Sutherland et al. 2004a).

122 The lack of scientific evidence on the effects of salvage logging was highlighted in 2000

123 (McIver and Starr 2000). In 2004, Lindenmayer and colleagues (Lindenmayer et al. 2004)

124 called for a revision of post-disturbance management policies, arguing that salvage logging

125 can have long-lasting negative effects on biodiversity, undermine the -largely unrecognised- 
126 ecological benefits of natural disturbances, and impair ecosystem recovery. Numerous

127 studies were established in subsequent years to assess the ecological consequences of this 128 practice, covering a wide array of disturbance types and severities, biomes, forest 129 compositions, logging methods, and response variables (Thorn et al. 2018). As a result, the 130 above-mentioned motivations for salvage logging have been challenged [e.g. wildfire risk 131 (Donato et al. 2006) and economics (Leverkus et al. 2012)], and many other effects of this 132 practice have been described (e.g. Lindenmayer et al. 2008, Beghin et al. 2010, Priewasser et 133 al. 2013, Wagenbrenner et al. 2015, Hernández-Hernández et al. 2017). Nonetheless, under 134 some circumstances, salvage logging can meet both management and conservation 135 objectives and address societal concerns. For example, post-bark beetle salvage logging 136 lodgepole pine forests in Colorado commonly reduces canopy fuels and regenerates new 137 stands without negatively effecting native plant diversity or soil productivity (Collins et al. 138 2011, 2012, Fornwalt et al. 2017, Rhoades et al. 2018). As a consequence, controversy 139 surrounding salvage logging among managers, environmentalists, politicians and academics, 140 remains lively (Schiermeier 2016, Leverkus et al. 2017, Lindenmayer et al. 2017, Müller et 141 al. 2018).

143 The ecological impacts of salvage logging can broadly be categorised according to 144 whether they affect:

a) The physical structure of ecosystems. An immediate consequence of logging is 146 the reduction in parameters such as standing and downed woody debris, living 147 canopy cover, and habitat structural complexity (Lee et al. 2008, Waldron et al. 148 2013, Peterson et al. 2015). 
b) Particular elements of the biota and species assemblages. The removal of dead wood can affect many species, particularly deadwood-dependent taxa (as concluded in a recent global review on this topic; Thorn et al. 2018).

c) Forest regeneration capacity. Salvage logging has the potential to alter residual growing stock, soil seed bed, canopy and soil seed banks, and species interactions such as competition, seed dispersal, seed predation, and herbivory (Greene et al. 2006, Collins et al. 2010, Puerta-Piñero et al. 2010, Castro et al. 2012, Castro 2013).

d) Key ecosystem processes and services. Ecosystem services are the benefits that people obtain from ecosystems; they are the link between particular elements of the ecosystem or functions that they perform (i.e. the biophysical component), the benefits that society obtains and, ultimately, the value placed on them (i.e. the human well-being component; Fig 1; Haines-Young and Potschin 2010). They are categorised into provisioning, cultural, regulating, and supporting services (Millennium Ecosystem Assessment 2003). As outlined above, salvage logging is most often conducted to recover the value of the affected wood. In the case of timber and other provisioning services, the human well-being component is often well defined and quantified. However, salvage logging also may affect cultural, regulating and supporting ecosystem services throughout the ecosystem services cascade. This implies that some of the effects outlined in a), b) and c) can also be considered to fall into the category of ecosystem services (Fig 1; Leverkus and Castro 2017). In the case of supporting and regulating services, the biophysical component is usually better understood than the human well-being component (Boerema et al. 2016), and this is likely also the case regarding the responses to salvage logging (Leverkus and Castro 2017). 
175 Although ecosystem services have seldom been explicitly addressed in the scientific

176 literature on salvage logging, they provide a common framework that allows balancing 177 economic benefits from timber against the wide array of ecological variables that are also 178 affected by post-disturbance management (Leverkus and Castro 2017). This framework 179 represents an Ecosystem Approach (Secretariat of the Convention on Biological Diversity 180 2000), i.e. the consideration of multiple benefits provided by ecosystems -rather than only 181 market values- to guide sustainable management decisions.

182 Salvage logging can affect ecosystem services by altering processes such as soil erosion 183 and hydrological regimes (Wagenbrenner et al. 2016), nutrient cycling (Kishchuk et al. 184 2015), carbon sequestration (Serrano-Ortiz et al. 2011b), seed dispersal (Castro et al. 2012), 185 vegetation cover (Macdonald 2007), tree regeneration (Castro et al. 2011, Marzano et al. 186 2013, Boucher et al. 2014), resistance to invasive species (Holzmueller and Jose 2012), 187 resilience to subsequent disturbances (Fraver et al. 2011), and many others (McIver and Starr 188 2000, Karr et al. 2004, Beschta et al. 2004, Lindenmayer and Noss 2006, Lindenmayer et al. 189 2008). Some authors argue that ecological responses to salvage logging may result in 190 synergistic effects due to the two successive disturbance events (the natural disturbance and 191 then logging) occurring close in time (Van Nieuwstadt et al. 2001, Wohlgemuth et al. 2002, 192 Karr et al. 2004, Lindenmayer et al. 2004, DellaSala et al. 2006, Lindenmayer and Noss 193 2006). Others have found that environmental drivers other than salvage logging are more 194 important in determining ecosystem regeneration (Kramer et al. 2014, Peterson and Dodson 195 2016, Royo et al. 2016, Rhoades et al. 2018). Further, studies often report contradictory 196 results, and there is currently no comprehensive, global assessment of the studies that have 197 addressed salvage logging effects on ecosystem processes. 
198 Systematic maps aim to collate the empirical evidence on particular topics and describe

199 the characteristics of the studies on those topics (James et al. 2016). In contrast to systematic

200 reviews, they do not aim to synthesise the results of individual studies. Rather, they help

201 managers identify the literature on a topic that is most relevant to their needs as well as

202 knowledge clusters and knowledge gaps to suggest future systematic review lines and topics

203 for further empirical study.

204 Here, we provide a systematic map addressing the ecological effects of salvage logging,

205 with a focus on regulating and supporting ecosystem services. The focus on ecosystem

206 services intends to leverage the relevance and applicability of academic studies for

207 non-academic stakeholders, including land managers who face the question of how to

208 manage disturbed forests, as well as the general public. A global overview of this subject that

209 also addresses potential reasons for heterogeneity in the effects measured by different studies

210 could aid managers and policy-makers worldwide in finding the necessary scientific

211 information to make decisions regarding salvage logging. Such decisions require answering

212 questions such as: Is salvage logging likely to enhance the recovery of disturbed forests

213 under particular forest types and disturbance conditions? And, Does the trade-off between

214 provisioning and other kinds of ecosystem services result in a positive overall balance for

215 specific management intervention? We describe the state of the literature that addresses these 216 questions.

\section{Materials and methods}

219 We followed the guidelines for systematic reviews in environmental management as 220 prescribed by the Collaboration for Environmental Evidence (CEBC 2010) and several other

221 texts (Sutherland et al. 2004b, Pullin and Stewart 2006, Koricheva et al. 2013, James et al. 
222 2016). The Methods described below are an expansion of those presented in our protocol 223 (Leverkus et al. 2015a).

\section{Research question}

225 We established a search strategy to identify the studies answering the following primary 226 research question:

227 Does post-disturbance salvage logging affect regulating and supporting ecosystem services?

228 This question implies the following key elements:

- Population: Forests affected by one of the following disturbances: windstorms, pest $230 \quad$ insect outbreaks, or wildfire.

231 - Intervention: Salvage logging, i.e. the harvesting of trees from areas after disturbance 232 events.

233 - Comparator: Forests after disturbance where no salvage logging was conducted.

234 - Outcome: Variables that could be regarded as indicators of regulating or supporting 235 ecosystem services.

236 We expected that the studies collectively would provide varying and apparently 237 contradictory answers to the primary research question. To search for potential reasons 238 underlying this heterogeneity, we considered the secondary research question:

239 Does the response of ecosystem services to post-disturbance salvage logging vary with the:

$240 \quad$ type and severity of the disturbance?

241 - geographic region?

242 - intensity, method, or timing of salvage logging?

243 - forest type? 
- type of study design?

245

246

247

\section{Literature searches}

The primary literature search was conducted in English in Web of Science (WoS) and

Scopus with the aim of answering the primary research question. The terms were searched in titles, abstracts and keywords and were based on the Population and the Intervention. The final search string (Table S1) was established after the scoping exercise described in the protocol (Leverkus et al. 2015a). The search in WoS was initially made on 18 Aug 2015 and updated on 5 May 2017 to encompass all studies published until 31 Dec 2016. In WoS, the search was restricted to the fields of Environmental Sciences and Ecology/ Forestry/ Biodiversity Conservation/ Zoology/ Plant Sciences/ Meteorology and Atmospheric Sciences/ Entomology/ Water Resources, and in Scopus to Agricultural and Biological Sciences/ Environmental Science/ Earth and Planetary Sciences/ Multidisciplinary.

We performed secondary searches to find other publications, including grey literature, with simplified Population and Intervention terms. These searches were made in the Directory of Open Access Journals (https://doaj.org/), the CABI database of forest science (http://www.cabi.org/forestscience/), and websites of the Canadian Forest Service (http://cfs.nrcan.gc.ca/publications) and the US Forest Service (http://www.treesearch.fs.fed.us/). We also searched in Google Scholar. For complete search terms, see Table S1.

As supplementary bibliographic searches, the reference lists of relevant articles (review articles and books) were screened for additional articles to complement the list of articles 
265 identified using the search terms. A list of the publications was sent to all the authors of this 266 systematic map, most of who have research experience on salvage logging. Authors were 267 asked to identify relevant articles that were omitted from the search, and these articles were 268 then assessed against the study inclusion criteria, as described next.

\section{Study inclusion criteria}

To be considered for the review, studies had to be empirical and fulfil each of the

271 following inclusion criteria:

a) Relevant population: forest after wildfire, insect outbreak, or windstorm disturbance. Prescribed burning was not considered, as such fires tend to burn at lower 274 intensity than uncontrolled wildfires.

b) Relevant intervention: salvage logging. Different methods of wood extraction and intensities of intervention were considered. We excluded studies where salvage logging was confounded with other subsequent interventions, such as tree planting or insecticide

c) Relevant comparator: forest disturbed by the same disturbance event but not subject to salvage logging. We did not consider areas of disturbed forest prior to logging as a 281 comparator [i.e. Before-After (BA) study designs], as post-disturbance ecosystems are 282 highly dynamic and the effects of salvage logging could be confounded with the effects of the 283 time elapsed since the disturbance. As comparators, we considered the disturbed but 284 unsalvaged areas of Control-Intervention (CI) and Before-After-Control-Intervention 285 (BACI) designs. 
d) Relevant outcome: response variable that could broadly be regarded as a regulating or supporting ecosystem service. As it was expected that ecosystem services would rarely be directly addressed, we used variables considered to be indicators or proxies for ecosystem services (e.g. the quality of stream water for water purification, the abundance of seed dispersers for seed dispersal, plant biomass or cover for primary productivity, or the abundance of invasive species for invasion resistance). We also included studies addressing

292 post-disturbance tree regeneration, such as seedling density, survival, and growth.

293 Provisioning ecosystem services such as timber were excluded because they are tightly

294 linked to market conditions, which can vary considerably across locations and time. Rather

295 than neglecting the importance of such ecosystem services (which are a major driver of the 296 decision to salvage log disturbed forests), our intention was to complement the list of 297 ecosystem services that can be affected by this practice. We also excluded cultural services 298 because we expected few studies on this topic. Also, any variables directly related to the 299 number of standing trees were excluded on the basis that the intervention directly aims at 300 their extraction and reductions are thus a logical outcome. Finally, biodiversity was not 301 included in the systematic map because such responses were thoroughly reviewed in a recent 302 meta-analysis (Thorn et al. 2018).

303 We did not explicitly impose geographic restrictions on the studies, although the 304 searches were restricted to publications in English.

\section{Article screening}



through a stepwise elimination procedure. The articles were screened in the following steps: 1. Each title was read in the first step, and articles with irrelevant titles were discarded. This step was completed in a conservative way to avoid discarding any potentially relevant publications. Before screening all the titles, two members of the review team (ABL and LG)

311 screened 401 titles and the difference in outcomes was assessed through a kappa test. As the 312 results indicated heterogeneity of application of selection criteria (see Results), the inclusion 313 criteria were discussed again prior to screening all the titles. After screening the titles, the 314 word "salvage" was searched in the titles, keywords and abstracts of all the papers that were 315 recorded as irrelevant based on title. Their titles were screened again under a more inclusive 316 approach, and those considered potentially relevant were re-included for the next step. 
326 well as the study-site descriptions (including tables and figures). Relevant articles were

327 categorised according to the study quality assessment criteria defined below.

\section{Study quality and validity assessment}

329 Quality appraisal is not a necessary process in systematic mapping (James et al. 2016).

330 Nevertheless, based on the retrieved literature, we identified some quality issues related both

331 to the methodology and to the reporting in individual publications that provided insight into

332 the validity of the publication for inclusion in the map. First, regarding quality in reporting,

333 the lack of proper description of the study site and the sampling methods (i.e. not possible to

334 assess study inclusion criteria and/or study validity based on methodological quality due to

335 deficiencies in reporting) led to study exclusion.

336 The remaining studies were placed in the following three broad categories based on 337 methodological quality:

338 1. Empirical studies with treatments applied at appropriate spatial scales and with true

339 replication at the scale of management operations and with randomised allocation of

340 treatments to spatial units. An appropriate scale was considered as one that would generally

341 be used in post-disturbance management under local conditions, or that would reasonably

342 allow the measured responses to appear.

3432 . Studies as in 1 above, but without randomisation in the allocation of treatments to

344 spatial units. This is often the case, as the authors of the retrieved articles rarely had control

345 over the salvage logging process. This quality aspect is relevant from the point of view of

346 susceptibility to bias and it should be considered in subsequent systematic reviews. Although 16 
347 we did not use this criterion to reject studies in this systematic map, we did record whether

348 the spatial units where the intervention and the comparator were established were chosen by

349 the researchers (see Systematic map database, below).

3. Empirical studies without true replication or at inappropriate spatial scales. Studies

351 with pseudo-replicated designs were placed in this category. One of the most frequent cases

352 was that of one disturbance event affecting a reserve (unsalvaged comparator) and adjacent,

353 unprotected forest (salvaged intervention area). Such designs are highly susceptible to

354 confounding factors related to the management history and objectives of the different

355 management ("treatment") units and hence to bias, so we decided to exclude such studies

356 from the systematic map. As a matter of consistency, we also eliminated all other studies that

357 contained only one true replicate unit per treatment. It should be noted that in some studies,

358 the degree of true replication was very hard to assess from the study site descriptions, and in

359 other cases there was ambiguity in what could be considered true replication. In such cases,

360 other articles from the same sites were assessed and, where necessary, authors were

361 contacted to clarify their study designs.

\section{Systematic map database and data coding strategy}

363 We constructed a database with information relative to each publication, which included

364 bibliographic information and data related to the secondary research questions. This

365 encompassed data on stand, disturbance and salvage logging characteristics, study designs,

366 and the response variables that were measured. For a detailed description of the data included

367 in the systematic map database, see Appendix A1. 
372 Results and discussion

\section{$373 \quad$ Literature searches}

We retrieved 4341 publications from the primary searches (Fig 2). A total of 274

375 publications was assessed at full-text length, and 90 were kept in this systematic map (Fig 2;

376 see Supplementary Table S2 for publications excluded at this stage and the reasons for

377 exclusion). For detailed descriptions of the results of the literature searches and screening,

378 see Appendix A2. The remainder of the systematic map is primarily grounded on the 90

379 publications that were kept, which are included in the systematic map database 380 (Supplementary Table S3).

The following results are presented at the level we considered most relevant for each

382 addressed characteristic: some at the level of publications $(n=90)$, others at the level of 383 studies $(\mathrm{n}=49)$ (see Appendix A1), and others at the level of stand types within study sites or 384 within publications (for example, in cases where more than one stand was addressed in a 385 single study; $\mathrm{n}>49$ ). The level of each result is always indicated in the text, and the database 386 allows assessing any data at any desired level.

\section{Origin and distribution of publications}


388 389 390

392

Of the 90 publications included in the systematic map database, 81 were obtained from the primary search in the Web of Science. The cumulative number of publications has increased dramatically in the last two decades, and particularly in the last decade (Fig 3).

The 90 publications resulted from 49 studies, including studies with multiple study sites. Individual studies produced an average of $1.8 \pm 1.2$ publications (mean $\pm \mathrm{SD}$; range: 1-6), although it should be noted that not all publications from all studies are included in this systematic map [e.g. some papers from the Bavarian Forest National Park in Germany that dealt with salvage logging effects on biodiversity were excluded (Beudert et al. 2015, Thorn et al. 2015a, 2015b)]. Studies were generally established within one clearly defined study area, such as a publicly owned forest (e.g., National Forest) with adjacent private forestland, but eight studies (yielding 12 publications) either addressed two or more study sites that were located in different regions (separated by more than $100 \mathrm{~km}$; e.g. Wagenbrenner et al. 2015) or had a sampling design of regional scale, with multiple sites (e.g. Priewasser et al. 2013) (Table 1).

The publications included in the database were overwhelmingly concentrated in North America and Europe, with only two publications from another continent and no representation from the tropics or the Southern Hemisphere (Fig 4; Table 1). Even within these two geographic clusters, the publications were not equally distributed. In North America, there were nearly twice as many publications from the U.S.A than from Canada, and even publications from Canada were more abundant than those from all Europe (where half of the publications came from Spain). One could predict that studies on post-disturbance 
logging would occur more frequently in places where more natural disturbance occurs, or where natural disturbance is more often followed by logging. However, disturbances are common across forests globally (Seidl et al. 2017), and there is no obvious reason to consider that the countries not included in the systematic map lack salvage logging.

A possible explanation for the paucity of studies in the tropics lies in differences in

414 human-related causes and consequences of disturbances across regions. Disturbances like 415 wildfire in regions at the frontline of land-use change, such as many tropical regions, often 416 constitute an instrument for deforestation and land conversion rather than a natural process

417 followed by regeneration. In contrast, developed countries have generally reached more 418 stable land uses, so that disturbed forests will be expected to regrow, either for production or 419 for nature conservation. In this way, assessing the effects of salvage logging on ecosystems 420 makes more sense in cases where management or conservation objectives are to maintain 421 forest cover, as is more often the case in Europe and North America than in other regions. 422 Even in the few exceptions where salvage logging was addressed in tropical areas, the 423 research was conducted by foreign researchers (Van Nieuwstadt et al. 2001). Most of the 424 studies outside these two zones, including studies in Chile (Smith-Ramírez et al. 2014) and 425 Australia (Blair et al. 2016), failed to pass the inclusion criteria regarding the relevance of 426 response variables. Other non-mutually exclusive reasons for the predominance of European 427 and North American studies, as highlighted in a systematic map on active interventions for 428 biodiversity conservation (Bernes et al. 2015), are: a) the large extents of forest, b) the greater 429 abundance of researchers and availability of funding, and c) the large emphasis on research in 430 ecology and environmental management in Europe and North America. Finally, an important 20 
431 factor could be the language selected for the literature search -English-, which was

432 originally aimed at identifying scientific studies from over the world but was biased against

433 studies from nations where English is either not the official language or not spoken at a

434 sufficient level of proficiency to facilitate publication in indexed journals.

\section{Disturbance characteristics}

436 Wildfire was the most frequent disturbance type, with 51 publications (27 studies), followed 437 by wind (26 publications, 12 studies), and insect outbreaks (13 publications, 11 studies).

438 McIver and Starr (2000) conducted a review that highlighted several mechanisms through 439 which burnt forests could be particularly vulnerable to subsequent logging disturbance, 440 including effects on burnt soil and vegetation. This review also noted a lack of empirical 441 evidence regarding the consequences of post-fire logging, which triggered numerous 442 research projects on logging after wildfire [e.g., McIver and McNeil (2006), Donato et al. 443 (2006), Castro et al. (2010)]. Wildfire produces some unique ecological responses, such as 444 significant reductions in small-diameter aboveground biomass, as well as direct and indirect 445 wildlife mortality. Wildfire also generates direct impacts on people living in or near

446 fire-prone forests and spectacular images in the media. These factors have likely generated 447 more public and political demand for understanding the various implications of wildfire as 448 compared to windstorms or insect outbreaks, including impacts related to subsequent salvage 449 logging. However, logging after large storms (e.g., Kramer et al. 2014), and after massive 450 insect outbreaks (e.g., Collins et al. 2011), has recently attracted increasing attention. The 451 three kinds of disturbances addressed here have increased -and will likely continue to 
452 increase - in frequency and extent due to climate change and other factors related to 453 ecosystem conversion and changes in land-use intensity (Seidl et al. 2017). Addressing 454 questions related to post-disturbance management is a logical response to increasingly 455 prevalent situations. Many ecological responses to disturbances largely depend on disturbance severity, 457 which highlights the relevance of studying the response to disturbance, and to subsequent 458 logging, under different degrees of severity. The severity of natural disturbance among the 459 retrieved publications ranged between 10 and 100\% (Fig 5A; note the limitations in these 460 data described in the Systematic map database and coding strategy section in Appendix A1).

461 We found that wildfire was generally described as having greater disturbance severity than 462 insect outbreaks or windstorms. Studies on logging after wildfire or insect outbreaks were 463 generally tightly clustered at high severity values, whereas disturbance severity by wind was 464 less severe and more variable. Most of the studies included in the systematic map were 465 performed within patches subject to disturbances of specific severity, thereby controlling for 466 this factor as much as possible. In only a few cases (8 out of 49) did the studies directly 467 address disturbance severity as an explanatory variable, either through the selection of stands 468 within different degrees of severity (e.g. Brewer et al., 2012) or by sampling severity 469 gradients within plots (e.g. Royo et al., 2016). Although the selection of plots of different 470 disturbance severity is an appropriate way to increase the robustness of the study design, it 471 may come at the cost of lower replication. In contrast, measuring disturbance severity at 472 smaller scales as a covariate can help increase the explanatory power of management 473 variables without sacrificing replication. Of course, this is not always possible, and it hinges 22 
474 on the spatial scale at which disturbance severity varies and the spatial scale required to 475 accurately assess the response variable of interest.

476 We did not collect information on the spatial extent of the disturbances because in many 477 cases this information was not available. However, it can be argued that large disturbances 478 will generally attract more research and provide opportunities for greater replication. For 479 example, disturbances in North America commonly affect large areas (e.g. the 2016 fire near 480 Fort McMurray, Canada, which affected more than half a million ha). Salvage logging is, 481 however, quite often performed in areas affected by small- or medium-scale disturbances, 482 which are common in Europe and tend to be confined to areas with pre-existing road 483 infrastructure. Scientific studies performed in these areas might suffer from constraints in the 484 sampling design (thus leading to exclusion from the systematic map) but, in these situations, 485 logging intensity is likely to reach $100 \%$ across the disturbed area. As a consequence, 486 subjects worthy of in-depth analysis that are not covered by this systematic map include the 487 relationships among disturbance extent, the extent and intensity of salvage logging, and the 488 ecological response to disturbance and subsequent salvage logging.

\section{Intervention characteristics}

490 Ecological responses to salvage logging are often considered to vary with the time elapsed 491 between the disturbance and logging, particularly in the case of discrete disturbance events 492 like wildfire. For example, post-fire logging may have greater impact on soils if it is 493 conducted directly after wildfire because it may delay post-fire recovery (Wagenbrenner et 494 al. 2016). If logging occurs during or after the first growing season, natural regeneration can 
495

496

497

498

499

500

501

502

503

504

be most severely affected due to the physical destruction of resprouting stems and emerging seedlings (Martínez-Sánchez et al. 1999, Castro et al. 2011). The studies included in the systematic map most often included information on when logging was conducted, yet individual studies did not explicitly test the effect of different timing of salvage logging. Salvage logging took place between immediately and 10.5 years following the disturbance, with an average of $1.8 \pm 2.0$ (mean $\pm 1 \mathrm{SD}$ ) years across publications. Burnt stands were generally those salvage logged most quickly (after $1.1 \pm 0.8$ years), followed by wind-affected stands $(1.7 \pm 0.8$ years; Fig $5 B)$. In the case of disturbance by insects, salvage logging often started several years after the beginning of the outbreak, and the variability in the timing of salvage logging was much greater than for the other two disturbance types (4.4 \pm 3.7 years). Insect outbreaks most often take several years to develop, during which each tree goes through several stages of decline (Sullivan et al. 2010), and logging can take place at any stage from before the beginning of the outbreak -pre-emptive logging, not addressed here- to logging after several years of infestation. Logging is sometimes conducted in an attempt to prevent the infestation of particular stands or the expansion of insect populations (Müller et al. 2018), and in other cases it is performed to avoid wood decay or the accumulation of fuel once the stand has been affected. These are likely reasons for the greater variability in the timing of salvage logging related to insect outbreaks than after disturbance by fire or wind.

The intensity of salvage logging can be another crucial factor explaining salvage logging effects, as already identified more than six decades ago (Roy 1956). The studies in the systematic map included a wide range of salvage logging intensity for the three disturbance 24 
517 types considered, although intensity was mostly categorised in excess of $90 \%$. Salvage

518 logging intensity ranged between 25 and $100 \%$, and it averaged $80 \pm 24 \%$ (including up to 4

519 values per publication). Average intensities were $79 \pm 24 \%$ for wildfire, $90 \pm 15 \%$ for insect

520 outbreaks, and $79 \pm 27 \%$ for wind damage (Fig 5C; as with disturbance severity, note the

521 limitations in these data, described in Appendix A1). In some cases, the effect of different

522 logging intensity was assessed within individual studies; this often included qualitative

523 differences in logging practices such as the removal of slash or the retention of standing dead

524 trees. Notably, in one experimental study, stands under five classes of logging intensity were

525 established, ranging from 0 to $100 \%$ (Ritchie et al. 2013). The authors further assessed the

526 effect of amount of basal area retained, which explained the variation in some of the response

527 variables better than the categorical experimental factor (Ritchie et al. 2013). Such studies

528 can provide important insights into the responses to salvage logging and can evaluate the

529 effectiveness of Best Management Practices, as logging -and other disturbances- may not

530 necessarily produce generalizable effects but rather effects that vary nonlinearly according to

531 disturbance intensity or severity (Buma 2015, Foster et al. 2016, Leverkus et al. 2018). This

532 has long been acknowledged in traditional green-tree silviculture, where the retention

533 forestry approach was created under the acknowledgement that the effects of commercial

534 clearcutting can be greatly mitigated by leaving behind structures that favour the continuity

535 of the forest ecosystem (Gustafsson et al. 2012, Lindenmayer et al. 2012). The rapid

536 deterioration of wood quality following disturbance-induced mortality reduces the

537 profitability of salvage operations compared to green-tree silviculture, and this could be a

538 limitation for retention approaches. Nevertheless, the potential benefits of the retention of 25 
biological legacies (Franklin et al. 2000) during post-disturbance harvest operations should

540 be more profoundly explored (Lindenmayer et al. 2018, Thorn et al. 2018).

541 The methods employed in salvage logging operations can also modulate the effect of the

542 intervention. For example, mechanized harvesting equipment is more likely to compact soils

543 than manual cutting with chainsaws, but it may also produce novel, positive effects like

544 forming ruts that fill with water and create persistent aquatic habitat (Ernst et al. 2016).

545 Logging operations were often not described well enough in publications included in the

546 systematic map to identify logging methods, sometimes because the operations were not

547 observed by the researchers. Harvesting with feller-bunchers was mentioned in 15 studies

548 (not publications), and manual cutting in 10 studies. Ground-based yarding was mentioned in

54920 studies, and by helicopter in two studies. Extraction of wood by helicopter is well known

550 to reduce soil impacts compared to ground-based yarding. However, helicopter use is

551 extremely costly; this, combined with the low economic value of disturbance-affected timber

552 and depressed price that typically follow large disturbance events, are likely reasons for the

553 scant mentions of helicopters.

\section{Stand characteristics}

555 Of the 49 studies included in the systematic map, 11 were established in broadleaf forests or

556 included broadleaf stands, 33 were established in or included conifer stands, 10 included

557 mixed stands, and 3 included combinations of stand types without differentiation. In most

558 cases, the stands fell into the "mature" category. There were 37 tree species dominating or 

co-dominating the stands addressed in the retrieved publications. For further details on the 560 characteristics of stands among the retrieved studies, see Appendix A3.

\section{Characteristics of study designs}

562 True replication is an important factor reducing the potential for bias of individual studies.

563 True replication of salvage logging generally did not exceed $\mathrm{N}=10$ stands (Fig 6; presented

564 at the scale of publications because some publications of the same studies made use of 565 different subsets of a larger design; e.g., Leverkus et al. 2014, 2016). Most studies addressed 566 the issue of low replication by establishing hierarchical sampling designs (i.e. with several 567 sub-units within salvage and control units) and by controlling the effects of potentially 568 confounding co-variables. These strategies were also employed in many of the studies that 569 were excluded due to lack of true replication (Table S2). As a result, we do not discard the 570 possibility that some of those excluded studies could provide valuable insights despite 571 pseudo-replication, yet for the purpose of inclusion in the systematic map, we elected to stay 572 with the study inclusion criteria established in the protocol aimed at reducing the potential for 573 bias (Leverkus et al. 2015a).

In 11 of the 49 studies, the selection of stands for management intervention was at least 575 under partial control by the researchers and thus included randomisation in the allocation of 576 treatments to spatial units. In the rest of the studies, researchers made use of areas that were 577 either salvaged or left unsalvaged to achieve management objectives rather than to conduct 578 research. Both approaches provided several advantages and disadvantages. 579 Non-experimental studies have a risk of bias between intervention and comparator stands, for 
580

581

582

583

584

585

586

example due to the selection of more productive stands, or those nearest to roads, for salvage operations. Further, the choice not to salvage log particular stands is sometimes justified by reasons such as fiscal constraints and litigation; stream, hillside, and habitat protection; or inaccessibility (McGinnis et al. 2010), highlighting the potential for bias. Still, in non-experimental studies, care was generally taken to select salvaged and unsalvaged stands of similar pre-disturbance conditions to minimise such bias. In addition, some studies controlled for random spatial variation by implementing a BACI design -i.e. by measuring how the response variables changed over time from pre-logging to post-logging and in stands with and without the salvage logging intervention, thus providing a robust method for addressing bias. Such a BACI design was implemented in $36 \%$ of the 11 studies where salvage logging was performed experimentally and in $19 \%$ of the 37 non-experimental studies. One good example of experimental design is the one established after the Summit Fire in Oregon, which included randomisation, blocking, treatments applied at an appropriate spatial scale, replication, consideration of disturbance severity and salvage logging intensity, and a BACI sampling design (McIver and Ottmar 2007). Such studies are extremely difficult to implement, as exemplified by one paper that reports the conceptualisation of a randomised complete block design that, however, could not be turned to practice due to legal constraints and which resulted in a pseudo-replicated design comparing salvaged private forest $v s$ unsalvaged public land (Slesak et al. 2015) -hence leading to exclusion from our systematic map.

Not all true experimental studies are necessarily ideal, and some can suffer problems of inappropriate spatial scale and lack of replication (e.g., Francos et al. 2018) -but such 28 
602 problems were not detected in the retrieved studies. However, a general disadvantage of 603 experiments that were under the control of researchers is that the logging intervention was 604 typically performed in close compliance with environmental prescriptions (e.g., Ne'eman et 605 al. 1997, McIver and Ottmar 2007, Leverkus et al. 2014), so that the intervention may have 606 lesser effects than under non-experimental, "real-world" management. Besides, some 607 non-experimental studies had the advantage that they could be conducted at spatial scales 608 larger than what would be possible under experimental approaches by selecting several 609 disturbance patches with and without intervention that fulfilled certain criteria across entire 610 regions or countries (Priewasser et al. 2013, Águas et al. 2014). In this systematic map, most 611 studies (36) were established within the perimeter of a single disturbance event, thereby 612 establishing the disturbance as the constraint on the inference population. However, two 613 studies (one post-fire and one post-insect) included two disturbance events, four included 614 four events, one included five, one included 14, and one included 20 (all post-fire). Three 615 studies on post-windthrow logging addressed one disturbance event (e.g. one storm) but 616 within 7,11 , or 30 spatially independent blowdown patches; one study assessed 90 individual 617 patches caused by two storms.

618 As a corollary of the previous discussion, it is difficult to apply strict, identical quality 619 criteria to all studies, and there is not one single ideal study design. We consider all studies 620 included in this systematic map to be of sufficient quality for providing relevant information 621 under certain conditions. 
622 Characteristics of the responsesStudies explicitly focusing on the response of

623 ecosystem services to salvage logging were scant. Most publications addressed ecosystem

624 elements and structures, fewer studied ecosystem functions, and very few addressed the

625 human well-being component of ecosystem services directly (Fig 1). This is consistent with

626 the findings of a global literature review on ecosystem service studies (Boerema et al.

627 2016), and it highlights the need to better address the human component of salvage logging

628 effects to improve the transferability of results to management decisions (Leverkus and

629 Castro 2017). It should also be noted that most of the publications (79\%) included data on

630 one or two measurements of the response variable undertaken at different times, and the

631 maximum was 20 measurements (Fig 7, inset). Four publications included continuous

632 measurements taken over 3 or 6 years.

633 The most frequent response variables examined were related to tree regeneration

634 (addressed by $51 \%$ of the publications; Fig. 7). These included the density, basal area,

635 growth, and survival of trees established after disturbance. This was no surprise, as

636 establishment of trees is perhaps the most direct indicator of the recovery of the previous

637 ecosystem. Further, some agencies, such as the US Forest Service, are required by law to

638 monitor and rectify tree regeneration failure associated with management activities. In many

639 situations, lack of appropriate regeneration means that trees would have to be planted, so that

640 natural regeneration provides direct value for society (Fig 1). In fact, as early as in 1956, a

641 report (Roy 1956) already advised "When you find good reproduction, protect it. Try to

642 save the high costs of artificial regeneration." 

$42 \%$ of publications). Typically, this would include vegetation cover, a useful measure of protection from soil erosion or primary productivity. Cover of pits and mounds, as well as cover of deadwood, may be used as indicators of the microclimatic and micro-topographic habitat availability and heterogeneity. Bare soil cover could be an indicator of available seedbed in measurements made right after the disturbance, or of ground disturbance and lack of regeneration in both early and subsequent measurements. Finally, skid trail cover would indicate soil disturbance and compaction. characteristics of deadwood (addressed by $41 \%$ of publications). This included snags, downed logs, branches and twigs, often separated by species, size and decay stage. Deadwood after disturbance is an important component associated with many post-disturbance specialists, including birds and beetles (Thorn et al. 2018). Standing trees

656 can act as habitat for species that live in tree hollows (Lindenmayer and Possingham 1996) 657 and as perches or visual cues for seed dispersers (Castro et al. 2012, Cavallero et al. 2013). 658 Deadwood constitutes a pool of nutrients that is released to the soil in the mid- and long-term 659 through decomposition (Marañón-Jiménez and Castro 2013, Molinas González et al. 2017). 660 It can also ameliorate microclimatic conditions to enhance tree regeneration (Castro et al. 661 2011) and help reduce herbivory by large ungulates (Leverkus et al. 2015b). However, there 662 is also a risk that the wood left behind by disturbance constitutes the means of propagation of 663 a subsequent disturbance such as wildfire or insect outbreaks. As a result, in many studies, 664 the aim of deadwood characterisation was to assess the amount and features of fuels, 31 
665 including the modelling of future fuel characteristics and of potential fire behaviour (McIver 666 and Ottmar 2007, Keyser et al. 2009, Donato et al. 2013, Hood et al. 2017). One publication 667 with a chronosequence approach that was excluded from the map for design-related reasons 668 provides a thorough assessment of the time frames at which fuels are enhanced or reduced by 669 salvage logging (Peterson et al. 2015). In fact, risk reduction of subsequent disturbance is one 670 of the main justifications for salvage logging (Müller et al. 2018), including fire but also the 671 risk of bark beetle outbreaks after windstorms (Leverkus et al. 2017) and other linked 672 disturbances (Buma 2015). Nevertheless, we identified only two studies addressing 673 resilience to subsequent wildfire as a response variable (Fraver et al. 2011, Buma and 674 Wessman 2012). This is likely due to the complex concatenation of disturbance events 675 required to assess such a variable empirically: it requires both intervention and comparator 676 stands to be followed by the same subsequent disturbance and compliance with the additional 677 criteria established in our protocol. Fuel characterisation and modelling of fire behaviour are 678 thus logical ways to address such questions, and our systematic map may have left out 679 relevant studies in this regard. Conversely, the amount of deadwood also can be used as an 680 indicator of the size of the carbon pool in disturbed ecosystems. The trade-off between $\mathrm{C}$ 681 retention and wildfire prevention can be solved by assessing the $\mathrm{C}$ cycle directly 682 (Serrano-Ortiz et al. 2011a) or by focusing independently on recalcitrant C pools (large trees, 683 snags, coarse wood, and soil) and labile fuels (understory shrubs, fine wood, and duff) 684 (Powers et al. 2013); the studies in the systematic map generally allow this approach due to 685 the explicit consideration of different size classes. 
The fourth most frequent type of response variable was non-tree vegetation (beyond mere percent cover values; addressed by $28 \%$ of publications). Although we avoided including biodiversity responses in this map due to the existence of a recent review on the topic (Thorn et al. 2018), we did include vegetation as an indicator of the recovery of ecosystem structure, habitat, and soil retention. measurements related to soil fertility. The remaining response variable categories were addressed by $<15 \%$ of the publications (Fig 7). Both erosion control and the abundance of exotic or invasive species were addressed in only six publications, which is surprising given that they constitute some of the core concerns of managers after natural disturbances. Negative results and the absence of invasive species could partially explain the lack of published results on this topic (e.g., Leverkus et al. 2014). Next, non-deadwood C pool was addressed in five studies. Biological indicators of nutrient cycling and riparian ecosystem functioning were addressed in four publications. Again, the latter variable comes as one of the main concerns regarding salvage logging yet with very little research (Karr et al. 2004).

701 This likely has to do with the spatial scale defined for inclusion in the systematic map (that of 702 salvage logging intervention), which excluded several studies implemented at the scale of 703 watersheds and with problems of replication. Only one study addressed seed dispersal and 704 one addressed drinking water quality (perhaps the one publication most clearly focusing on 705 the human well-being side of the ecosystem services cascade; Fig 1). Avalanche protection in 706 steep hills is another important ecosystem service affected by salvage logging (Wohlgemuth 
et al. 2017), yet it was not included in the systematic map as a response because the one study addressing it (Schönenberger et al. 2005) lacked replication.

\section{Conclusions}

710 The systematic map presented here provides a rigorous account of the empirical studies

711 addressing the effects of salvage logging on supporting and regulating ecosystem services

712 that fulfil some qualitative requirements. It shows that substantial research has been

713 conducted in the last two decades, particularly after the publication of an article in Science in

7142004 calling for a careful revision of post-disturbance management practices (Lindenmayer

715 et al. 2004). Our systematic map is based on a comprehensive and systematic screening of the

716 scientific literature on post-disturbance logging written in English and considers a range of

717 stand, disturbance and logging characteristics and of outcomes. It should help managers and

718 policy makers identify the most relevant studies addressing the effects of salvage logging and

719 thus spare them the work of searching from scratch. It is also relevant for scientists who aim

720 to synthesize previous work and it identifies knowledge gaps to help direct future work. For

721 example, we identified a large geographic gap across all continents except Europe and North

722 America. We also found that there has been only very limited research focusing on the link

723 between ecosystem elements and processes and the benefits and values for human society,

724 which ultimately define many management schemes. It should also be noted that very few of

725 the retrieved studies specifically addressed the effects of deadwood retention. Whereas

726 small-scale retention is nowadays a well-known practice in green-tree harvesting and much

727 research has been conducted on the topic (Fedrowitz et al. 2014), the benefits of such 
728 practices in disturbed forests are not yet well known and require substantial additional

729 research (Lindenmayer et al. 2018, Thorn et al. 2018). Finally, the systematic map identified

730 some areas with substantial research where systematic review or meta-analysis can be

731 performed:

732

733

734

735

736

737

738

\section{Acknowledgments}

740 ABL acknowledges postdoctoral funding from the Spanish Ministerio de Economía y

741 Competitividad (FJCI-2015-23687) and mobility grant (CAS17/00374) from Ministerio de

742 Educación, Cultura y Deporte. Additional funding was provided by projects P12-RNM-2705

743 from Junta de Andalucía, CGL2014-53308-P of the Spanish Government, and Remedinal 3

744 (S2013/MAE-2719) of the Madrid Government.

- The effect of salvage logging on recalcitrant $v s$. labile deadwood components (i.e. C pool vs. fuel loads) and how these vary over time.

- The effect of salvage logging on tree regeneration.

- The effect of the time between disturbance and subsequent logging on response variables.

- The effect of disturbance type on the ecological effects of salvage logging. 
747 [Millennium Ecosystem Assessment], M. 2003. MA Conceptual Framework. In Ecosystems

748 and human well-being: A framework for assessment. Island Press. pp. 25-36. 749 doi:10.1079/PHN2003467.

750 Águas, A., Ferreira, A., Maia, P., Fernandes, P.M., Roxo, L., Keizer, J., Silva, J.S., Rego,

751 F.C., and Moreira, F. 2014. Natural establishment of Eucalyptus globulus Labill. in

752 burnt stands in Portugal. For. Ecol. Manage. 323: 47-56. Elsevier B.V. 753 doi:10.1016/j.foreco.2014.03.012.

754 Beghin, R., Lingua, E., Garbarino, M., Lonati, M., Bovio, G., Motta, R., and Marzano, R. 755 2010. Pinus sylvestris forest regeneration under different post-fire restoration practices 756 in the northwestern Italian Alps. Ecol. Eng. 36(10): 1365-1372. Elsevier B.V. 757 doi:10.1016/j.ecoleng.2010.06.014.

758 Bernes, C., Jonsson, B.G., Junninen, K., Lõhmus, A., Macdonald, E., Müller, J., and 759 Sandström, J. 2015. What is the impact of active management on biodiversity in boreal 760 and temperate forests set aside for conservation or restoration? A systematic map. 761 Environ. Evid. 4(1): 25. BioMed Central. doi:10.1186/s13750-015-0050-7.

762 Beschta, R.L., Rhodes, J.J., Kauffman, J.B., Gresswell, R.E., Minshall, G.W., Karr, J.R., 763 Perry, D.A., Hauer, F.R., and Frissell, C.A. 2004. Postfire management on forested 764 public lands of the Western United States. Conserv. Biol. 18(4): 957-967. 765 doi:10.1111/j.1523-1739.2004.00495.x.

766 Beudert, B., Bässler, C., Thorn, S., Noss, R., Schröder, B., Dieffenbach-Fries, H., Foullois, 767 N., and Müller, J. 2015. Bark beetles increase biodiversity while maintaining drinking 
water quality. Conserv. Lett. 8(4): 272-281. doi:10.1111/conl.12153.

769

770

771

772

773

774

775

776

777

778

779

780

781

782

783

784

785

786

787

Blair, D.P., McBurney, L.M., Blanchard, W., Banks, S.C., and Lindenmayer, D.B. 2016. Disturbance gradient shows logging affects plant functional groups more than fire. Ecol. Appl.: n/a-n/a. doi:10.1002/eap.1369.

Boerema, A., Rebelo, A.J., Bodi, M.B., Esler, K.J., and Meire, P. 2016. Are ecosystem services adequately quantified? J. Appl. Ecol. In press: 10.1111/1365-2664.12696. doi:10.1111/1365-2664.12696.

Boucher, D., Gauthier, S., Noël, J., Greene, D.F., and Bergeron, Y. 2014. Salvage logging affects early post-fire tree composition in Canadian boreal forest. For. Ecol. Manage. 325: 118-127. Elsevier B.V. doi:10.1016/j.foreco.2014.04.002.

Brewer, J.S., Bertz, C.A., Cannon, J.B., Chesser, J.D., and Maynard, E.E. 2012. Do natural disturbances or the forestry practices that follow them convert forests to early-successional communities? Ecol. Appl. 22(2): 442-458. doi:10.1890/11-0386.1.

Buma, B. 2015. Disturbance interactions: characterization, prediction, and the potential for cascading effects. Ecosphere 6(April): Art70. doi:10.1890/ES15-00058.1.

Buma, B., and Wessman, C.A. 2012. Differential species responses to compounded perturbations and implications for landscape heterogeneity and resilience. For. Ecol. Manage. 266: 25-33. Elsevier B.V. doi:10.1016/j.foreco.2011.10.040.

Castro, J. 2013. Postfire Burnt-Wood Management Affects Plant Damage by Ungulate Herbivores. Int. J. For. Res. 2013: 1-6. doi:10.1155/2013/965461. 
788 Castro, J., Allen, C.D., Molina-Morales, M., Marañón-Jiménez, S., Sánchez-Miranda, Á., 789 and Zamora, R. 2011. Salvage logging versus the use of burnt wood as a nurse object to 790 promote post-fire tree seedling establishment. Restor. Ecol. 19(4): 537-544. 791 doi:10.1111/j.1526-100X.2009.00619.x.

792 Castro, J., Moreno-Rueda, G., and Hódar, J.A. 2010. Experimental test of postfire 793 management in pine forests: Impact of salvage logging versus partial cutting and 794 nonintervention on bird-species assemblages. Conserv. Biol. 24(3): 810-819. 795 doi:10.1111/j.1523-1739.2009.01382.x.

796 Castro, J., Puerta-Piñero, C., Leverkus, A.B., Moreno-Rueda, G., and Sánchez-Miranda, A. 797 2012. Post-fire salvage logging alters a key plant-animal interaction for forest 798 regeneration. Ecosphere 3(10): art90.

799 Cavallero, L., Raffaele, E., and Aizen, M.A. 2013. Birds as mediators of passive restoration 800 during early post-fire recovery. Biol. Conserv. 158: 342-350. $801 \quad$ doi:10.1016/j.biocon.2012.10.004.

802 CEBC. 2010. Guidelnes for Systematc Reviews in Environmenta Management Version 4.0. 803 In Environmental Evidence. Bangor, UK.

804 Collins, B.J., Rhoades, C.C., Battaglia, M.A., and Hubbard, R.M. 2012. The effects of bark 805 beetle outbreaks on forest development, fuel loads and potential fire behavior in salvage 806 logged and untreated lodgepole pine forests. For. Ecol. Manage. 284: 260-268. Elsevier $807 \quad$ B.V. doi:10.1016/j.foreco.2012.07.027.

808 Collins, B.J., Rhoades, C.C., Hubbard, R.M., and Battaglia, M.A. 2011. Tree regeneration 38 
809

810

and future stand development after bark beetle infestation and harvesting in Colorado lodgepole pine stands. For. Ecol. Manage. 261(11): 2168-2175. Elsevier B.V. doi:10.1016/j.foreco.2011.03.016.

Collins, B.J., Rhoades, C.C., Underhill, J., and Hubbard, R.M. 2010. Post-harvest seedling recruitment following mountain pine beetle infestation of Colorado lodgepole pine stands: a comparison using historic survey records. Can. J. For. Res. 40(12): 2452 2456. doi:10.1139/X10-172.

Crouzeilles, R., Ferreira, M.S., Chazdon, R.L., Lindenmayer, D.B., Sansevero, J.B.B., Monteiro, L., Iribarrem, A., Latawiec, A.E., and Strassburg, B.B.N. 2017. Ecological restoration success is higher for natural regeneration than for active restoration in tropical forests. Sci. Adv. 3: 1701345. doi:10.1126/sciadv.1701345.

DellaSala, D.A., Karr, J.R., Schoennagel, T., Perry, D., Noss, R.F., Lindenmayer, D., Beschta, R., Hutto, R.L., Swanson, M.E., and Evans, J. 2006. Post-fire logging debate ignores many issues. Science (80-. ). 314(October): 51-52.

Donato, D.C., Fontaine, J.B., Campbell, J.L., Robinson, W.D., Kauffman, J.B., and Law, B.E. 2006. Post-wildfire logging hinders regeneration and increases fire risk. Science (80-. ). 311: 352. doi:10.1126/science.1127481.

Donato, D.C., Simard, M., Romme, W.H., Harvey, B.J., and Turner, M.G. 2013. Evaluating post-outbreak management effects on future fuel profiles and stand structure in bark beetle-impacted forests of Greater Yellowstone. For. Ecol. Manage. 303: 160-174. Elsevier B.V. doi:10.1016/j.foreco.2013.04.022. 
830

831

832

835

836

837

841

842

Ernst, R., Hölting, M., Rodney, K., Benn, V., Thomas-Caesar, R., and Wegmann, M. 2016. A frog's eye view: logging roads buffer against further diversity loss. Front. Ecol. Environ. 14(7): 353-355.

Fedrowitz, K., Koricheva, J., Baker, S.C., Lindenmayer, D.B., Palik, B., Rosenvald, R., Beese, W., Franklin, J.F., Kouki, J., Macdonald, E., Messier, C., Sverdrup-Thygeson, A., and Gustafsson, L. 2014. Can retention forestry help conserve biodiversity? A meta-analysis. J. Appl. Ecol. 51: 1669-1679. doi:10.1111/1365-2664.12289.

Fornwalt, P.J., Rhoades, C.C., Hubbard, R.M., Harris, R.L., Faist, A.M., and Bowman, W.D. 2017. Short-term response of understory plant communities to salvage logging in beetle-affected lodgepole pine forests, Colorado, USA. For. Ecol. Manage. 409(July 2017): 84-93. Elsevier. doi:10.1016/j.foreco.2017.10.056.

Foster, C.N., Sato, C.F., Lindenmayer, D.B., and Barton, P.S. 2016. Integrating theory into disturbance interaction experiments to better inform ecosystem management. Glob. Chang. Biol. 22(4): 1325-1335. doi:10.1111/gcb.13155.

Francos, M., Pereira, P., Alcañiz, M., and Úbeda, X. 2018. Post-wildfire management effects on short-term evolution of soil properties (Catalonia, Spain, SW-Europe). Sci. Total Environ. 633: 285-292. Elsevier B.V. doi:10.1016/j.scitotenv.2018.03.195.

Franklin, J.F., Lindenmayer, D., Macmahon, J.A., Mckee, A., Perry, D.A., Waide, R., and Foster, D. 2000. Threads of continuity. Conserv. Pract. 1(1): 8-17.

Fraver, S., Jain, T., Bradford, J.B., D’Amato, A.W., Kastendick, D., Palik, B., Shinneman, D., and Stanovick, J. 2011. The efficacy of salvage logging in reducing subsequent fire 
851 852

856

857

858

860

861

862

863

864

865

866

867

868

869

severity in conifer-dominated forests of Minnesota, USA. Ecol. Appl. 21(May 2007): 1895-1901.

Greene, D.F., Gauthier, S., Noël, J., Rousseau, M., and Bergeron, Y. 2006. A field experiment to determine the effect of post-fire salvage on seedbeds and tree $\begin{array}{llll}\text { regeneration. } & \text { Front. } & \text { Ecol. } & \text { Environ. }\end{array}$ doi:10.1890/1540-9295(2006)004[0069:AFETDT]2.0.CO;2.

Gustafsson, L., Baker, S.C., Bauhus, J., Beese, W.J., Brodie, A., Kouki, J., Lindenmayer, D.B., Lõhmus, A., Martínez Pastur, G., Messier, C., Neyland, M., Palik, B., Sverdrup-Thygeson, A., Volney, W.J.A., Wayne, A., and Franklin, J.F. 2012. Retention forestry to maintain multifunctional forests: A world perspective. Bioscience 62(7): 633-645. doi:10.1525/bio.2012.62.7.6.

Haines-Young, R., and Potschin, M. 2010. The links between biodiversity, ecosystem services and human well-being. In Ecosystem Ecology: A new Synthesis. Edited by D.G. Raffaelli and C.L. Frid. Cambridge University Press. pp. 110-139. doi:10.1017/CBO9780511750458.007.

Hernández-Hernández, R., Castro, J., Del Arco Aguilar, M., Fernández-López, Á.B., and González-Mancebo, J.M. 2017. Post-fire salvage logging imposes a new disturbance that retards succession: The case of bryophyte communities in a Macaronesian laurel forest. Forests 8(7): 252. doi:10.3390/f8070252.

Holzmueller, E.J., and Jose, S. 2012. Response of the invasive grass Imperata cylindrica to disturbance in the southeastern forests, USA. Forests 3(4): 853-863. 
873

874 logging on surface fuel loads and fuel moisture in beetle-infested lodgepole pine forests.

Hood, P.R., Nelson, K.N., Rhoades, C.C., and Tinker, D.B. 2017. The effect of salvage

875 For. Ecol. Manage. 390: 80-88. Elsevier B.V. doi:10.1016/j.foreco.2017.01.003.

876 James, K.L., Randall, N.P., and Haddaway, N.R. 2016. A methodology for systematic 877 mapping in environmental sciences. Environ. Evid. 5(1): 7. BioMed Central. 878 doi:10.1186/s13750-016-0059-6.

879 Johnstone, J.F., Allen, C.D., Franklin, J.F., Frelich, L.E., Harvey, B.J., Higuera, P.E., Mack, 880 M.C., Meentemeyer, R.K., Metz, M.R., Perry, G.L.W., Schoennagel, T., and Turner, 881 M.G. 2016. Changing disturbance regimes, ecological memory, and forest resilience. 882 Front. Ecol. Environ. 14(7): 369-378. doi:10.1002/fee.1311.

883 Karr, J.R., Rhodes, J.J., Minshall, G.W., Hauer, F.R., Beschta, R.L., Frissell, C.A., and Perry, 884 D.A. 2004a. The effects of postfire salvage logging on aquatic ecosystems in the 885 American West. Bioscience 54(11): 1029-1033. doi:10.1641/0006-3568.

886 Karr, J.R., Rhodes, J.J., Minshall, G.W., Hauer, F.R., Beschta, R.L., Frissell, C. a., and Perry, 887 D. a. 2004 b. The effects of postfire salvage logging on aquatic ecosystems in the 888 $\begin{array}{llll}\text { American } & \text { West. } & \text { Bioscience } & \text { 54(11): }\end{array}$ doi:10.1641/0006-3568(2004)054[1029:TEOPSL]2.0.CO;2.

Keyser, T.L., Smith, F.W., and Shepperd, W.D. 2009. Short-term impact of post-fire salvage logging on regeneration, hazardous fuel accumulation, and understorey development in ponderosa pine forests of the Black Hills, SD, USA. Int. J. Wildl. Fire 18: 451-458. 
doi:10.1071/WF08004.

894

896

897

898

900

901

902

903

904

905

906

907

908

909

910

911

912

Kishchuk, B.E., Thiffault, E., Lorente, M., Quideau, S., Keddy, T., and Sidders, D. 2015. Decadal soil and stand response to fire, harvest, and salvage-logging disturbances in the western boreal mixedwood forest of Alberta, Canada. Can. J. For. Res. 45: 141-152.

Koricheva, J., Gurevitch, J., and Mengersen, K. (Editors). 2013. Handbook of Meta-analysis in Ecology and Evolution. Princeton University Press, Princeton and Oxford.

Kramer, K., Brang, P., Bachofen, H., Bugmann, H., and Wohlgemuth, T. 2014. Site factors are more important than salvage logging for tree regeneration after wind disturbance in Central European forests. For. Ecol. Manage. 331: 116-128. Elsevier B.V. doi:10.1016/j.foreco.2014.08.002.

Kurz, W.A., Dymond, C.C., Stinson, G., Rampley, G.J., Neilson, E.T., Carroll, A.L., Ebata, T., and Safranyik, L. 2008. Mountain pine beetle and forest carbon feedback to climate change. Nature 452(April): 987-990. doi:10.1038/nature06777.

Lee, E.-J., Lee, W.-S., and Rhim, S.-J. 2008. Characteristics of small rodent populations in post-fire silvicultural management stands within pine forest. For. Ecol. Manage. 255(56): 1418-1422. doi:10.1016/j.foreco.2007.10.055.

Leverkus, A.B., and Castro, J. 2017. An ecosystem services approach to the ecological effects of salvage logging: valuation of seed dispersal. Ecol. Appl. 27(4): 1057-1063. doi:10.1002/eap.1539.

Leverkus, A.B., Gustafsson, L., Rey Benayas, J.M., and Castro, J. 2015a. Does 
913 post $\square$ disturbance salvage logging affect the provision of ecosystem services? A

914 systematic review protocol. Environ. Evid. 4: art16. BioMed Central. 915 doi:10.1186/s13750-015-0042-7.

916 Leverkus, A.B., Jaramillo-López, P.F., Brower, L.P., Lindenmayer, D.B., and Williams,

917 E.H. 2017. Mexico’s logging threatens butterflies. Science (80-. ). 358(6366): 1008.

918 Leverkus, A.B., Lorite, J., Navarro, F.B., Sánchez-Cañete, E.P., and Castro, J. 2014. Post-fire

919 salvage logging alters species composition and reduces cover, richness, and diversity in

920 Mediterranean plant communities. J. Environ. Manage. 133: 323-331. Elsevier Ltd.

921 doi:10.1016/j.jenvman.2013.12.014.

922 Leverkus, A.B., Puerta-Piñero, C., Guzmán-Álvarez, J.R., Navarro, J., and Castro, J. 2012.

923 Post-fire salvage logging increases restoration costs in a Mediterranean mountain

924 ecosystem. New For. 43(5-6): 601-613. doi:10.1007/s11056-012-9327-7.

925 Leverkus, A.B., Rey Benayas, J.M., and Castro, J. 2016. Shifting demographic conflicts

926 across recruitment cohorts in a dynamic post-disturbance landscape. Ecology 97(10):

$927 \quad 2628-2639$.

928 Leverkus, A.B., Rojo, M., and Castro, J. 2015b. Habitat complexity and individual acorn

929 protectors enhance the post-fire restoration of oak forests via seed sowing. Ecol. Eng.

930 83: 276-280. Elsevier B.V. doi:10.1016/j.ecoleng.2015.06.033.

931 Leverkus, A.B., Thorn, S., Gustafsson, L., and Lindenmayer, D.B. 2018. Salvage logging in

932 the world's forests: Interactions between natural disturbance and logging need 933 recognition. Under Rev. 
934 Lewis, K., and Thompson, D. 2011. Degradation of wood in standing lodgepole pine killed 935 by mountain pine beetle. Wood Fiber Sci. 43(2): 130-142.

936 Lindenmayer, D., Thorn, S., and Banks, S. 2017. Please do not disturb ecosystems further.

937 Nat. Ecol. Evol. 1(January): art31. Macmillan Publishers Limited. 938 doi:10.1038/s41559-016-0031.

939 Lindenmayer, D.B., Burton, P.J., and Franklin, J.F. 2008. Salvage logging and its ecological $940 \quad$ consequences. Island Press, Washington, D.C.

941 Lindenmayer, D.B., Foster, D.R., Franklin, J.F., Hunter, M.L., Noss, R.F., Schmiegelow, 942 F.A., and Perry, D. 2004. Salvage harvesting policies after natural disturbance. Science 943 (80-. ). 303(February): 1303.

944 Lindenmayer, D.B., Franklin, J.F., Lõhmus, a., Baker, S.C., Bauhus, J., Beese, W., Brodie, 945 a., Kiehl, B., Kouki, J., Pastur, G.M., Messier, C., Neyland, M., Palik, B., 946 Sverdrup-Thygeson, a., Volney, J., Wayne, a., and Gustafsson, L. 2012. A major 947 shift to the retention approach for forestry can help resolve some global forest 948

951 to salvage logged: quantifying bird responses to different levels of disturbance severity. $952 \quad$ J. Appl. Ecol. In press.

953 Lindenmayer, D.B., and Noss, R.F. 2006. Salvage logging, ecosystem processes, and 954 biodiversity conservation. Conserv. Biol. 20(4): 949-958. 
956

957

958

959

960

961

962

963

964

965

966

967

968

969

970

971

972

973

974

Lindenmayer, D.B., and Possingham, H.P. 1996. Ranking Conservation and Timber Management Options for Leadbeater' s Possum in Southeastern Australia Using Population Viability Analysis. Conserv. Biol. 10(1): 235-251.

Macdonald, S.E. 2007. Effects of partial post-fire salvage harvesting on vegetation communities in the boreal mixedwood forest region of northeastern Alberta, Canada. For. Ecol. Manage. 239(1-3): 21-31. doi:10.1016/j.foreco.2006.11.006.

Man, R., Chen, H.Y.H., and Schafer, A. 2013. Salvage logging and forest renewal affect early aspen stand structure after catastrophic wind. For. Ecol. Manage. 308: 1-8. Elsevier B.V. doi:10.1016/j.foreco.2013.07.039.

Mansuy, N., Thiffault, E., Lemieux, S., Manka, F., Paré, D., and Lebel, L. 2015. Sustainable biomass supply chains from salvage logging of fire-killed stands: a case study for wood pellet production in eastern Canada. Appl. Energy 154: 62-73. Elsevier Ltd, Oxford. doi:10.1016/j.apenergy.2015.04.048.

Marañón-Jiménez, S., and Castro, J. 2013. Effect of decomposing post-fire coarse woody debris on soil fertility and nutrient availability in a Mediterranean ecosystem. Biogeochemistry 112(1-3): 519-535. doi:10.1007/s10533-012-9744-X.

Martín-López, B., Gómez-Baggethun, E., García-Llorente, M., and Montes, C. 2014. Trade-offs across value-domains in ecosystem services assessment. Ecol. Indic. 37(PART A): 220-228. Elsevier Ltd. doi:10.1016/j.ecolind.2013.03.003. 
975 Martínez-Sánchez, J.J., Ferrandis, P., De las Heras, J., and Herranz, J.M. 1999. Effect of 976 burnt wood removal on the natural regeneration of Pinus halepensis after fire in a pine 977 forest in Tus valley (SE Spain). For. Ecol. Manage. 123: 1-10.

978 Marzano, R., Garbarino, M., Marcolin, E., Pividori, M., and Lingua, E. 2013. Deadwood 979 anisotropic facilitation on seedling establishment after a stand-replacing wildfire in 980 Aosta Valley (NW Italy). Ecol. Eng. 51: 117-122. Elsevier B.V. 981 doi:10.1016/j.ecoleng.2012.12.030.

982 McGinnis, T.W., Keeley, J.E., Stephens, S.L., and Roller, G.B. 2010. Fuel buildup and 983 potential fire behavior after stand-replacing fires, logging fire-killed trees and herbicide 984 shrub removal in Sierra Nevada forests. For. Ecol. Manage. 260(1): 22-35. Elsevier $985 \quad$ B.V. doi:10.1016/j.foreco.2010.03.026.

986 McIver, J.D., and McNeil, R. 2006. Soil disturbance and hill-slope sediment transport after 987 logging of a severly burned site in Northeastern Oregon. West. J. Appl. For. 21: 123$988 \quad 133$.

989 McIver, J.D., and Ottmar, R. 2007. Fuel mass and stand structure after post-fire logging of a 990 severely burned ponderosa pine forest in northeastern Oregon. For. Ecol. Manage. 991 238(1-3): 268-279. doi:10.1016/j.foreco.2006.10.021.

992 McIver, J.D., and Starr, L. 2000. Environmental effects of postfire logging: Literature review 993 and annotated bibliography. Gen. Tech. Rep. PNW-GTR-486. Portland, OR: U.S. 994 Department of Agriculture, Forest Service, Pacific Northwest Research Station.

995 Moher, D., Liberati, A., Tetzlaff, J., Altman, D.G., and The PRISMA Group. 2009. Preferred 47 
996

997

998

999

1000

1001

1002

1003

1004

1005

1006

1007

1008

1009

Van Nieuwstadt, M.G.. L., Sheil, D., and Kartawinata, K. 2001. The Ecological

1010 Consequences of Logging in the Burned Forests of East Kalimantan, Indonesia.

1011 Conserv. Biol. 15(4): 1183-1186. doi:10.1046/j.1523-1739.2001.0150041183.x.

1012 Noss, R.F., Franklin, J.F., Baker, W.L., Schoennagel, T., and Moyle, P.B. 2006. Managing

1013 fire-prone forests in the western United States. Front. Ecol. Environ. 4: 481-487.

1014 Noss, R.F., and Lindenmayer, D.B. 2006. The ecological effects of salvage logging after 1015
Conserv.

Biol.

20(4):

946-948. 
doi:10.1111/j.1523-1739.2006.00498.x.

1017 Pausas, J.G., and Fernández-Muñoz, S. 2012. Fire regime changes in the Western 1018 Mediterranean Basin: from fuel-limited to drought-driven fire regime. Clim. Change $1019 \quad \mathbf{1 1 0}(1-2): 215-226$.

1020 Peterson, D.W., and Dodson, E.K. 2016. Post-fire logging produces minimal persistent 1021 impacts on understory vegetation in northeastern Oregon, USA. For. Ecol. Manage. 1022 370: 56-64. Elsevier B.V. doi:10.1016/j.foreco.2016.04.004.

1023 Peterson, D.W., Dodson, E.K., and Harrod, R.J. 2015. Post-fire logging reduces surface 1024 woody fuels up to four decades following wildfire. For. Ecol. Manage. 338: 84-91. $1025 \quad$ Elsevier B.V. doi:10.1016/j.foreco.2014.11.016.

1026 Powers, E.M., Marshall, J.D., Zhang, J., and Wei, L. 2013. Post-fire management regimes 1027 affect carbon sequestration and storage in a Sierra Nevada mixed conifer forest. For. 1028 Ecol. Manage. 291: 268-277. doi:10.1016/j.foreco.2012.07.038.

1029 Prestemon, J.P., and Holmes, T.P. 2010. Economic impacts of hurricanes on forest owners.

1030 In U S Forest Service Pacific Northwest Research Station General Technical Report 1031 PNW-GTR 802, Part 1.pp. 207-221.

1032 Priewasser, K., Brang, P., Bachofen, H., Bugmann, H., and Wohlgemuth, T. 2013. Impacts of 1033 salvage-logging on the status of deadwood after windthrow in Swiss forests. Eur. J. For. 1034 Res. 132(2): 231-240. doi:10.1007/s10342-012-0670-1.

1035 Puerta-Piñero, C., Sánchez-Miranda, A., Leverkus, A., and Castro, J. 2010. Management of 

burnt wood after fire affects post-dispersal acorn predation. For. Ecol. Manage. 260(3): 345-352. ELSEVIER SCIENCE BV. doi:10.1016/j.foreco.2010.04.023.

1038

1039

1040

1041

1042

1043

1044

1045

1046

1047

1048

1049

1050

1051

1052

1053

1054

1055

Pullin, A.S., Knight, T.M., Stone, D.A., and Charman, K. 2004. Do conservation managers use scientific evidence to support their decision-making? Biol. Conserv. 119(2): 245252. doi:10.1016/j.biocon.2003.11.007.

Pullin, A.S., and Stewart, G.B. 2006. Guidelines for systematic review in conservation and environmental management. Conserv. Biol. 20(6): 1647-1656. doi:10.1111/j.1523-1739.2006.00485.x.

R Core Team. 2016. R: A language and environment for statistical computing. R Foundation for Statistical Computing, Vienna, Austria, R Foundation for Statistical Computing, Vienna, Austria.

Rhoades, C.C.., Pelz, K.A.., Fornwalt, P.J.., Wolk, B.H.., and Cheng, A.S. 2018. Overlapping bark beetle outbreaks, salvage logging and wildfire restructure a lodgepole pine ecosystem. Forests In press.

Ritchie, M.W., Knapp, E.E., and Skinner, C.N. 2013. Snag longevity and surface fuel accumulation following post-fire logging in a ponderosa pine dominated forest. For. Ecol. Manage. 287: 113-122. Elsevier B.V. doi:10.1016/j.foreco.2012.09.001.

Roy, D.F. 1956. Salvage logging may destroy Douglas-fir reproduction. USDA For. Serv. Calif. For. Range Exp. Station. For. Res. Notes No. 107: 5.

Royo, A.A., Peterson, C.J., Stanovick, J.S., and Carson, W.P. 2016. Evaluating the 
1056 ecological impacts of salvage logging: Can natural and anthropogenic disturbances promote coexistence? Ecology 97(6): 1566-1582. doi:10.1890/15-1093.1.

Schelhaas, M.J., Nabuurs, G.J., and Schuck, A. 2003. Natural disturbances in the European forests in the 19th and 20th centuries. Glob. Chang. Biol. 9: 1620-1633. doi:10.1046/j.1365-2486.2003.00684.x.

Schiermeier, Q. 2016. Pristine forest at risk. Nature 530: 393. doi:10.1038/530394a.

Schönenberger, W., Noack, A., and Thee, P. 2005. Effect of timber removal from windthrow slopes on the risk of snow avalanches and rockfall. For. Ecol. Manage. 213(1-3): 197208. doi:10.1016/j.foreco.2005.03.062.

Schroeder, L.M., and Lindelöw, A. 2002. Attacks on living spruce trees by the bark beetle Ips typographus (Col . Scolytidae) following a storm-felling: a comparison between stands with and without removal of wind-felled trees. Agric. 4: 47-56.

Secretariat of the Convention on Biological Diversity. 2000. Sustaining life on Earth: How the Convention on Biological Diversity promotes nature and human well-being. Secr. Conv. Biol. Divers.: 14.

Seidl, R., Thom, D., Kautz, M., Martin-Benito, D., Peltoniemi, M., Vacchiano, G., Wild, J., Ascoli, D., Petr, M., Honkaniemi, J., Lexer, M.J., Trotsiuk, V., Mairota, P., Svoboda, M., Fabrika, M., Nagel, T.A., and Reyer, C.P.O. 2017. Forest disturbances under climate change. Nat. Clim. Chang. 7(6): 395-402. Nature Publishing Group. doi:10.1038/nclimate3303. 
1076 Serrano-Ortiz, P., Marañón-Jiménez, S., Reverter, B.R., Sánchez-Cañete, E.P., Castro, J., 1077 Zamora, R., and Kowalski, A.S. 2011a. Post-fire salvage logging reduces carbon 1078 sequestration in Mediterranean coniferous forest. For. Ecol. Manage. 262(12): 22871079 2296. Elsevier B.V. doi:10.1016/j.foreco.2011.08.023.

1080 Serrano-Ortiz, P., Marañón-Jiménez, S., Reverter, B.R., Sánchez-Cañete, E.P., Castro, J., 1081 Zamora, R., and Kowalski, A.S. 2011b. Post-fire salvage logging reduces carbon 1082 sequestration in Mediterranean coniferous forest. For. Ecol. Manage. 262(12): 22871083 2296. doi:10.1016/j.foreco.2011.08.023.

1084 Slesak, R.A., Schoenholtz, S.H., and Evans, D. 2015. Hillslope erosion two and three years 1085 after wildfire, skyline salvage logging, and site preparation in southern Oregon, USA. 1086 For. Ecol. Manage. 342: 1-7. Elsevier B.V. doi:10.1016/j.foreco.2015.01.007.

1087 Smith-Ramírez, C., Maturana, V., Gaxiola, A., and Carmona, M. 2014. Salvage logging by 1088 indigenous people in a Chilean conifer forest. For. Sci. 60(6): 1100-1106.

1089 Sullivan, T.P., Sullivan, D.S., Lindgren, P.M.F., and Ransome, D.B. 2010. Green-tree 1090 retention and life after the beetle: Stand structure and small mammals 30 years after 1091 salvage harvesting. Silva Fenn. 44(5): 749-774.

1092 Sun, Y., Gu, L., Dickinson, R.E., and Zhou, B. 2012. Forest greenness after the massive 2008 1093 Chinese ice storm: integrated effects of natural processes and human intervention. 1094 Environ. Res. Lett. 7(3): 35702. doi:10.1088/1748-9326/7/3/035702.

1095 Sutherland, W.J., Pullin, A.S., Dolman, P.M., and Knight, T.M. 2004a. The need for 1096 evidence-based conservation. Trends Ecol. Evol. 19(6): 305-308. 
doi:10.1016/j.tree.2004.03.018.

1098

1099

1100

1101

1102

1103

1104

1105

1106

1107

1108

1109

1110

1111

1112

1113

1114

Sutherland, W.J., Pullin, A.S., Dolman, P.M., and Knight, T.M. 2004b. The need for evidence-based conservation. Trends Ecol. Evol. 19(6): 305-8. doi:10.1016/j.tree.2004.03.018.

Thorn, S., Bässler, C., Bernhardt-Römermann, M., Cadotte, M., Heibl, C., Schäfer, H., Seibold, S., and Müller, J. 2015a. Changes in the dominant assembly mechanism drives species loss caused by declining resources. Ecol. Lett. 19(2): 109-215. doi:10.1111/ele.12548.

Thorn, S., Bässler, C., Brandl, R., Burton, P., Cahall, R., Campbell, J.L., Castro, J., Choi, C.-Y., Cobb, T., Donato, D., Durska, E., Fontaine, J., Gauthier, S., Hebert, C., Hothorn, T., Hutto, R., Lee, E.-J., Leverkus, A., Lindenmayer, D., Obrist, M., Rost, J., Seibold, S., Seidl, R., Thom, D., Waldron, K; Wermelinger, B., Winter, M.-B., Zmihorski, M., and Müller, J. 2018. Impacts of salvage logging on biodiversity - a meta-analysis. J. Appl. Ecol. 55: 279-289. doi:10.1111/1365-2664.12945.

Thorn, S., Bässler, C., Svoboda, M., and Müller, J. 2016. Effects of natural disturbances and salvage logging on biodiversity - Lessons from the Bohemian Forest. For. Ecol. Manage. Elsevier B.V. doi:10.1016/j.foreco.2016.06.006.

Thorn, S., Hacker, H.H., Seibold, S., Jehl, H., Bässler, C., and Müller, J. 2015b. Guild-specific responses of forest Lepidoptera highlight conservation-oriented forest management - Implications from conifer-dominated forests. For. Ecol. Manage. 337: 41-47. Elsevier B.V. doi:10.1016/j.foreco.2014.10.031. 
1118 Titus, J.H., and Householder, E. 2007. Salvage logging and replanting reduce understory 1119 cover and richness compared to unsalvaged-unplanted sites at Mount St. Helens, 1120 Washington. West. North Am. Nat. 67(2): 219-231. doi:10.3398/1527-0904(2007)67[219:SLARRU]2.0.CO;2.

1122 Turner, M.G. 2010. Disturbance and landscape dynamics in a changing world. Ecology 1123 91(10): 2833-2849. doi:10.1890/10-0097.1.

1124 Wagenbrenner, J.W., MacDonald, L.H., Coats, R.N., Robichaud, P.R., and Brown, R.E. 1125 2015. Effects of post-fire salvage logging and a skid trail treatment on ground cover, 1126 soils, and sediment production in the interior western United States. For. Ecol. Manage. 335: 176-193. Elsevier B.V. doi:10.1016/j.foreco.2014.09.016.

1128 Wagenbrenner, J.W., Robichaud, P.R., and Brown, R.E. 2016. Rill erosion in burned and 1129 salvage logged western montane forests: Effects of logging equipment type, traffic 1130 level, and slash treatment. J. Hydrol. 541(Part B): 889-901. Elsevier B.V. 1131 doi:10.1016/j.jhydrol.2016.07.049.

1132 Waldron, K., Ruel, J.C., and Gauthier, S. 2013. Forest structural attributes after windthrow 1133 and consequences of salvage logging. For. Ecol. Manage. 289: 28-37. Elsevier B.V. 1134 doi:10.1016/j.foreco.2012.10.006.

1135 Waldron, K., Ruel, J.C., Gauthier, S., De Grandpré, L., and Peterson, C.J. 2014. Effects of 1136 post-windthrow salvage logging on microsites, plant composition and regeneration. 1137 Appl. Veg. Sci. 17(2): 323-337. doi:10.1111/avsc.12061.

1138 Wohlgemuth, T., Kull, P., and Wüthrich, H. 2002. Disturbance of microsites and early tree 54 
1139 regeneration after windthrow in Swiss mountain forests due to the winter storm Vivian

1140 1990. For. Snow Landsc. Res. 77(1/2): 17-47.

1141 Wohlgemuth, T., Schwitter, R., Bebi, P., Sutter, F., and Brang, P. 2017. Post-windthrow 1142 management in protection forests of the Swiss Alps. Eur. J. For. Res. 136: 1029-1040.

1143 Springer Berlin Heidelberg. doi:10.1007/s10342-017-1031-x.

1144

1145 


\section{Tables}

1147

1148 Table 1. Distribution of publications and study sites across geographic areas

\begin{tabular}{lllll}
\hline Continent & Country & N Publications & N Studies & N multi-site studies \\
\hline \multirow{2}{*}{ North America } & USA & 42 & 25 & 3 \\
& Canada & 25 & 12 & 4 \\
& Spain & 10 & 4 & 0 \\
& Switzerland & 4 & 1 & 1 \\
& Germany & 2 & 2 & 0 \\
& Portugal & 2 & 1 & 1 \\
& Estonia & 1 & 1 & 0 \\
\multirow{5}{*}{ Asia } & Czech Republic & 2 & 1 & 0 \\
& Israel & 1 & 1 & 0 \\
\hline Total & South Korea & 1 & 1 & 0 \\
\hline
\end{tabular}

1149

1150 


\section{Figure captions}

1152 Figure 1. Ecosystem services cascade illustrated for the case of seed dispersal by 1153 European jays (Garrulus glandarius L.) within a post-fire management 1154 experimental setting. The diagram shows the link between the biophysical and the 1155 human well-being components of ecosystem services. Particular elements of the 1156 ecosystem perform functions that produce benefits for society via an ecosystem service.

1157 Society places a value on these benefits, whether economic or not. The resulting value 1158 feeds back to affect the ecosystem elements through management decisions. In the 1159 example (shown in the dashed boxes below each component of the conceptual diagram), 1160 burnt snags represent a supporting element for the seed caching activity of a major seed 1161 disperser, whose activity yields natural colonisation of the burnt area and reduces the 1162 economic cost of reforestation. Appreciation of this value can enhance the likelihood 1163 that snags be retained in post-fire management. Figure adapted from Haines-Young and 1164 Potschin (2010), Martín-López et al. (2014), and Leverkus and Castro (2017).

1165 References in the diagram: (1) = Molinas-González et al. (2017); (2) = Castro et al. 1166 (2012); (3) = Leverkus et al. (2016); (4) = Leverkus and Castro (2017). 
1175 Figure 4. Location of the individual studies included in the systematic map. Number

1176 codes are indicated for reference (column Site_ref in the systematic map database, Table

1177 S3). Inset: Korean Peninsula.

1179 Figure 5. Disturbance and salvage logging characteristics. A) Disturbance severity

1180 considered in the analysed publications. This includes 1-3 points per publication,

1181 according to whether one general disturbance severity was reported or the publication

1182 explicitly included sampling areas of different severity levels. B) Time elapsed between

1183 the disturbance and subsequent salvage logging. Each data point represents one

1184 publication. C) Logging intensity in the analysed publications. This includes 1-4 points

1185 per publication. Note that this applies to the Intervention only, as each publication also

1186 included a Comparator with $0 \%$ logging intensity. In all plots, the thick horizontal lines

1187 are medians, and the boxes indicate the first and third quartiles of the values. Whiskers

1188 are either the minimum/maximum values or 1.5 times the interquartile range of the data,

1189 in which case outliers are shown as points. The values of disturbance severity and

1190 logging intensity are broad approximations. Sample sizes for the graphics are: for fire

119153,51 and 69 (panels A, B and C, respectively); for insect outbreaks 15, 13 and 15; and

1192 for wind 31, 26 and 21 for wind.

1193

1194 Figure 6. The number of spatially independent salvage logging replicate units used

1195 in the 90 publications, classified by disturbance type.

1197 Figure 7. Number of publications that reported different measured response

1198 variables, for each disturbance type. Nutrient= biological indicators of nutrient

1199 cycling; Carbon= non-wood carbon pool; Water= drinking water quality; Erosion= soil 
1200 erosion by wind or water; Invasives= Invasive and/or exotic species; Cover= ground 1201 cover, including cover of vegetation; Resilience= capacity to regenerate after subsequent 1202 wildfire (i.e. wildfire after salvage logging); Riparian= riparian ecosystem functioning; 1203 Dispersal $=$ seed dispersal; Soil chem. $=$ soil chemical properties; Soil phys. $=$ soil 1204 physical properties; Deadwood $=$ stand structure and deadwood amount and 1205 characteristics; Temp. $=$ air, water or soil temperature; Regen. $=$ tree regeneration; 1206 Vegetation= Vegetation composition. Note that biodiversity responses were excluded 1207 from the systematic map. Inset: distribution of publications according to the number of 1208 individual measurements taken for the response variables. Both y axes have the same 1209 meaning. 


\section{Supporting Information}

1214 Appendix A1. Systematic map database and data coding strategy

1215 Appendix A2. Literature searches and screening-Results

1216 Appendix A3. Stand characteristics -Results and Discussion

1217 Table S1. Search strings used in the systematic map.

1218 Table S2. Publications excluded at full-text screening and reasons for exclusion.

1219 Table S3. Systematic Map Database. For details on coding and variable names, see 1220 Appendix A1.

1224 